\title{
LogiCluster: um método para agrupamento de dados web categóricos e contínuos usando regressão logística
}

\author{
Gustavo Pinheiro
}

Orientador: Prof. Dr. Dilvan de Abreu Moreira

Dissertação apresentada ao Instituto de Ciências Matemáticas e de Computação - ICMC-USP, como parte dos requisitos para obtenção do título de Mestre em Ciências - Área de Ciências de Computação e Matemática Computacional.

\section{"VERSÃO REVISADA APÓS A DEFESA"}

$\begin{array}{ll}\text { Data da Defesa: } & 18 / 08 / 2003 \\ \text { Visto do Orientador: } & =1\end{array}$

USP - São Carlos

Agosto/2003 


\section{Agradecimentos}

À meu pai pelo constante apoio e incentivo.

Ao meu orientador Prof. Dilvan Moreira pela oportunidade que me concedeu, pela paciência na espera por resultados e pela liberdade concedida quanto aos rumos deste trabalho.

Ao meu "co-orientador" Prof. Dr. Dorival Leão Júnior pelas idéias e pela grande ajuda, sem a qual este trabalho não se realizaria.

E, finalmente, aos meus colegas Percival, Elaine, Orlando, Flávia e Fernando pela grande prestatividade. 


\section{ÍNDICE}

Resumo ....................................................................................................1

Abstract .......................................................................................2

Capítulo 1 - Introdução................................................................3

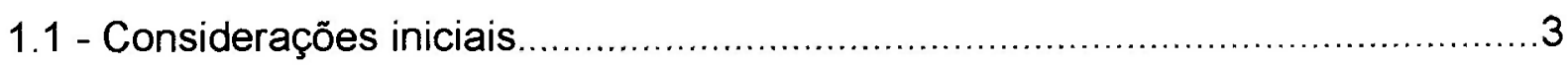

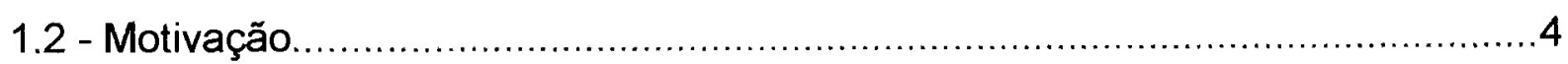

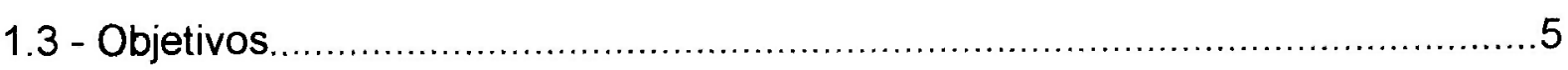

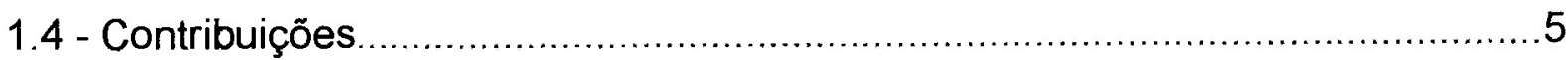

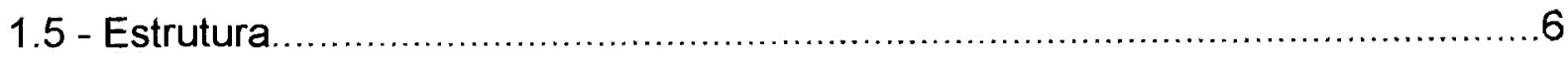

Capitulo 2 - Medição de Audiência na Web...............................8

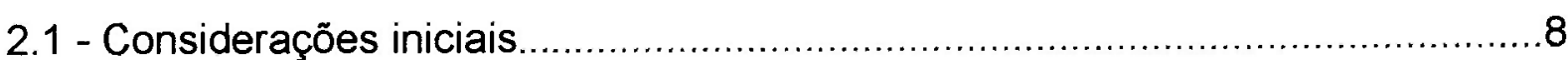

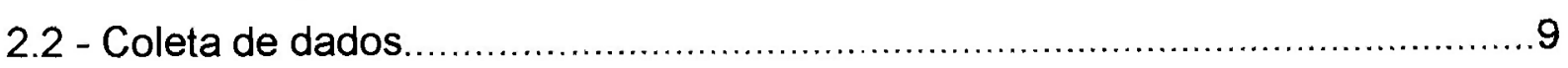

2.2.1 - Arquivos de log de servidores Web.............................................. 10

2.2 .2 - Programas independentes .......................................................... 11

2.2.3 - Identificação de usuários únicos ..................................................13

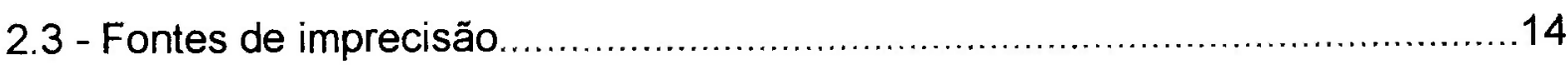

2.4 - Considerações finais...................................................................... 15

Capítulo 3 - Descoberta de Conhecimento em Dados............17

3.1 - Considerações iniciais........................................................................ 17

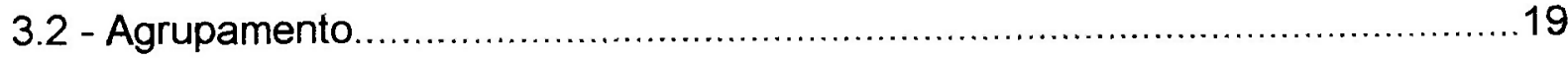

3.3 - Aspectos importantes de um algoritmo de agrupamento............................20

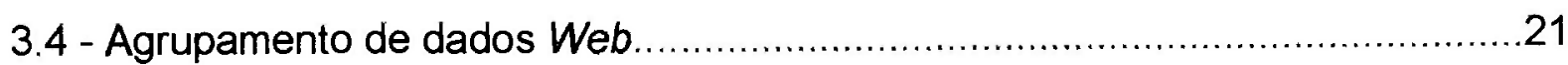

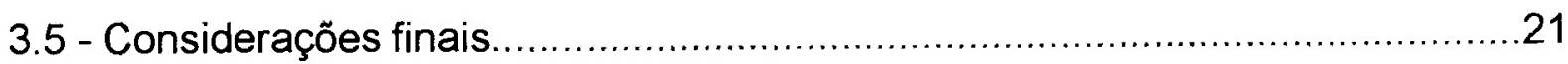

Capitulo 4 - 0 método LogiCluster........................................22

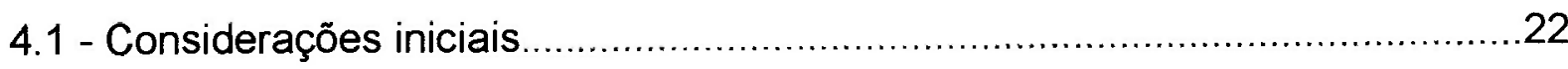

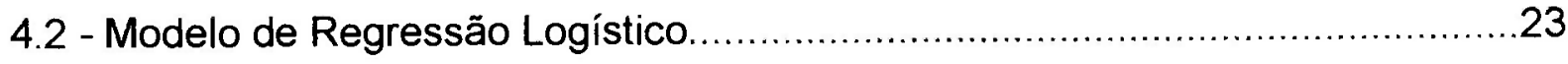

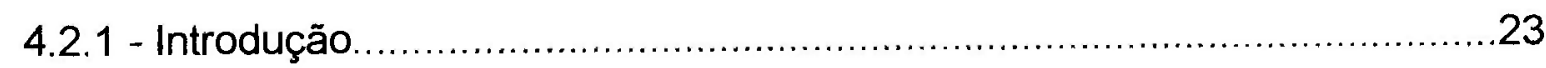

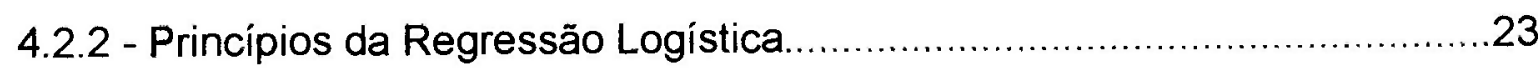

4.2.3 - Desenvolvendo o Modelo de Regressão Logística .................................24 


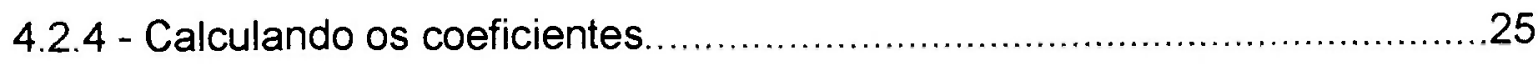

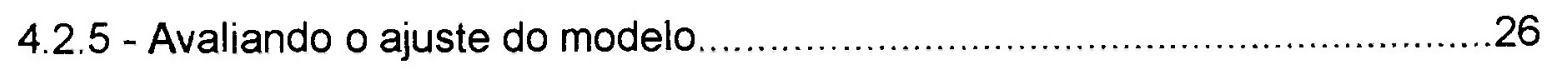

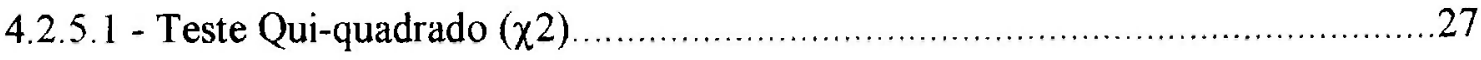

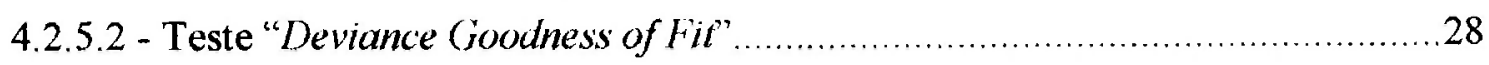

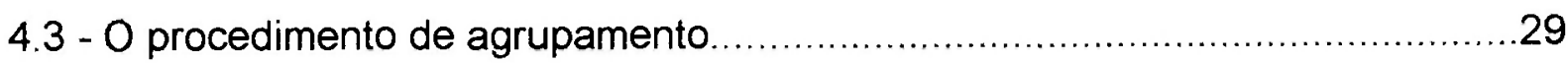

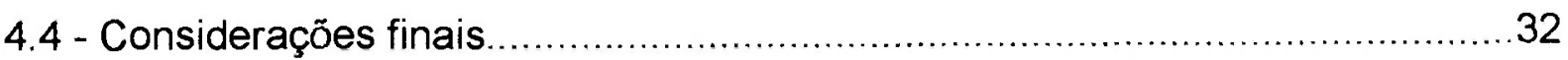

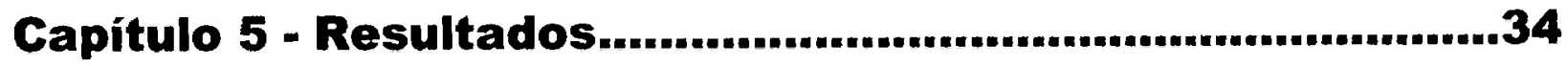

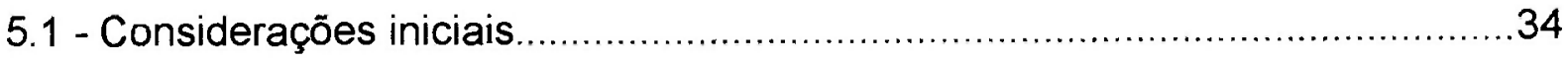

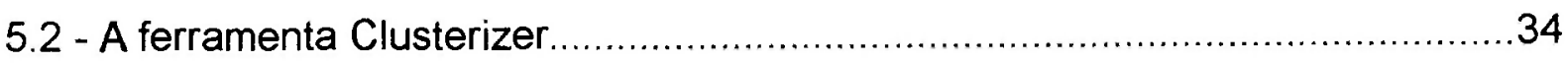

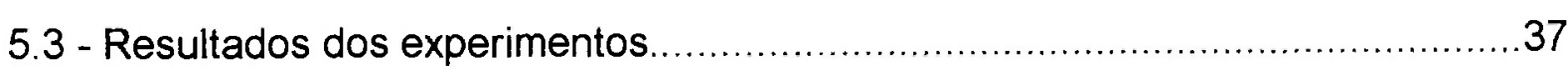

5.3.1 - Dados do Web site Agents Research (http://java.icmc.usp.br) ...............39

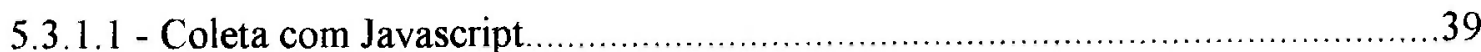

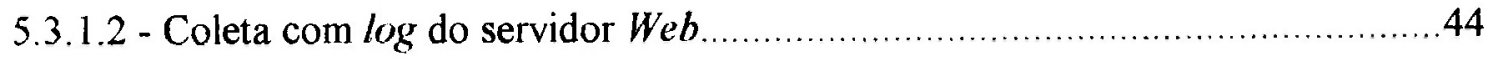

5.3.2 - Dados do Web site ICMC-USP (http.//www.icmc.usp.br) .......................50

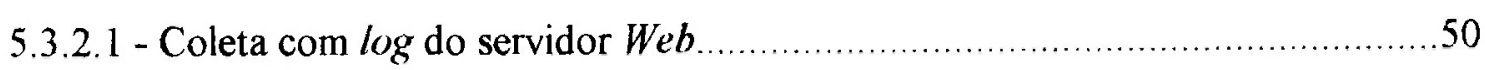

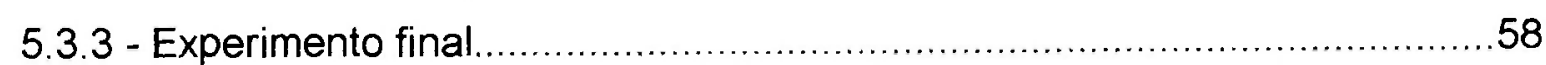

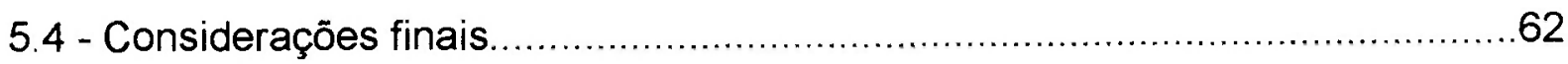

Capítulo 6 - Conclusão.......................................................64

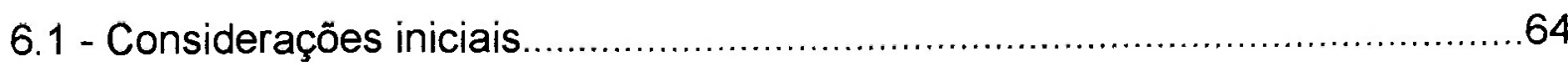

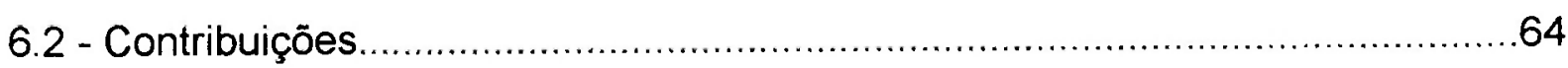

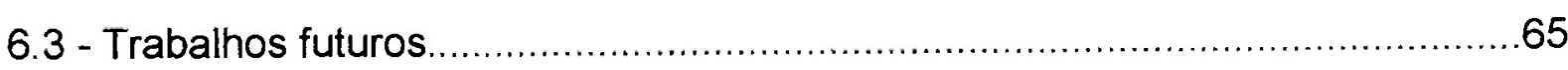

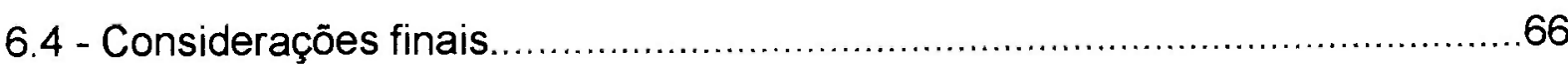

Referências bibliográficas......................................................67 


\section{Lista de Figuras}

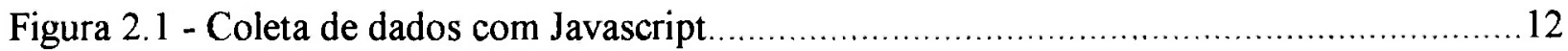

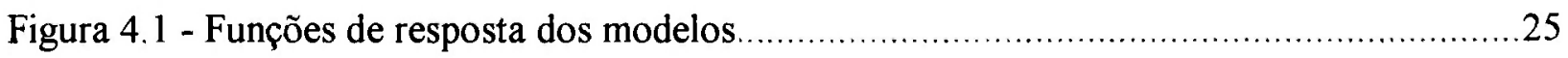

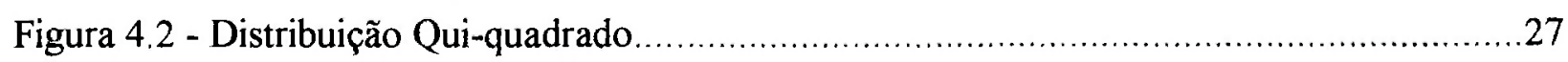

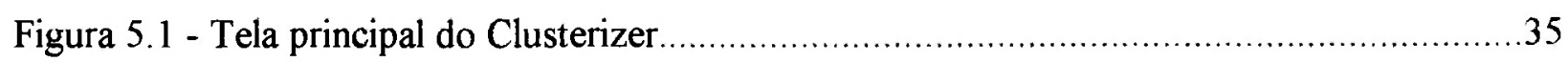

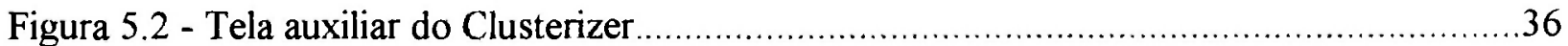

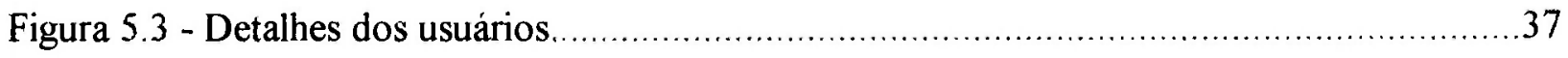

Figura 5.4 - Sumário gerado pelo Minitab para regressão usando as variáveis period e te ..........43

Figura 5.5 - Sumário gerado pelo Minitab para regressão usando as variáveis period e sr..........44

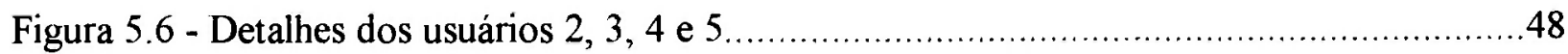

Figura 5.7 - Sumário gerado pelo Minitab para regressão usando as variáveis period e os..........48

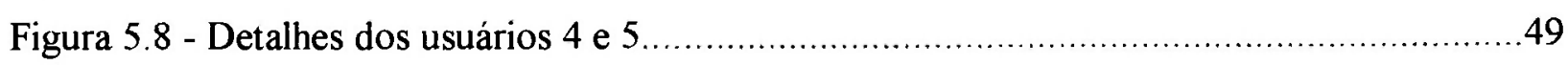

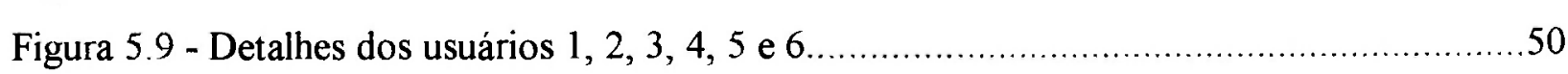

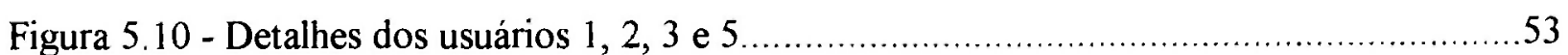

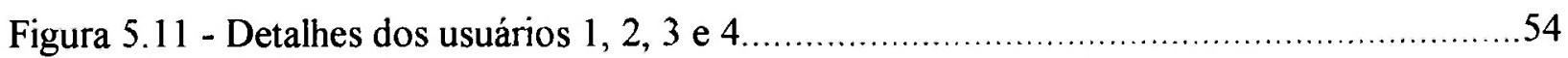

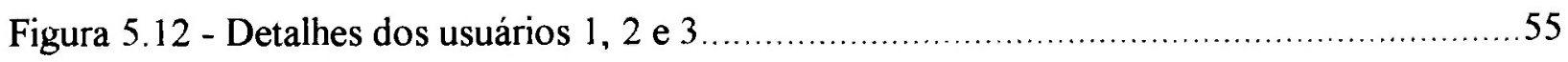

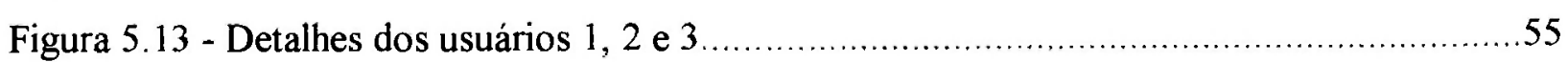

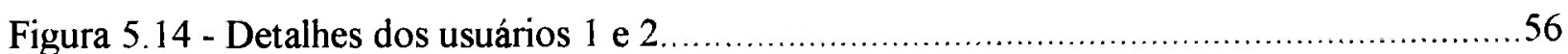

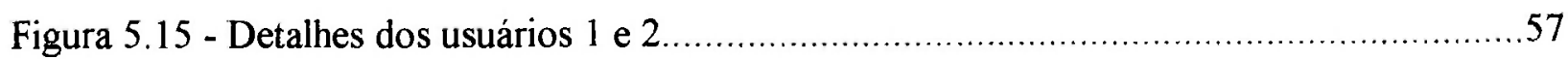

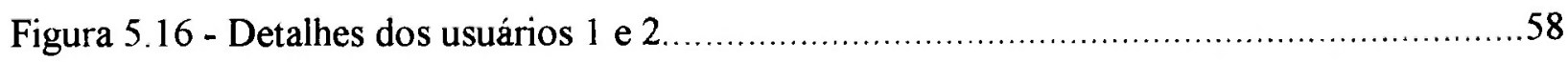

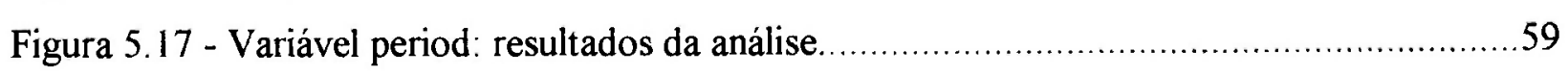

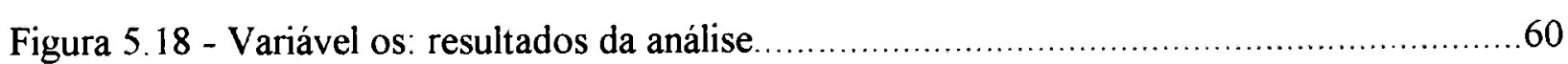

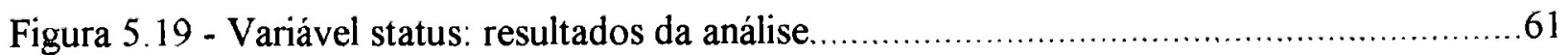

Figura 5.20 - Variáveis os e status: resultados da análise ....................................................62

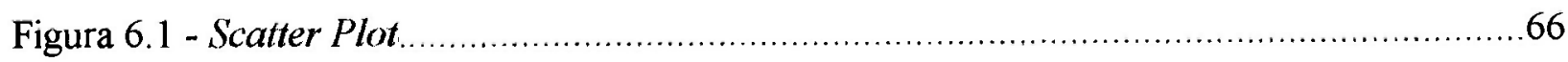




\section{Lista de Tabelas}

Tabela 2.1 - Empresas que usam a abordagem user-centric ................................................ 8

Tabela 2.2 - Algumas empresas que usam a abordagem site-centric.........................................

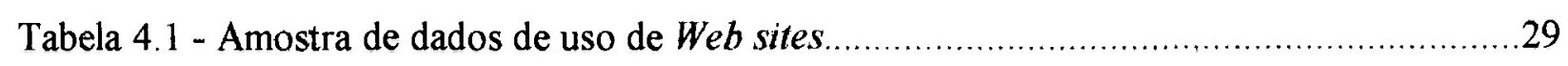

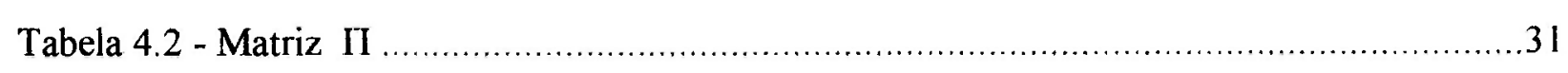

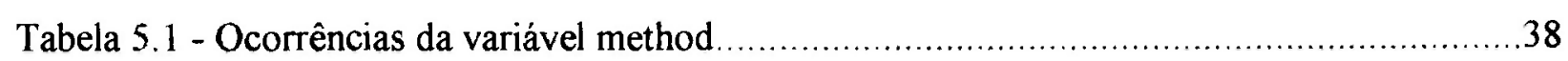

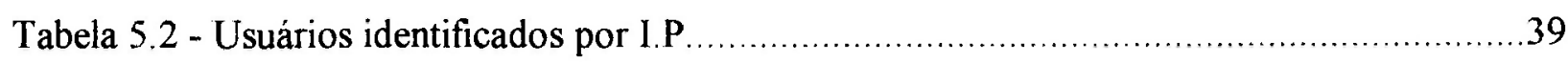

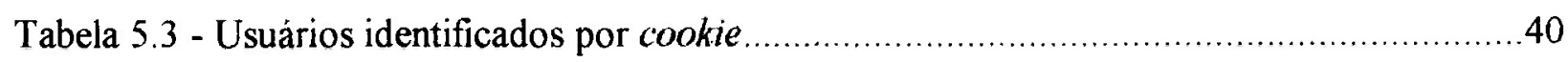

Tabela 5.4 - Registro com variáveis coletadas via Javascript ..............................................42

Tabela 5.5 - Registro com variáveis coletadas via log do servidor Web-(Agents Research) ......47

Tabela 5.6 - Registro contendo dados coletados via log do servidor Web - (ICMC)..................52 


\section{Resumo}

No Ensino à Distância via Internet, o professor não tem contato físico com seus alunos e, por isso, perde consideravelmente a percepção da interação destes em relação ao material didático. Além disso, pode-se atingir um número muito grande de usuários caso o meio de ensino seja a Web. Então, é importante dar ao professor ferramentas que o ajudem a conhecer seus alunos e a planejar sua atuação de forma a atender melhor um grande número de alunos

Sabe-se que a $W e b$ é um meio que pode ser ricamente instrumentado. Em principio, cada clique num hyperlink, cada visita e outros dados de atividade online podem ser capturados e armazenados para futura análise. Entretanto, a quantidade de dados que se obtem pode ser imensa, tornando sua análise trabalhosa e demorada. Surge, então, o problema de analisar esses dados a fim de se extrair informações úteis. Pesquisas na área de Mineração de Dados fornecem ferramentas úteis para tratar este problema, sendo que métodos de agrupamento são particularmente interessantes. Uma das dificuldades encontradas nesta nova área, chamada de Web Usage Mining (WUM), é lidar simultaneamente com dados categóricos e contínuos

Neste trabalho desenvolveu-se um novo método de agrupamento, o LogiCluster, baseado no Modelo de Regressão Logística, o qual é adequado para dados categóricos e contínuos, tanto em separado quanto em conjunto. 


\begin{abstract}
In Distance Learning, teacher and students are physically apart. This characteristic causes a considerable loss in the perception the teacher has of the students learning process. Even worst, if a distance course is provided openly through the Web, the audience could be huge. Therefore, tools that can help a teacher get a better understanding of his students could be very useful

A Web site can be highly monitored. Every visit to a page, every mouse click in a hyperlink and many other online activities can be captured and stored for future analysis. The amount of stored data can reach enormous quantities, which become a challenge for data analysis. It is very difficult to extract useful information from this data. Data Mining tools, such as clustering methods, could be very useful in dealing with such large amounts of data. But one of the problems with this new research area, Web Usage Mining (WUM), is to deal with categorical and continuous data simultaneously

In this work, a new method of clustering is presented, the LogiCluster. It is based in the Logistic Regression Model and can handle categorical and continuous data simultaneously. The data can be purely categorical or mixed with continuous data
\end{abstract}




\section{CAPÍTULO 1 - INTRODUÇÃO}

\section{1 - Considerações iniciais}

A Internet vem se expandindo a grande velocidade e se tornando cada vez mais acessível. Estimase que o número de usuários ativos fique por volta de 245 milhões de pessoas e que o número de pessoas com acesso à Internet em suas residências seja algo em torno de 400 milhões [Nielsen, 2003]. No Brasil, os números são 7,8 milhões e 14 milhões de pessoas, respectivamente [IBOPE, 2003]. A facilidade com que se pode disponibilizar conhecimento a um grande número de pessoas, associada às capacidades multimídia do World Wide Web, vieram a caracterizar uma infraestrutura tecnológica que pode ser muito útil na área de Educação à Distância via Internet.

Isto se comprova pelo grande número de sistemas de apoio ao ensino via Internet existentes. São exemplos desses sistemas: WebCT [WebCT, 2003]; Angel [Angel, 2003]; Blackboard [Blackboard, 2003]; IBM Lotus LearningSpace [LearningSpace, 2003]; TelEduc [TelEduc, 2003]; Aulanet [Aulanet, 2003]; WebCoM [Silva \& Moreira, 2000]; TopClass [TopClass]; eClass [Abowd, 1999].

A Educação à Distância (EAD) é caracterizada pela separação fisica e, possivelmente, temporal entre professores e alunos. Também é caracterizada pela utilização de meios técnicos de comunicação para transmitir os conteúdos educativos [Keegan, 1996], como é o caso da EAD via Internet.

Talvez a característica que mais diferencie a EAD da educação tradicional, em sala de aula, seja a separação fisica entre as partes. Esta característica empobrece a comunicação aluno-professor, que tem no tipo presencial sua forma mais rica. Conseqüentemente, diminui a percepção que o professor tem do desenvolvimento do aluno durante um curso. Além disso, na EAD via Internet pode-se atingir um número de alunos muito grande a um custo relativamente baixo por aluno, e a audiência numerosa certamente dificulta a atuação do professor.

Ferramentas que ajudem os professores a entender melhor os perfis de seus alunos podem compensar, ao menos em parte, as perdas decorrentes da separação fisica entre as partes. Com algum conhecimento sobre as características dos alunos, os professores podem ser mais eficientes 
na tarefa de educar na medida em que podem adequar o conteúdo educativo e planejar melhor sua atuação em função dos perfis de seus alunos.

No caso da EAD via Internet, onde um dos pontos principais de interação entre os alunos e os professores é geralmente o conteúdo educativo disponibilizado na forma de um Web site, uma maneira interessante de se saber algo sobre os alunos é analisar seu comportamento no site.

Sabe-se que dados $W e b$ podem atingir grandes volumes e isto torna a tarefa de analisá-los complexa, podendo tornar-se impossível para um examinador humano munido de ferramentas convencionais, como planilhas e representações gráficas comuns. Pesquisas na área de Mineração de Dados (MD) fornecem ferramentas úteis para tratar este problema.

No decorrer deste capítulo serão apresentadas a motivação, os objetivos deste trabalho, as possíveis contribuições ao conhecimento científico da área e a forma como esta dissertação foi organizada.

\section{2 - Motivação}

Monitorar o uso de um sistema de EAD pode ser útil ao professor uma vez que pode levá-lo a perceber as características de seus alunos quanto ao processo de aprendizagem. Esse conhecimento pode ajudá-lo a melhorar o sistema, por exemplo, através da melhoria do material. Alguns dos sistemas citados no item 1.1 fornecem ao professor informações sobre o uso que é feito do sistema (ex. WebCT e Angel). Mas, geralmente, essas informações são apenas estatísticas básicas, como contagem de acessos ao sistema, quais alunos acessaram o material num dado período, etc. Técnicas e ferramentas capazes de realizar análises mais sofisticadas sobre o uso desses sistemas podem ser muito úteis.

Nos últimos anos, têm surgido um número relevante de trabalhos tratando da aplicação de técnicas de Mineração de Dados em dados de uso de Web sites, por exemplo, [Cooley et al., 1997], [Srivastava et al., 2000] e [Shahabi \& Banaei-Kashani. 2001]. Convencionou-se chamar essa linha de pesquisa de Web Usage Mining (WUM). Em [Zaiane, 2001], apresentou-se uma visão geral da WUM com foco em EAD. Foi destacada a falta de trabalhos voltados a este domínio. Entretanto, é apontado que boa parte da pesquisa feita em WUM, que geralmente foca $o$ e-Commerce, é suficientemente genérica para ser aproveitada em EAD. Portanto, estudar a 
aplicação da WUM ao EAD via Internet é unı tópico importante e carente de estudos.

Um tópico específico da Web Usage Mining é a aplicação de técnicas de agrupamento (clustering) [Srivastava et al., 2000]. Julgou-se interessante aplicar um algoritmo de agrupamento aos dados, gerados pelos alunos ao acessar um site de um curso, uma vez que eles, em princípio, poderiam fornecer uma solução automática para o problema de identificar grupos de alunos com perfis semelhantes

Dados de acesso a Web sites são predominantemente categóricos, como, por exemplo, a URL visitada e o navegador usado. Alguns dados interessantes são, porém, numéricos e contínuos. $\mathrm{O}$ método de agrupamento a ser utilizado deve ser capaz de lidar com os dois tipos simultaneamente. Além disso, sabe-se que algoritmos de agrupamento, geralmente, não escalam bem e o domínio em questão costuma gerar grandes volumes de dados com um bom número de parâmetros. Não se encontrou na literatura nenhum algoritmo de agrupamento que trabalhasse simultaneamente com dados categóricos e contínuos. Surgiu, então, o interesse em se pesquisar novas formas de se efetuar agrupamento.

\section{3 - Objetivos}

O conhecido Modelo de Regressão Logístico foi desenvolvido para lidar com variáveis de resposta binárias e variáveis explanatórias categóricas ou continuas (em conjunto ou não). Foi a partir deste que se desenvolveu um novo método de agrupamento, o LogiCluster, a ser apresentado e utilizado neste trabalho

A ideia básica do método proposto é usar o Modelo Logístico para analisar os dados de pares de alunos (dois a dois) e, então, avaliar se são similares ou não. Uma vez determinada a similidade dos usuários é tarefa trivial agrupá-los

Em suma, o objetivo deste trabalho é apresentar um método de agrupamento em dados

\section{4 - Contribuições}

De modo geral, a principal contribuição deste trabalho é o desenvolvimento de um novo método de agrupamento de dados baseado no Modelo de Regressão Logístico. Não foram encontradas 
referências bibliográficas que tratassem do uso deste modelo como forma de se agrupar elementos

Outra contribuição relevante é o uso do Modelo de Regressão Logístico num domínio atípico: a World Wide Web. Este modelo é tipicamente empregado nas áreas de Ciências Biológicas e Médicas como forma, por exemplo, de se analisar a influência de variáveis (ex. peso e idade) na ocorrência de doenças.

E importante ressaltar que o desenvolvimento deste trabalho, apesar de motivado por um problema da área de EAD, não se prendeu a conceitos ou sistemas desta. A técnica e a ferramenta desenvolvida podem ser aplicadas a outros tipos de sistemas Web e, até mesmo, outro domínio onde se tenha simultaneamente dados com variável de resposta categórica e contínua

Por ter sido desenvolvido tendo em mente a aplicação em um sistema de EAD via Internet, este trabalho fez frequente uso do termo aluno neste capitulo. Porém, o aluno nada mais é que o usuário de um sistema de EAD via Internet e, como dito anteriormente, este trabalho se aplica a outros sistemas Web. Então, o termo usuário é mais genérico e será usado no resto da dissertação.

\section{5 - Estrutura}

Esta monografia está organizada de forma a apresentar o contexto teórico do qual depende o desenvolvimento deste trabalho, seus aspectos práticos e os resultados obtidos.

Podem ser coletadas diversas informações de um Web site. Em princípio, cada clique num hyperlink, cada visita e outros dados de atividade online podem ser capturados e armazenados para futura análise. As diferentes formas de se coletar dados de uso de um site, com suas vantagens e desvantagens, são discutidas no Capítulo 2 .

Conceitos básicos da área de Mineração de Dados, conceitos relevantes sobre algoritmos de agrupamento e sua aplicação a dados de uso de Web sites são os tópicos apresentados e discutidos no Capítulo 3.

No Capitulo 4, serão apresentados os princípios do Modelo de Regressão Logística e como, a partir deste modelo, se desenvolveu o procedimento de agrupamento LogiCluster. 
Foi parte deste trabalho a implementação de um conjunto de ferramentas capaz de efetuar a coleta dos dados e aplicar as técnicas propostas. Os resultados obtidos através do uso destas ferramentas são apresentados e discutidos no Capítulo 5 .

Finalmente, as conclusões obtidas neste trabalho serão apresentadas e discutidas no Capítulo 6 


\section{CAPÍTULO 2 - MEDIÇÃO DE AUDIÊNCIA NA WEB}

\section{1 - Considerações iniciais}

A coleta de dados de uso de Web sites é usualmente tratada por medição de audiência. Existem duas abordagens básicas adotadas pela indústria para a medição de audiência: user-centric e sitecentric. A abordagem user-centric se caracteriza pelo foco no usuário ou cliente, e a site-centric pelo foco no Web site (lado do servidor).

$\mathrm{Na}$ abordagem user-centric, a medição é feita em relação ao usuário. As empresas que adotam essa abordagem recrutam usuários que constituem amostras representativas de uma categoria e, através de cálculos estatísticos, traçam um panorama demográfico. Programas instalados nas máquinas clientes registram toda a navegação do recrutado.

Isso é o equivalente $W e b$ para o que é feito na televisão. É interessante notar que empresas que prestam este tipo de serviço na TV, passaram a aplicar seu knowhow na WWW. Por exemplo, o IBOPE (Instituto Brasileiro de Opinião Pública e Estatística) no Brasil e o Nielsen nos EUA (veja Tabela 2.1).

A princípio, a abordagem user-centric parece ser a ideal uma vez que o interesse principal é conhecer o usuário. Porém, essa abordagem implica em grandes dificuldades na execução de experimentos práticos. Pode ser dificil recrutar usuários. É necessário utilizar um programa de captura instalado na máquina cliente, o qual deve ser adequado a sistemas heterogêneos, com diferentes sistemas operacionais e navegadores.

\begin{tabular}{|cc|}
\hline \multicolumn{2}{|c|}{ Tabela 2.1 - Empresas que usam a abordagem user-centric } \\
\hline Emyrita & \\
\hline IBOPE e-Ratings & www.ibope.com.br/eratings \\
\hline Nielsen/NetRatings & www.nielsen-netratings.com \\
\hline
\end{tabular}

$\mathrm{Na}$ abordagem site-centric a medição é feita em relação a um site. Isto pode ser feito de diferentes formas, que serão discutidas no item 2.2. Dadas as atuais tecnologias de 
desenvolvimento para a $W e b$, é possível coletar uma enorme variedade de dados no lado servidor. Isto tornou viável a utilização desta abordagem neste trabalho.

Provavelmente pelas razões apontadas anteriormente, a abordagem site-centric se tornou a mais popular. As empresas que usam essa abordagem são numerosas (veja Tabela 2.2).

Tabela 2.2 - Algumas empresas que usam a abordagem site-centric

\begin{tabular}{|c|c|}
\hline Empresi & Enderes raw \\
\hline Accrue Software & www.accrue.com \\
\hline IBM Surfaid & surfaid.dfw.ibm.com \\
\hline Analog & www.analog.cx \\
\hline LogDoor (p/ Mac) & www.opendoor.com/logdoor \\
\hline Pilot Hit List & www.marketwave.com/products_solutions/hitlist.html \\
\hline NetGenesis & www.customercentricsolutions.com \\
\hline NetTracker & www.sane.com \\
\hline WebStat & www.webstat.com \\
\hline WebTrends & www.webtrends.com \\
\hline ClickTracks & www.clicktracks.com \\
\hline
\end{tabular}

\section{2 - Coleta de dados}

Os dados, que são tipicamente coletados quando se monitora o uso de um Web site, são:

- Endereço I.P. (Internet Protocol) do visitante: todos os computadores conectados à Internet são identificados por um número. O I.P. geralmente é relacionado a um nome de domínio (ex: www.internet.com). É uma informação importante uma vez que pode auxiliar na identificação de um usuário;

- Data e hora do pedido: este dado pode ser usado para estimar o tempo que um usuário passou em uma página visitada. É preciso atentar para o formato adotado;

- Método HTTP do pedido (GET, POST, HEAD): indica o tipo do pedido feito pelo cliente ao servidor Web. Útil apenas para se detectar atividades suspeitas. Por exemplo, um hacker pode enviar um pedido, com o método DELETE, numa tentativa de apagar um hiperdocumento; 
- URL requerido: é o endereço do recurso pedido ao servidor $W e b$, ou seja, qual documento o usuário acessou;

- Status HTTP: é um código que indica a situação da transação entre o cliente e o servidor. Pode ser usado para identificar problemas no serviço;

- URL do referente (Referrer URL): Identifica a página que estava sendo visitada antes do atual pedido. Pode ser uma URL de um outro Web site ou do próprio site. Neste caso, este dado é usado para se determinar a sequência de acessos executada por um usuário;

- Agente do cliente (User agent): geralmente é um navegador. Contém tipicamente informação sobre o tipo e versão do navegador e do sistema operacional do usuário. $\dot{E}$ útil na identificação de robôs;

- Cookies: São pequenos arquivos de texto enviados junto com a resposta de um pedido do navegador. Pode conter informações que identifiquem o usuário;

A coleta dos dados citados pode ser feita basicamente de duas maneiras: usando-se o arquivo de $\log$ do servidor Web ou softwares independentes. Nesta última categoria incluem-se códigos ECMAScript (Javascript) adicionados aos hiperdocumentos, applets Java, servlets Java, programas CGI, etc.

\subsection{1 - Arquivos de log de servidores Web}

Arquivos de $\log$ de servidores Web são arquivos de texto onde cada linha (ou entrada) corresponde aos dados de uma requisição de arquivo recebida. Alguns servidores permitem que estas entradas sejam registradas numa tabela em um banco de dados relacional.

Para ter uma idéia do tipo de dados que usualmente constituem um $\log$, vejamos uma entrada típica que contém os seguintes campos: tempo, I.P. do cliente, método HTTP, URI, status e versão HTTP:

1998-05-02 17:42:15 172.16.255.255 GET/default.htm 200 HTTP/1.0

Esta entrada indica que em 2 de Maio de 1998, as 5:42 P.M. (Universal Time Coordinate), um usuário com número I.P. 172.16.255.255 executou um comando HTTP GET para o arquivo 
Default.htm usando o protocolo HTTP versão 1.0. O pedido foi retornado sem erros (código de status 200)

Esta é, sem dúvida, a solução mais simples e mais adotada. É uma funcionalidade padrão da maioria desses programas, e exige poucos recursos de hardware. O processamento dos arquivos pode ser feito em outra máquina ou num momento mais apropriado. No mercado existem inúmeras opções de programas que analisam esses logs e geram estatísticas de uso do sıte em questão.

Em contrapartida, é uma solução relativamente pouco flexível. Nem todos servidores Web possibilitam a customização do formato do $\log$, e muitos ficam presos a formatos proprietários ou ao chamado common log file format (CLF), que fornece poucas informações. Por exemplo, o IIS 5.0 (servidor Web da Microsoft) se prende a quatro formatos preexistentes (W3C, NSCA, IIS e ODBC $\log$ file format ${ }^{\prime}$ ), enquanto o Apache (multiplataforma, mas comumente usado em plataformas Unix) permite que se escolha individualmente os campos que compõem o log

Uma vez que o servidor $W e b$ registra todo pedido de arquivo que recebe, quando um navegador recupera um documento hipertexto composto, por exemplo, por texto e duas imagens são geradas três entradas no arquivo de $\log$ (uma para o documento html e uma para cada imagem). Mas o que nos interessa saber é se o documento como um todo foi visto [Frost \& Strauss, 1996]. Então, informações desnecessárias são registradas e precisam ser eliminadas antes da análise dos dados.

Uma limitação relevante se deve ao fato de que os logs só registram pedidos de arquivos e nada dizem sobre a interação do usuário com o documento. Por exemplo, nada é registrado sobre o preenchimento de formulários, sobre cliques em checkboxes e outras interações com um hiperdocumento. Além disso, existem problemas na identificação de usuários e sessỗes de acesso (ver item 2.2.3).

\subsection{2 - Programas independentes}

Escrever programas que façam a coleta dos dados independentemente do servidor Web é uma solução mais versátil. No mercado encontram-se várias empresas que fornecem soluções desse tipo, sendo a mais comum aquela que usa código Javascript ${ }^{2}$. A empresa fornece um trecho de

1 Usualmente, a documentação dos softwares servidores Web contém mais informações sobre estes formatos. Nas referências são listados os orgãos responsáveis

2 A linguagem Javascript foi inicialmente proposta pela empresa Netscape. Acabou se tornando muito popular, e 
código que deve ser adicionado a todas as páginas a serem monitoradas. Esse pequeno programa, que é processado pelo navegador, coleta e envia os dados através de uma string de consulta numa URL. Para tanto, usa-se o atributo src de uma tag HTML <img> para fazer um pedido de arquivo e passar os dados coletados através da URL (veja Figura 2.1). É uma solução interessante pois permite a coleta de dados que são impossíveis de se coletar no lado do servidor e permite que os dados sejam facilmente enviados para uma máquina diferente da que roda o servidor $W e b$ Entretanto, se usada a mesma máquina do servidor $W e b$, esse método pode duplicar o número de conexões no pior caso. Mas, geralmente, uma página é composta por mais de um arquivo (cada um gera uma conexão) e por isso o custo computacional desta técnica tende a ser baixo.

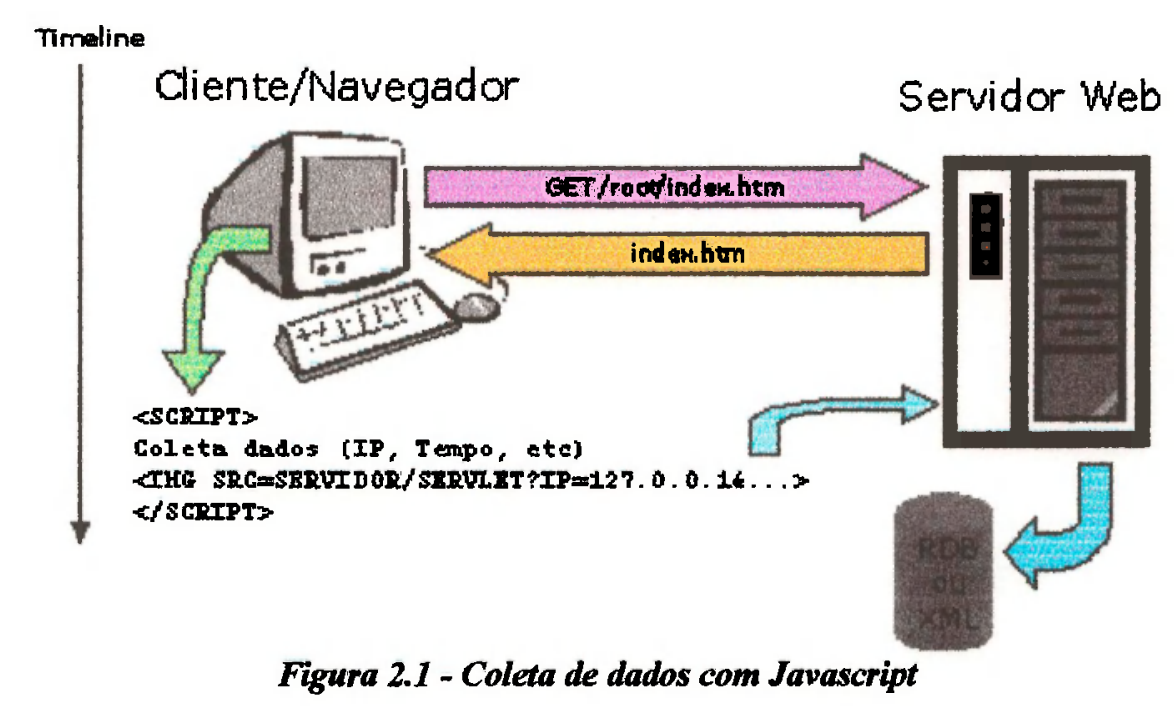

Por exemplo, para se medir o tempo exato de visualização de um documento (com o arquivo de log pode-se apenas estimar esse dado através de clickstreams $^{3}$ ) pode-se usar os eventos onLoad e onUnload do objeto Document. A sequência de eventos é a seguinte: o arquivo é requerido ao servidor (1 conexão); ao carregar a página, os dados coletados são (inclusive a hora) registrados em variáveis no lado cliente; quando a página for fechada, o evento onUnload é ativado; subtraise a hora atual da hora inicial e envia-se todos os dados ao servidor (1 conexão).

Para receber os dados podem ser usados códigos script (PHP, ASP ou JSP), programas CGI ou servlets Java. Servlets e JSPs ${ }^{4}$ têm a melhor portabilidade e escalabilidade e são, portanto, a

hoje é suportada pela grande maioria dos navegadores (com pequenas diferenças). Foi normalizada pela ECMA e recebeu o nome de ECMAScript.

3 Clickstream é o nome dado a uma sequência de acessos. Então, para se estimar o tempo de estada em uma página, subtrai-se da hora de acesso a uma página o tempo em que foi acessada a página anterior.

4 JSPs são transformadas em servlets pelo servidor de aplicação Java. Portanto, de um ponto de vista estritamente computacional, ambos possuem as mesmas características quanto à performance, escalabilidade etc. 
principal solução a ser considerada. Alternativamente, pode-se usar applets Java no lugar de Javascript, entretanto eles tendem a resultar em downloads maiores e o navegador do cliente pode não estar preparado para executá-los, ou seja, não pode não possuir uma Máquina Virtual Java instalada.

Uma solução muito versátil é a utilização de Javascript em conjunto com servlets Java ou JSPs. Com essa combinação, pode-se coletar dados tanto sobre a interação cliente-servidor, como I.P. do cliente, quanto sobre a interação usuário/hiperdocumento, como o tempo de visualização.

\subsection{3 - Identificação de usuários únicos}

O aspecto mais delicado do monitoramento é a identificação de usuários únicos. Há um certo consenso em se usar cookies e/ou exigir registro do usuário como método de identificação. Alguns usam o número I.P. do cliente somado a outro identificador (cookie, tipo de navegador, etc). A fim de entender o problema, vejamos duas situações típicas:

- Numa faculdade, possivelmente existem diversos laboratórios com microcomputadores compartilhados por muitos usuários, então deve ser comum a situação em que diferentes usuários acessam um mesmo Web site de uma mesma máquina e de um mesmo navegador, portanto com mesmo I.P. e mesmo cookie de identificação. Neste caso a única possibilidade de identificação confiável é a exigência de registro ("login")

- Caso o aluno acesse o Web site de sua casa, provavelmente ele estará usando uma conexão discada com atribuição dinâmica de I.P. onde, a cada conexão, seu micro pode receber um número diferente. Alguns provedores, como a $\mathrm{AOL}$, podem alterar o I.P. várias vezes durante uma sessão de acessos. Entretanto, um cookie poderia identificá-lo de forma relativamente segura. Entretanto, várias pessoas na mesma casa podem compartilhar o micro.

Não há, portanto, forma $100 \%$ segura de se identificar um usuário único de forma passiva. É necessário que se estimule a identificação ativa e voluntária do usuário. Um artificio comum é fornecer acesso a determinadas áreas do site somente mediante cadastro. No entanto, a obrigatoriedade de se identificar a cada acesso pode ser desestimulante para o usuário. Com um cookie de identificação, podemos tentar "adivinhar" quem é a pessoa por trás do micro. Por exemplo, uma pessoa usando um micro que é também usado por outras pessoas acessa um site qualquer. Código JSP na página do site logo identifica um cookie no navegador que fez o acesso, 
e cruza seus dados com o banco de dados de usuários cadastrados retornando a página principal alterada dinamicamente. O usuário veria em sua tela algo como "Bom Dia José", e logo à frente um pequeno link com a frase "Se você não é o José, identifique-se aqui".

\section{3 - Fontes de imprecisão}

Firewalls e proxies podem ser uma grande fonte de imprecisão em medidas de audiência. Firewalls "mascaram" o 1.P. das máquinas por trás deles e geralmente bloqueiam o recebimento de determinados tipos de arquivos que são considerados inseguros (applets muitas vezes são bloqueados). Proxies servem páginas que têm guardadas em suas caches diretamente a seus clientes, este acesso não será registrado no $\log$ do servidor $W e b$ que contém a página, como proxies não são incomuns, uma considerável parcela dos acessos a um site pode ficar fora de suas estatísticas. Segundo [Nichols, 2003], é comum que 30\% dos acessos a um site sejam servidos via cache de um proxy e muitas vezes esse número pode passar de $80 \%$. O mesmo pode ocorrer por causa da memória cache do próprio navegador. Usando diretrizes em cabeçalhos HTTP (por exemplo, Pragma = No Cache) pode-se minimizar os problemas com memórias cache. Pode-se, também, definir a data de expiração do documento com datas já passadas.

A técnica que utiliza Javascript não enfrenta essas dificuldades. Mesmo se a página requerida for servida por uma memória cache (do proxy ou navegador), o navegador ainda tentará recuperar a suposta imagem referenciada pelo tag img uma vez que uma página dinâmica (JSP ou servlet que recebe os dados) não pode ser armazenada em cache. Essa característica é uma das maiores vantagens dessa técnica. Fïrewalls também não são problema uma vez que o cỏdigo Javascript fica embutido no código HTML e, portanto, não sofre restrição.

Em sites dinâmicos, pode ocorrer de um mesmo arquivo gerar diversas páginas HTML diferentes de acordo com a interação do usuário. Existem casos extremos onde todo o conteúdo é implementado com esse princípio de forma que detectar a interação do usuário requer soluções especificas. Sites implementados inteiramente em linguagem Flash [Macromedia, 2003], por exemplo, são registrados no $\log$ do servidor como um único arquivo. Nesse caso, pode-se aplicar a mesma idéia da técnica Javascript, ou seja, coleta-se os dados com código Flash e depois eles podem ser enviados via atributo sre de uma tag img 
Geralmente, quando se mede a audiência de um Web site, deseja-se atestar que muitas pessoas o visitam. Mas nem sempre há uma pessoa por trás de um acesso, e esse é um problema de grande relevância. Na rede, existem softwares chamados de agentes ou robôs que podem acessar um site. Por exemplo, softwares que catalogam sites para mecanismos de busca, agentes que buscam informação, etc. Existem listas disponibilizadas na rede, constantemente atualizadas, dos principais robôs $[\mathrm{ABC}, 2003]$. Entretanto, no caso de um navegador offline, também caracterizado como agente ou robô, pode-se supor que seu usuário está interessado no conteúdo que o robô deve recuperar. Neste caso, pode ser legítimo contabilizar o acesso.

Percebe-se, então, que nem todo dado coletado deve ser utilizado, pois pode ter sido gerado por fontes ilegítimas. É necessário definir quais acessos não devem ser contabilizados. Deve-se definir regras de filtragem que excluam esses dados não qualificados. Geralmente essas regras se baseiam no I.P. do visitante, no URL requerido, no status HTTP ou no tipo MIME. Por exemplo, pode-se usar o I.P. para excluir dados gerados por atividade interna de manutenção. O status HTTP é muito usado para excluir acessos que não foram servidos adequadamente. Além disso, muitas vezes uma conexão lenta pode fazer com que um usuário abandone um site, gerando dados atípicos de acesso. É interessante, então, tentar detectar esse problema.

\section{4 - Considerações finais}

A melhor solução do ponto de vista técnico para se monitorar um site é, sem dúvida, desenvolver programas específicos para a aplicação em questão. Geralmente, usar código Javascript para coletar dados no lado cliente e servlets Java, ou JSPs, para lidarem com os dados no lado servidor é a melhor forma de implementar esta solução. Porém, isso implica em ter acesso ao código-fonte da aplicação para que se possa adicionar o código Javascript aos hiperdocumentos que se quer monitorar.

Para se avaliar as técnicas desenvolvidas neste trabalho, é interessante analisar dados de sites com diferentes características de uso. No ambiente de pesquisa onde este trabalho foi desenvolvido, tinha-se acesso ao código-fonte de apenas um Web site. Foi preciso, então, recorrer a arquivos de $\log$ de servidores $W e b$ a fim de se obter dados de outros sites. Como os logs são simples arquivos de texto contendo os dados, basta obter uma cópia. O principal problema, em usar arquivos de $\log$, vem da dificuldade de se identificar usuários únicos. 
Foram utilizados dados dos seguintes sites:

- Agents Research (http//java.icmc.usp.br); site mantido pelo Prof. Dr. Dilvan de Abreu Moreira. Apresenta a linha de pesquisa seguida por este. Contém material didático de diversos cursos ligados ao ICMC-USP;

- Homepage do Instituto de Ciências Matemáticas e de Computação (http://www.icmc.usp.br): este site contém informações gerais sobre o Instituto, como docentes, áreas de pesquisa etc.

Como esses dados serão analisados e que resultados serão obtidos são os assuntos dos próximos capítulos. 


\section{CAPÍTULO 3 - DESCOBERTA DE CONHECIMENTO EM DADOS}

\section{1 - Considerações iniciais}

Analisar grandes volumes de dados é tarefa complexa e pode tornar-se até impossível para um examinador humano munido de ferramentas convencionais, como planilhas e representações gráficas comuns. A situação é agravada se os dados forem gerados a grande velocidade. Este, geralmente, é o caso de dados de acesso a Web sites. Frequentemente, há ainda a necessidade de análise em curto prazo. Desenvolveram-se, então, técnicas de extração de informação com auxílio de computador que constituem um ramo da pesquisa em Ciências da Computação usualmente chamado de Mineração de Dados (MD) ou, em inglês, Data Mining.

$\mathrm{Na}$ literatura existem definições variadas. Uns definem MD de forma bem abrangente. [Whestphal \& Blaxton, 1998] define MD como um processo interativo cujo sucesso é caracterizado pela descoberta, seja através de métodos automáticos ou não. Estes métodos podem ser cálculos estatísticos, árvores de decisão, técnicas de visualização de informação entre outros.

Outros definem MD de forma mais restrita. Segundo [Fayyad, 1996], MD é uma etapa de um processo maior chamado de Knowledge Discovery in Data (KDD), ou de Descoberta de Conhecimento em Dados. O KDD é o processo não-trivial de identificar padrões válidos, novos, potencialmente úteis e, por fim, compreensíveis, em dados. É um processo que trata da descoberta de conhecimento em grandes quantidades de dados armazenados em bases de dados O KDD envolve uma série de etapas que tratam desde a preparação dos dados para análise até a validação dos resultados. A etapa mais complexa é a de MD, a qual consiste na aplicação de algoritmos para produzir padrões, que descrevam os dados, ou para produzir modelos, que permitam a predição de novos valores.

Dado o objetivo da análise, os algoritmos para MD podem ser divididos em duas categorias: algoritmos preditivos e descritivos. A análise preditiva busca um modelo que permita a predição de elementos do domínio analisado. A análise descritiva busca padrões que descrevam o domínio. Seguem exemplos dos dois tipos de análise 
- Predição: esses algoritmos, também denominados algoritmos de aprendizado supervisionado, produzem um modelo preditivo com base em atributos. Podem ser, por exemplo, de:

- Classificação: é o processo de encontrar propriedades comuns entre um conjunto de dados de diferentes classes, de acordo com um modelo de classificação. Os atributos possuem valores discretos;

- Regressão: busca-se uma função que permita prever valores futuros de certos atributos em função dos valores já conhecidos;

- Descrição: utilizados para gerar uma descrição dos dados. São denominados algoritmos de aprendizado não-supervisionados e podem ser, por exemplo, de:

- Agrupamento (Clustering): tem como objetivo agrupar objetos semelhantes. Os algoritmos de agrupamento podem ser divididos em dois grupos: os baseados em particionamento e os baseados em hierarquia;

- Associação: é a descoberta de associações ou conexões entre objetos. Por exemplo, dados dois conjuntos de atributos $\mathrm{X}$ e $\mathrm{Y}$, descobre-se que os registros que contém $\mathrm{X}$ tendem a conter $\mathrm{Y}$. Podem-se obter inúmeras regras para um conjunto de dados, entretanto apenas as que se repetem com frequêencia são interessantes;

As tarefas de predição e descrição apontadas acima são, usualmente, resolvidas com técnicas de árvores de decisão, redes neurais e métodos estatísticos. $O$ uso de métodos estatísticos é, possivelmente, a abordagem padrão na análise de dados [Whestphal \& Blaxton, 1998]. Métodos estatísticos de Regressão são usados, principalmente, como técnica preditiva.

Um ponto a ser observado é que algumas técnicas são mais adequadas para determinados problemas que outras. Portanto, não há um método universal de MD. A escolha de um algoritmo para um determinado problema deve ser analisada empiricamente [Baranauskas, Monard \& Batista, 2000].

Neste Capitulo, serão apresentados conceitos relevantes sobre algoritmos de agrupamento e sua aplicação a dados de uso de Web sites 


\section{2 - Agrupamento}

Algoritmos de Agrupamento (Clustering) têm como objetivo agrupar objetos semelhantes de modo que os objetos de grupos diferentes sejam dissemelhantes. Esta é uma área atacada pela pesquisa em Estatística clássica e pela pesquisa em Computação nas sub-áreas de Inteligência Artificial (AI) e Aprendizado de Máquinas (Machine Learning).

As técnicas tradicionais de agrupamento podem ser classificadas em dois grupos: as baseadas em algoritmos de particionamento $\mathrm{e}$ as baseadas em algoritmos hierárquicos. Esta última é subdividida em algoritmos aglomerativos, ou bottom-up, e algoritmos divisivos, ou top-down [Kaufman \& Rousseeuw, 1990].

Algoritmos hierárquicos operam dividindo ou unindo grupos pré-existentes gerando uma estrutura hierárquica que expõe a ordem em que os grupos foram unidos ou divididos. Esta estrutura hierárquica é representada graficamente por dendrogramas, que é um tipo de gráfico bidimensional. Algoritmos aglomerativos começam com cada observação num grupo distinto e procedem com a união destes até que se atinja o critério de parada, enquanto algoritmos divisivos partem de um grupo contendo todas as observações e procedem com subdivisões até que se atinja o critério de parada, o qual geralmente é um número pré-definido de grupos. Os algoritmos aglomerativos são os mais usados desta categoria. Uma vantagem deste método é sua facilidade de lidar com diferentes funções de similaridade ou de distância (dissimilaridade). Isso possibilita flexibilidade quanto aos tipos de atributos analisados

Algoritmos hierárquicos tendem a ser pouco escaláveis devido à necessidade de se trabalhar com uma matriz de similaridade, ou distância, de tamanho $\mathrm{NxN}$ (onde $\mathrm{N}$ é o número de observações). Manter essa matriz em memória pode não ser viável. O algoritmo BIRCH [Zhang et al., 1996], que foi desenvolvido recentemente, é uma exceção nesta categoria e é também um exemplo do esforço atual em busca de algoritmos escaláveis. Outros exemplos são: SLINK [Sibson, 1973], COBWEB [Fisher, 1987], CURE [Guha et al., 1998] e CHAMELEON [Karypis et al., 1999]

Algoritmos baseados em particionamento partem de um número pré-determinado de grupos $(k)$ a serem formados e, então, realocam os dados interativamente até que se obtenha algum tipo de equilibrio. $O$ valor ótimo de $k$ não é conhecido de antemão e só pode ser descoberto experimentalmente 
São dois os principais métodos desta categoria. O primeiro é o chamado K-means [Hartigan, 1975]. Este se baseia no cálculo das centróides das observações, ou seja, da média ponderada dos parâmetros de cada observação, as quais são agrupadas em função da proximidade das centróides. É adequado para dados numéricos apenas e é muito sensível a outliers (pontos fora da curva). $\mathrm{O}$ outro método é o K-medoids, o qual trabalha com medóides ao invés de centróides. Um medóide pode ser definido como o objeto de um grupo cuja dissimilaridade média, em relação aos outros objetos do mesmo grupo, é mínima. É capaz de trabalhar com qualquer tipo de parâmetro e é pouco sensivel a oullıers. Exemplos de algoritmos que usam este método são: PAM, CLARA [Kaufman \& Rousseeuw, 1990] e CLARANS [Ng \& Han, 1994]

Uma outra sub-categoria de algoritmos de agrupamento é a de algoritmos baseados em densidade. Estes adequados para dados espaciais. Exemplo importantes são: DBSCAN [Ester et al., 1996], GDBSCAN [Sander et al., 1998], OPTICS [Ankerst et al., 1999] e DBCLASD [Xu et al., 1998].

Existem diversas outras técnicas que não se encaixam na classificação apresentada, como técnicas baseadas em redes neurais (ex. SOM [Kohonen, 1990]) ou algoritmos genéticos (ex. GGA [Hall et al., 1999])

\section{3 - Aspectos importantes de um algoritmo de agrupamento}

Algumas propriedades importantes em algoritmos de agrupamento são:

- Tipos de atributos que o algoritmo suporta (categóricos vs. numéricos vs temporais);

- Escalabilidade quanto à memória e quanto ao processamento;

- Habilidade em lidar com alta dimensionalidade, ou seja, muitos parâmetros;

- Habilidade em lidar com outliers ("pontos fora da curva").

Geralmente, um dado algoritmo lida com apenas um tipo de dado, seja categórico, numéricoespacial ou outro tipo qualquer. A maioria dos algoritmos tradicionais sofrem de baixa escalabilidade. Apenas recentemente a pesquisa na área tem dado maior foco a este problema. Lidar com alta dimensionalidade é um grande problema uma vez que quanto maior o número de 
atributos, maior a chance de existirem atributos irrelevantes, os quais atrapalham a identificação de grupos

\section{4 - Agrupamento de dados Web}

A maioria dos algoritmos de agrupamento lidam com dados numéricos, porém, dados de uso de Web sites são predominantemente categóricos, como, por exemplo, a URL visitada e o navegador usado. Alguns dados interessantes são, entretanto, contínuos. De qualquer modo, eles podem ser categorizados, basta dividi-los em intervalos e tratar cada intervalo como uma categoria. Porém, isto não é o ideal. Algoritmos que lidam com dados categóricos e vêm sendo usados para agrupar dados de uso de Web sites são o ROCK [Guha et al., 1999] e o CHAMELEON [Karypis et al., 1999].

Existem dois aspectos importantes ligados a este domínio. Primeiramente, a forma como os dados são organizados antes do processamento é muito importante. Alguns trabalham diretamente com o log do servidor Web, outros o processam em busca de sessões de uso ou de uma métrica qualquer (ver [Cooley et al., 1997]). Em segundo lugar, como o interesse está em identificar padrões de navegação, a ordem dos acesso é relevante. A maioria dos algoritmos não leva isto em conta. Os exemplos citados anteriormente não levam em conta a sequência de acessos.

\section{5 - Considerações finais}

A busca por algoritmos de agrupamento não é recente. Apesar do grande número de algoritmos desenvolvidos, poucos são adequados ao uso em dados de uso de Web sites. Os grandes problemas da aplicação dos algoritmos já conhecidos ao domínio Web vêm da típica baixa escalabilidade e da escassez de algoritmos capazes de lidar com dados categóricos.

Estes aspectos motivaram o desenvolvimento da técnica proposta neste trabalho, a qual lida tanto com dados categóricos, quanto contínuos. Os detalhes serão apresentados no próximo capítulo, o Capítulo 4 . 


\section{CAPÍTULO 4 - O MÉTODO LOGICLUSTER}

\section{1 - Considerações iniciais}

O problema que motivou o inicio desta pesquisa foi a falta de percepção que o professor tem do processo de aprendizagem de um aluno de um curso à distância via Internet. Além deste problema, na EAD via Internet pode-se atingir um número de alunos muito grande a um custo relativamente baixo por aluno, e a audiência numerosa certamente dificulta a atuação do professor. Buscou-se, então, ferramentas que pudessem ajudar os professores a entender melhor os perfis de seus alunos de modo a minimizar os problemas apontados.

Julgou-se interessante aplicar um algoritmo de agrupamento aos dados de uso do material didático online (Web site) uma vez que o algoritmo, em princípio, poderia identificar diferentes perfis entre os alunos automaticamente. Isso seria útil, uma vez que o professor poderia trabalhar em função de grupos de alunos ao invés de lidar com cada aluno separadamente.

Dados de uso de Web sites são predominantemente categóricos, como, por exemplo, a URL visitada e o navegador usado. Alguns dados interessantes são, porém, numéricos e contínuos. $\mathrm{O}$ algoritmo de agrupamento a ser utilizado deveria ser capaz de lidar com os dois tipos simultaneamente. Além disso, sabe-se que algoritmos de agrupamento, geralmente, não escalam bem e o domínio em questão costuma gerar grandes volumes de dados com um grande número de parâmetros. A grande maioria dos algoritmos de agrupamento conhecidos não atende satisfatoriamente aos aspectos citados. Surgiu, então, o interesse em se pesquisar novas formas de se efetuar agrupamento neste domínio.

O método proposto neste trabalho se baseia no Modelo de Regressão Logístico. Este modelo de regressão foi desenvolvido para lidar com variáveis de resposta binárias e variáveis explanatórias categóricas ou continuas (em conjunto ou não). Os alunos seriam tratados como variável de resposta e as variáveis URL, navegador, etc, representariam as variáveis explanatórias. Uma vez que a variável de resposta deve ser binária, a análise deve ser feita sobre os dados de pares de alunos (dois a dois), os quais são codificados com os valores zero (aluno A) e um (aluno B). Feita a análise sobre todos os pares de alunos, é possivel determinar quais deles são semelhantes (de acordo com o modelo desenvolvido) e proceder com o agrupamento em sí. 
Neste Capitulo, serão apresentados os princípios do Modelo de Regressão Logística e como, a partir deste, se desenvolveu o procedimento de agrupamento

\section{2 - Modelo de Regressão Logístico}

\subsection{1 - Introdução}

Modelos de Regressão se tornaram parte integrante de todo tipo de análise onde se quer medir a influência de determinadas variáveis (chamadas de variáveis explanatórias ou independentes) em relação a uma outra variável (variável de resposta ou dependente) [Hosmer \& Lemeshow, 1989]. O que distingue o Modelo de Regressão Logística do conhecido Modelo de Regressão Linear é o fato de o primeiro lidar com variáveis de resposta categóricas. A variável de resposta é usualmente binária, ou seja, só pode assumir dois valores. Este método vem sendo usualmente aplicado a dados referentes à área das Ciências Biológicas, portanto a aplicação a dados da Web é uma nova aplicação a ser discutida neste trabalho.

\subsection{2 - Princípios da Regressão Logística}

Dado o modelo de Regressão Linear:

$$
Y_{i}=\beta_{0}+\beta_{1} \cdot x_{i}+\varepsilon_{i}
$$

onde $Y_{i}$ corresponde à variável de resposta, $x_{i}$ corresponde à variável explanatória e $\varepsilon_{i}$ ao erro experimental. Em geral, assumimos que o erro experimental tem distribuição normal. Caso $Y_{t}$ seja dicotômica (possa assumir apenas dois valores discretos como 0 e 1), a resposta esperada $E_{(}\left(Y_{j} j\right.$ é a probabilidade de sucesso, ou seja, a probabilidade de que $Y$, seja igual a um.

Considera-se que $Y_{r}$ seja uma variável aleatória de Bernoulli para a qual tem-se a seguinte distribuição probabilística: $\boldsymbol{P}\left(\boldsymbol{Y}_{t}=\boldsymbol{I}\right)=\boldsymbol{\pi}_{i} \mathrm{e} \boldsymbol{P}\left(\boldsymbol{Y}_{\boldsymbol{i}}-\boldsymbol{0}\right)=\boldsymbol{I}-\boldsymbol{\pi}_{i}$ [Neter et al., 1996]. De acordo com a definição de valor esperado para uma variável aleatória, obtém-se:

$$
E\left(Y_{i}\right)=1 \cdot\left(\pi_{i}\right)+0 .\left(1-\pi_{i}\right)=\pi_{i}
$$

Equacionando (1) e (2) e considerando-se que $E\left(\varepsilon_{i}\right)=0$, obtém-se: 
Portanto, $E\left(Y_{i}\right)$ é a probabilidade de $Y_{i}$ ser 1 , dado $x_{i}$

Surge, então, a idéia central do método proposto neste trabalho. Assumindo-se que existam dados de uso do Web site referentes a dois usuários, pode-se calcular a probabilidade de que os dados de um sejam iguais aos do outro. Um usuário seria codificado como zero e o outro como um, e $\pi_{i}$ representaria a probabilidade dos dados do usuário zero serem iguais aos dados do usuário um. Pode-se, ainda, comparar todos os usuários dois a dois de forma que seja possível calcular $\pi_{i}$ entre todos, tornando trivial a tarefa de agrupá-los. Maiores detalhes são apresentados no item 4.3 .

\subsection{3 - Desenvolvendo o Modelo de Regressão Logística}

No Modelo de Regressão Logística a resposta está sujeita a uma restrição:

$$
0 \leq E(Y)=\pi<1
$$

Uma solução é o uso da seguinte função de resposta:

$$
E(Y)=\frac{e^{\left(\beta_{0}+\beta_{1} x\right)}}{1+e^{\left(R_{1}+\beta_{1} \cdots\right)}} \quad \text { (Modelo de Regressão Logística) }
$$

Esta função varia entre 0 e 1, é aproximadamente linear (exceto pelas extremidades) e, portanto, atende à restrição citada (ver figura 4.1).

A equação (4) pode ser linearizada da seguinte forma:

$$
\ln \left[\frac{\pi}{1-\pi}\right]=\beta_{0}+\beta_{1} \cdot x \quad \text { (Logit) }
$$

Esta transformação permite que se mantenham certas propriedades do Modelo de Regressão Linear que são importantes no desenvolvimento do Modelo de Regressão Logística, e é chamada de Transformação Logit ou simplesmente logit.

Outras funções de resposta (ou funções de link) podem ser usadas, por exemplo a chamada probit, e assim obtém-se outros modelos. Estes são chamados Modelos Lineares Generalizados. O Modelo Logístico é, portanto, um tipo de Modelo Linear Generalizado. 
O termo $\pi /[1-\pi]$ é chamado Odds Ratio (OR) e representa a probabilidade de $Y$ ser igual à 1 dividida pela probabilidade de $Y$ ser igual à 0 .

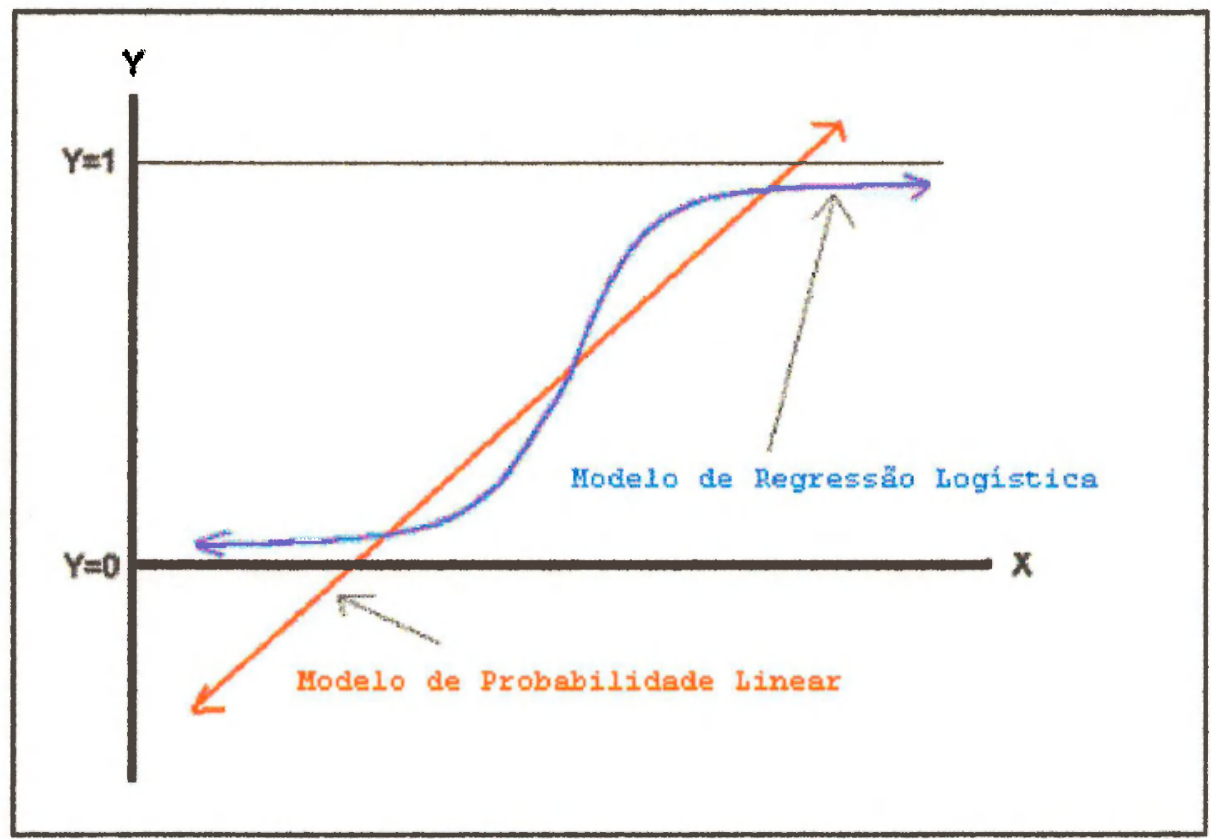

Figura 4.1 - Funçōes de resposta dos modelos

\subsection{4 - Calculando os coeficientes}

Para se estimar os coeficientes do Modelo usa-se, geralmente, um método chamado Máxima Verossimilhança (Maximum Likehood). A aplicação deste método implica na escolha de uma função que expresse a probabilidade de ocorrência dos dados observados em função dos parâmetros desconhecidos. A essa função se dá o nome de Função de Verossimilhança (Likehood Function). Maximizando-a, obtêm-se os coeficientes desejados.

Assumindo que se tem uma amostra de $n$ observações independentes do tipo $\left(Y_{i}, x_{i j}\right)$ onde $i=1$, $2, \ldots n$ é o número de observações e $j-1,2, \ldots p$ é o número de parâmetros do Modelo, então a contribuição da "iésima" amostra $\left(Y_{i}, x_{i j}\right)$ para a Função de Verossimilhança caso $Y_{i}$ seja 1 é $\pi\left(x_{i}\right)$. E se $Y_{i}$ for zero, $1-\pi\left(x_{i}\right)$. Uma forma matematicamente conveniente de se expressar isso é:

$$
\zeta\left(x_{i}\right)=\pi\left(x_{i}\right)^{y_{i}} \cdot\left[1-\pi\left(x_{i}\right)\right]^{1-y_{i}}
$$

Uma vez que as observações são independentes, a Função de Verossimilhança pode ser obtida 
pela multiplicação dos termos da equação acima. Desta forma:

$$
l(\beta)=\prod_{i=1}^{n} \zeta\left(x_{i}\right)
$$

Resta, agora, estimar o valor de $\beta$ que maximiza essa função. Porém, é mais fácil matematicamente trabalhar com o log da equação anterior. Essa equação é chamada de $\log$ Likehood:

$$
L(\beta)=\ln [l(\beta)]=\sum_{i \neq 1}^{n} y_{i} \ln \left[\pi\left(x_{i}\right)\right]+\left(1-y_{i}\right) \ln \left[1-\pi\left(x_{i}\right)\right]
$$

Diferenciando a equação acima em relação aos coeficientes $\beta$ e igualando os resultados à zero obtém-se um conjunto de equações que podem ser resolvidas por métodos numéricos, sendo que o método de Newton-Raphson é o mais usado. Estas equações são chamadas de Equações de Verossimilhança:

$$
\begin{aligned}
& \sum_{i=1}^{n}\left[y_{i}-\pi\left(x_{i}\right)\right]=0 \\
& \sum_{i=1}^{n} x_{i j}\left[y_{i}-\pi\left(x_{i}\right)\right]=0 \quad \text { para } j=1,2, \ldots p
\end{aligned}
$$

Existirão $(p+1)$ equações, onde $p$ é a quantidade de coeficientes $(\beta)$

\subsection{5 - Avaliando o ajuste do modelo}

A adequação do modelo obtido precisa ser avaliada antes que este possa ser usado. No caso da Regressão Logística em particular, é importante avaliar se a função de resposta é monotônica e sigmoidal (em forma de S), características fundamentais do Modelo. Isto pode ser verificado informalmente com representações gráficas. Esta verificação é formalizada por um teste denominado Teste Qui-quadrado $\left(\chi^{2}\right)$. Existem, ainda, outros procedimentos que podem ser aplicados ao modelo a fim de avaliá-lo como, por exemplo, o teste "Deviance Goodness of Fit "'est" que avalia o desvio do modelo [Neter et al., 1996] 


\subsubsection{1 - Teste Qui-quadrado $\left(x^{2}\right)$}

É o teste de ajuste nais antigo e bem conhecido que existe. Ele assume apenas que as $Y_{i}$ observações são independentes e que o tamanho da amostra é razoavelmente grande. Ele detecta grandes desvios em relação à função logística, porém pequenos desvios não são notados. A estatística Qui-quadrado de Pearson para o Modelo Logístico, segundo [Hosmer \& Lemeshow, 1989], é:

$$
X^{2}=\sum_{j=1}^{J} \frac{\left(y_{j}-m_{j} \hat{\pi}_{j}\right)^{2}}{m_{j} \hat{\pi}_{j}\left(1-\hat{\pi}_{j}\right)}
$$

onde $J$ é o número de valores distintos do logit, $m_{l}$ é o numero ocorrências do valor distinto $j$, $\lambda$ jé o valor ajustado $j$ e $y_{j}$ é o valor observado. Lembre-se que para cada observação, calcula-se um valor para o logit.

O procedimento parte das seguintes hipóteses:

$$
\begin{array}{ll}
\boldsymbol{H}_{\boldsymbol{\theta}}: & E(Y)=\left[1+e^{\left(-\beta^{\prime} \cdot X\right)}\right]^{-1} \\
\boldsymbol{H}_{\mathfrak{d}}: & E(Y) \neq\left[1+e^{\left(-\beta^{\prime} \cdot X\right)}\right]^{-1}
\end{array}
$$

A hipótese $\boldsymbol{H}_{\boldsymbol{o}}$ afirma que a função de resposta $E(Y)$ atende às propriedades esperadas, ou seja, é monotônica e sigmoidal, e, portanto, o modelo seria adequado. Valores altos de $X^{2}$ indicam que o modelo não é apropriado. A regra de decisão é (ver Figura 4.2):

$$
\begin{aligned}
& \text { Se } X^{2} \leq \chi^{2}\left(1-\alpha ; J_{-p+1}, \text { não rejeitamos } \boldsymbol{H}_{\boldsymbol{\theta}},\right. \\
& \text { Se } X^{2}>\chi^{2}\left(1-\alpha, J_{-p}+1\right), \text { rejeitamos } \boldsymbol{H}_{\boldsymbol{\sigma}} .
\end{aligned}
$$

onde $p$ é o número de covariáveis do modelo.

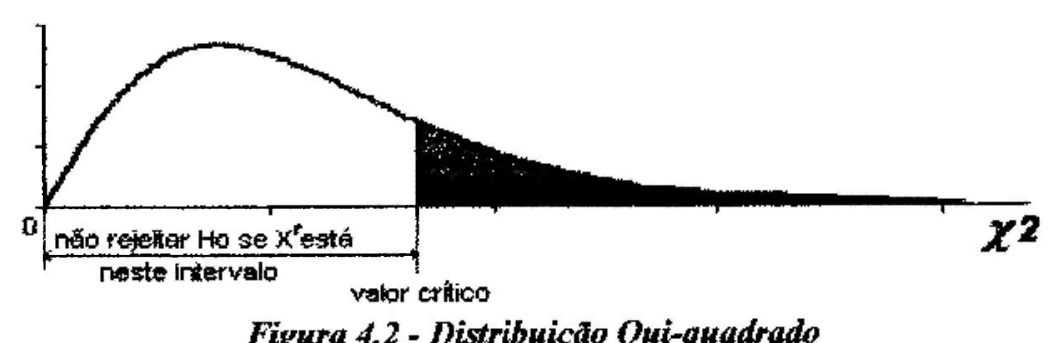


Pode-se enunciar a regra de decisão usando a estatística P-valor, a qual é igual à $1-\chi_{\text {(acumulada) }}^{2}$ neste caso. Desta forma:

\author{
Se P-valor $\geq \alpha$, não rejeitamos $\boldsymbol{H}_{\boldsymbol{\theta}}$, \\ Se P-valor $<\alpha$, rejeitamos $\boldsymbol{H}_{\boldsymbol{\theta}}$
}

Onde 1- $\alpha$ é confiabilidade esperada. Geralmente adota-se $\alpha-0,05(5 \%)$, o que implica em $95 \%$ de confiabilidade.

\title{
4.2.5.2 - Teste "Deviance Goodness of Fit"
}

Este teste se baseia numa estatística chamada "model deviance", ou desvio do modelo. Sabe-se que, se a amostra for suficientemente grande, o desvio do Modelo Logístico seguirá uma distribuição $\chi^{2}$ com $(n-p)$ graus de liberdade, onde $n$ é o número de observações e $p$ o número de covariáveis do modelo. Valores grandes para o desvio indicam que o modelo não é adequado. Inicialmente, são assumidas as seguintes hipóteses:

$$
\begin{aligned}
& \boldsymbol{H}_{\boldsymbol{g}} \text { : o modelo é adequado; } \\
& \boldsymbol{H}_{1} \text { : o modelo não é adequado. }
\end{aligned}
$$

A regra de decisão para este teste é: se o desvio do modelo for menor ou igual $(<)$ a $\chi^{2}(1-\alpha, n-q)$, o modelo é satisfatório; e se o desvio for maior que $(>) \chi^{2}(1-\alpha, n-q)$, o modelo não é adequado. Assim como no teste $\chi^{2}$, pode-se enunciar a regra de decisão usando a estatística P-valor, a qual é

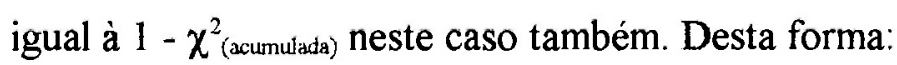

$$
\begin{aligned}
& \text { Se P-valor } \geq \alpha, \text { não rejeitamos } \boldsymbol{H}_{\boldsymbol{\theta}}, \\
& \text { Se P-valor }<\alpha \text {, rejeitamos } \boldsymbol{H}_{\boldsymbol{\sigma}} .
\end{aligned}
$$

O termo $1-\alpha$ é a confiabilidade esperada. Geralmente adota-se $\alpha=0,05(5 \%)$, o que implica em $95 \%$ de confiabilidade 


\section{3 - O procedimento de agrupamento}

Viu-se no item 4.2.2 que, com o Modelo de Regressão Logística, pode-se calcular a probabilidade $\left(\pi_{3}\right)$ de que os dados de um usuário sejam iguais aos de outro usuário. Para tanto, o primeiro passo é efetuar a regressão com os dados referentes aos dois usuários em questão. Estes representam a variável dependente no modelo, a qual pode assumir apenas dois valores, 0 e 1 . A Tabela 4.1 contém uma amostra dos dados usados neste trabalho para testar o procedimento:

Tabela 4.1 - Amostra de dados de uso de Web sites

\begin{tabular}{|c|c|c|c|c|c|c|}
\hline $2-7$ & prenotia & Exagentor & 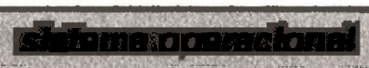 & $m$ mancin & status & bytes enviados \\
\hline 0 & manhã & MSIE & Windows XP & GET & 200 & 4784 \\
\hline 0 & manhã & MSIE & Windows XP & GET & 200 & 435784 \\
\hline 0 & manhã & MSIE & Windows XP & GET & 200 & 78 \\
\hline 0 & tarde & Netscape & Windows XP & POST & 200 & 7848 \\
\hline 0 & tarde & MSIE & Windows XP & GET & 404 & 658 \\
\hline 1 & madrugada & MSIE & Windows 2000 & GET & 200 & 2457 \\
\hline 1 & noite & MSIE & Windows 2000 & HEAD & 200 & 5277 \\
\hline 1 & noite & Netscape & Linux & GET & 404 & 757 \\
\hline 1 & manhã & Opera & Windows 2000 & GET & 200 & 75376 \\
\hline 1 & noite & Netscape & Linux & GET & 200 & 7657 \\
\hline
\end{tabular}

Para a execução da regressão, os dois usuários são codificados por zero e um, como visto na coluna Usuário da Tabela 4.1. As demais variáveis, chamadas explanatórias ou covariáveis, são categóricas exceto pela variável bytes enviados. O Modelo de Regressão Logística pode lidar com os dois tipos, tanto independentemente, quanto em conjunto.

Como resultado da regressão obtém-se as estimativas dos coeficientes $(\beta)$ da função Logit (equação 5 vista no item 4.3):

$$
\ln \left[\frac{\pi\left(x_{i}\right)}{1-\pi\left(x_{i}\right)}\right]=\beta_{0}+\beta_{1} \cdot x_{i 1}+\beta_{2} \cdot x_{i 2}+\ldots+\beta_{p} \cdot x_{i p}
$$

Desta equação se calcula a probabilidade $\pi\left(x_{i}\right)$ da variável de resposta ser igual a 1 dados $x_{i j}$ onde $j=1,2,3 \ldots p$ ( $p$ é o número de covariáveis) e $i=1,2,3 \ldots n$ ( $n$ é o número de observações)

Assim, substituindo-se os dados de um usuário na função, obtém-se a probabilidade destes serem iguais aos dados do usuário 1 . Se isto for feito com os dados do usuário 0 , obtém-se a 
probabilidade dos dados do usuário 0 serem iguais aos do usuário 1. Essa substituição deve levar em conta todas as $n$ observações referentes ao usuário, o que produzirá um número $n$ de probabilidades. De modo a se obter apenas um valor que indique a probabilidade de igualdade entre os usuários, decidiu-se trabalhar com a média aritmética dos valores ajustados referentes a cada observação.

Num primeiro momento, pode-se imaginar que o que se busca são valores altos $(0,9$ ou mais) para as probabilidades $\pi_{\imath}$, pois isso indicaria muita similaridade entre os dados dos usuários. Porém, lembrando que $P\left(Y_{i}=1\right)=\pi_{i}$ e $P\left(Y_{i}-0\right)-1-\pi_{i}$, considere a seguinte questão. se a

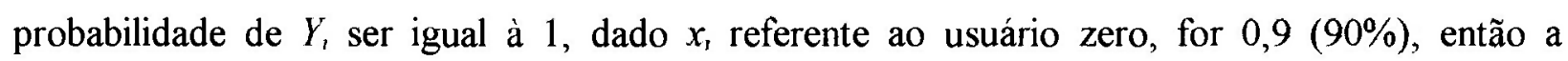
probabilidade de $Y_{t}$ ser 0 , dado o mesmo $x_{r}$, deveria ser 0,1 . Isto é incoerente. Como um modelo pode afirmar que os dados de zero têm apenas $10 \%$ de chance de serem iguais a eles mesmos? Caso isso ocorra, conclui-se que esse modelo representa mal os dados analisados

Então, assume-se que probabilidades superiores à 0,55 indicam um modelo inadequado. De qualquer modo, quando se obtêm baixas probabilidades, é seguro afirmar que os usuários são diferentes. Decidiu-se trabalhar com o seguinte intervalo $0,45 \leq \pi\left(x_{i}\right) \leq 0,55$. Ou seja, se o valor de $\pi\left(x_{i}\right)$ estiver contido neste intervalo, os dados dos usuários são considerados semelhantes $\mathrm{e}$ serão agrupados. Valores maiores que 0,55 serão descartados e valores menores que 0,45 apenas indicam baixa similaridade. $\mathrm{O}$ intervalo citado é arbitrário e pode ser refinado experimentalmente

Neste ponto, é importante notar que variáveis categóricas devem ser tratadas de maneira particular. Como se pode expressar numericamente de forma equivalente as diferentes categorias? Uma solução é desmembrar a variável em mais variáveis, chamadas variáveis de design, de modo que cada uma possa assumir apenas dois valores $(0$ e 1$)$ e as combinações destes valores representariam cada categoria. Por exemplo, a variảvel método (ver Tabela 4.1) possui três categorias: GET, POST e HEAD. Ela pode ser desmembrada em duas variáveis de design, $x_{a}$ e $x_{b}$. Então, $x_{a}=0$ e $x_{b}=0$ representariam a categoria GET, $x_{a}=0$ e $x_{b}=1$ representariam POST e $x_{a}=1$ e $x_{b}=1$ a categoria HEAD. Então, sempre que uma equação neste texto referenciar o número de covariáveis, deve-se considerar cada variável de design como uma covariável distinta.

O procedimento apresentado anteriormente pode ser executado para todas as combinações de usuários. Isto permitiria comparar as probabilidades de igualdade de todos, sendo possível agrupá-los. Por exemplo, vejamos na Tabela 4.2 o que se obtém ao aplicar o procedimento acima 
aos dados de seis diferentes usuários:

Tabela 4.2 - Matriz $\boldsymbol{I}$

\begin{tabular}{|c|c|c|c|c|c|c|}
\hline Evatinto & $d$ & 1 & $=$ & 3 & 4 & 3 \\
\hline 0 & & 0.2658 & 0.0 & 0.0074 & 0.2533 & 0.0097 \\
\hline 1 & & & 0.6 & 0.2802 & 0.1827 & sidur \\
\hline 22 & & & & 0.5407 & 0.0 & 0.0 \\
\hline 3 & & & & & 0.0 & 90 \\
\hline 4 & & & & & & 0.0203 \\
\hline 9 & & & & & & \\
\hline
\end{tabular}

Deu-se o nome de Matriz $\Pi$ à matriz obtida. Analisando-se a primeira linha da Tabela 4.2 pode-se notar que os usuários 2,3 e 5 possuem probabilidades muito baixas de serem iguais ao usuário $0 \mathrm{e}$ jamais poderiam formar um grupo com este. Nada se pode afirmar quanto aos usuários 1 e 4 . Na segunda linha, vê-se que 1 possui baixa probabilidade de igualdade em relação à 2 e 5 e, mais uma vez, nada se pode afirmar sobre 3 e 4 . Até agora, sabe-se que 0 não deve ser agrupado com 2,3 e 5. Sabe-se, também, que 1 não deve ser agrupado com 2 e 5.

$\mathrm{Na}$ terceira linha, encontra-se uma probabilidade de $55 \%$ de similaridade entre 2 e 3 . Este é um valor considerado alto e, portanto, 2 e 3 devem ser agrupados. Na mesma linha descobre-se, ainda, que 2 não deveria ser agrupado com 4 e 5 . Olhando-se as duas últimas linhas, conclui-se que 3,4 e 5 não poderiam pertencer ao mesmo grupo.

Finalmente, seriam obtidos os seguintes grupos: (0); (1); (2, 3); (4); (5).

As regressões entre cada combinação de usuário (dois a dois) consideram os mesmos atributos, com as mesmas categorias para todos. De qualquer modo, o modelo obtido pela regressão para um dado par de usuários pode não ser bom. Por isso, deve ser avaliada a adequação do modelo obtido (ver item 4.2.5) e, caso não seja adequado, este deve ser descartado. Eventualmente, a maioria dos modelos obtidos pode ter que ser descartada e, neste caso, é preciso reconsiderar os atributos da análise. Isso também pode ocorrer caso o algoritmo de regressão não venha a convergir. 


\section{4 - Considerações finais}

Com o Modelo de Regressão Logística pode-se calcular a probabilidade de que os dados de um usuário sejam iguais aos dados de outro. Efetuando-se este cálculo para todas as possíveis combinações entre usuários é possivel avaliar se usuários são similares sendo, então, possível agrupá-los

O procedimento de agrupamento pode ser sumarizado pelas seguintes etapas:

1. identificar as possiveis combinações de usuários e para cada combinação:

1. 1. efetuar a regressão logística;

1.2. substituir os dados do usuário tratado por zero na fórmula obtida de modo a calcular a média de $\pi_{1}$;

1.3.armazenar o valor da média de $\pi_{i}$

\section{2. uma vez obtida a Matriz $\Pi$}

2.1.varrer a primeira linha, a qual compara o usuário zero com todos os outros, procurando valores dentro do intervalo de corte $\left(0,45 \leq \pi\left(x_{i}\right) \leq 0,55\right)$;

2.2.formar um grupo (Grupo 0) com estes valores. Caso nenhum valor esteja acima do limite de corte, o usuário zero não possui similaridade significativa com os outros usuários e deve formar um grupo sozinho;

2.3.remover da análise os usuários que fazem parte do Grupo 0;

2.4. procurar o próximo usuário que não pertence a um grupo;

2.5.varrer a linha correspondente a esse usuário procurando valores dentro do intervalo de corte;

2.6. formar um grupo com estes valores;

2.7.voltar ao passo 2.4 até que se esgotem os usuários

O algoritmo que efetua a Regressão Logística é muito complexo, contudo existem diversos programas que possuem uma implementação deste Modelo de Regressão e que podem ser 
utilizados. São exemplos os conhecidos pacotes Minitab [Minitab, 2003] e S-Plus [S-Plus, 2003]

Ambos são amplamente usados no meio acadêmico e suas implementações do modelo atingiram grande robustez. Optou-se por usar o programa S-Plus devido à sua portabilidade (existem versões para Windows e Linux) e à sua maior flexibilidade quanto à inteface com outros programas

Os resultados obtidos com implementação da técnica serão apresentados no Capítulo 5. 


\section{CAPÍTULO 5 - RESULTADOS}

\section{1 - Considerações iniciais}

Neste capítulo, será apresentada a ferramenta desenvolvida com o propósito de testar o método de agrupamento proposto, o qual foi nomeado LogiCluster. Serão, também, apresentados os resultados obtidos da análise dos dados de uso de Web sites coletados conforme descrito no Capítulo 2

A ferramenta foi denominada Clusterizer. Ela implementa a lógica do algoritmo de agrupamento que foi apresentada no item 4.3. O procedimento de regressão é deixado à cargo do programa $\mathrm{S}$ Plus. Este programa possui uma interface nativa com a linguagem Java. Por esta razão optou-se por usar a Java na implementação. Um beneficio adicional em se usar Java vem do fato desta ser multiplataforma. Isto permite que a ferramenta seja usada com as ambas as versões do S-Plus, para Linux e para Windows.

Para facilitar a portabilidade do sistema para diferentes versões do S-Plus, optou-se por usar a interface nativa apenas como forma de disparar a execução de funções a partir de código Java. Os resultados do processamento feito pelo S-Plus são escritos em um arquivo XML, o qual é lido pelo programa Java ao fim do processo a fim de obter a Matriz $\Pi$ (ver item 4.3).

\section{2 - A ferramenta Clusterizer}

A interface gráfica do Clusterizer pode ser vista nas Figura 5.1, 5.2 e 5.3. Na primeira figura pode-se ver, acima e à direita, a Matriz $\Pi$ obtida dos resultados do S-Plus (veja Tabela 4.2 no item 4.3). Logo abaixo vê-se um conjunto de abas ("tabs") as quais contêm uma representação gráfica simples dos grupos formados e algumas tabelas com os valores de diversos testes de ajuste (ver item 4.2.5). No rodapé da interface há uma área reservada para exibição de informações textuais.

Os dois procedimentos básicos executados pelo programa são disparados pelos dois botões no canto superior esquerdo. Estes botões poderiam ser substituidos por um único botão, mas a 
separação facilita a depuração, se necessária. Note que a sequência dos procedimentos é importante e os botões devem ser acionados em ordem, de cima para baixo. $O$ procedimento disparado pelo primeiro botão é responsável por identificar as diferentes categorias da variável dependente (que é a variável que identifica os usuários), formatar seus dados adequadamente para leitura por parte do S-Plus, gerar o script para o mesmo e disparar sua execução. Quando terminada esta etapa, terá sido gerado um arquivo XML contendo os resultados das regressões. Finalmente, acionando-se o segundo botão, os dados serão lidos, apresentados pelo Clusterizer e os usuários agrupados.

Logo abaixo dos botões citados existe, ainda, dois campos onde se define o intervalo de corte (item 4.3), uma ComboBox que permite selecionar uma função de link diferente da logit (ver item 4.2.3) e uma lista dos elementos, ou usuários, que foram analisados. Acima desta lista há um botão que leva a uma nova tela onde são apresentados detalhes dos elementos (ver Figura 5.3).

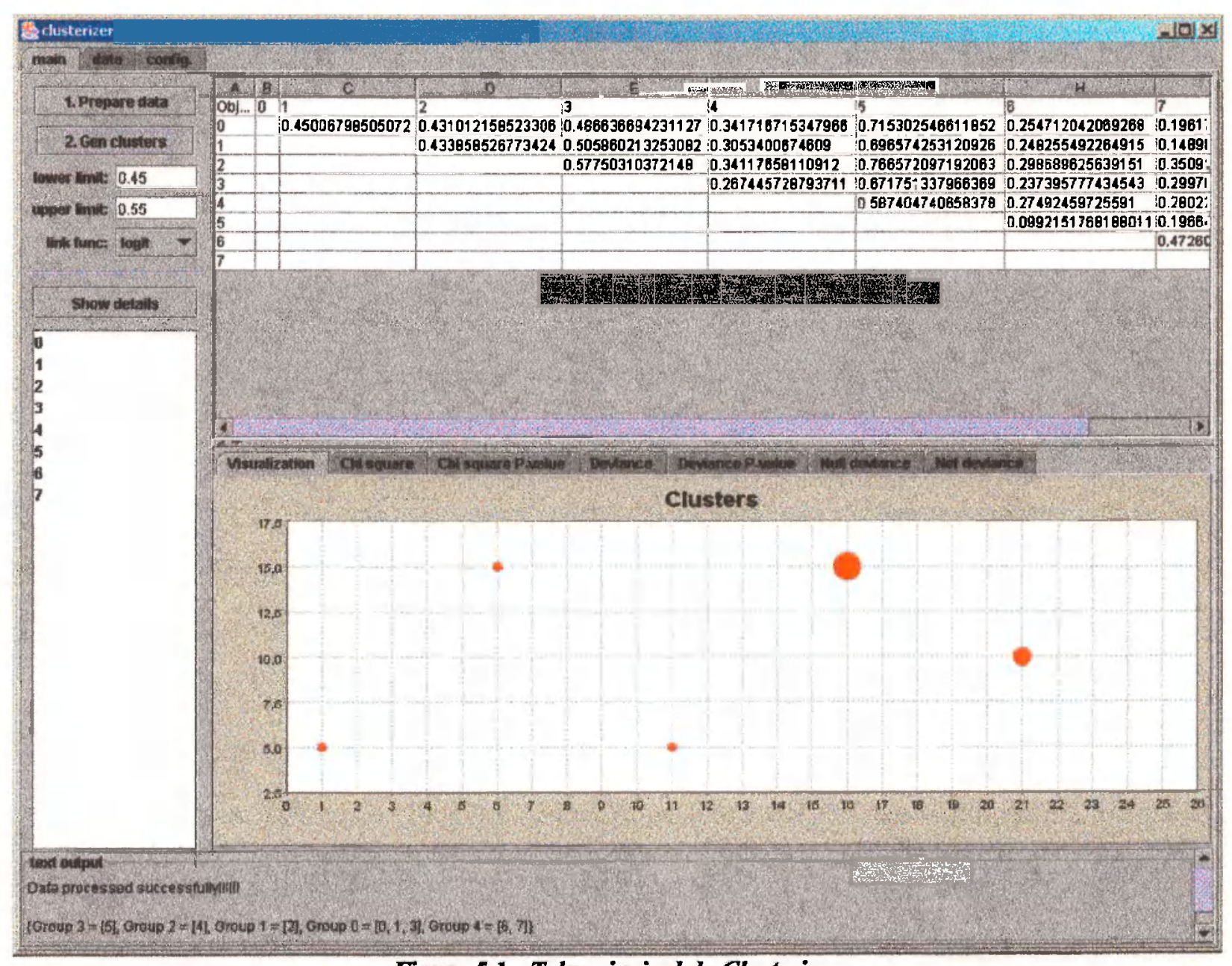

Figura 5.1 - Tela principal do Clusterizer

Antes de se executar o agrupamento, é preciso escolher a fonte de dados e selecionar os atributos 
para a análise. Isso se faz na interface vista na Figura 5.2. No canto superior esquerdo desta tela há uma ComboBox de nome datasource que permite a seleção da fonte dos dados. Á direita, há uma grande tabela onde se exibe uma amostra da fonte escolhida. Abaixo da ComboBox datasource existe outra onde se escolhe a variável dependente. Logo abaixo desta, o usuário pode definir limites mínimo e máximo para o número de observações referentes a cada categoria da variável dependente. O limite mínimo é importante para se garantir significância estatística. Já o máximo é particularmente útil quando se está analisando logs de Web sites e usando o número I.P. como forma de identificação de usuários. Neste caso, um número grande acessos (observações) vindos de um mesmo I.P. indicam servidores proxy ou firewalls e por traz destes, geralmente, existem diversos usuários. As categorias da variável dependente que respeitam os limite definidos são exibidas logo em seguida.

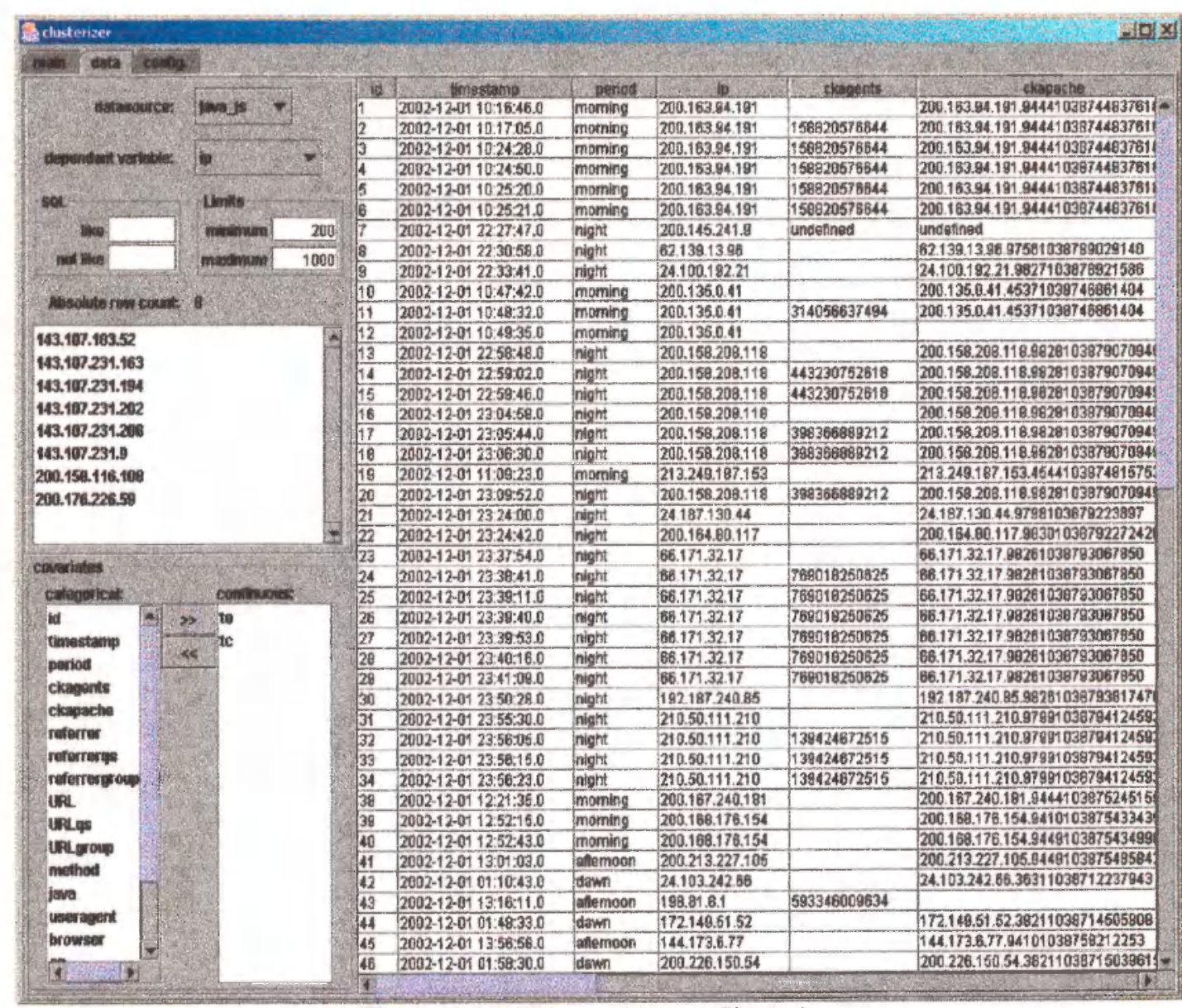

Figura 5.2 - Tela auxiliar do Clusterizer

No canto inferior direito, vê-se uma lista dos possiveis atributos (covariáveis) a serem 
selecionados. É preciso indicar quais são numéricos e quais são categóricos. Uma vez selecionadas a fonte de dados, as covariáveis e a variável dependente pode-se proceder com o agrupamento.

As configurações básicas para o funcionamento do programa são feitas numa terceira tela onde é definida a fonte dos dados a serem analisados (deve ser uma tabela em um banco de dados relacional), informações para "login" no banco de dados, o caminho no sistema de arquivos para o executável do S-Plus e o caminho para um diretório temporário de uso do Clusterizer.

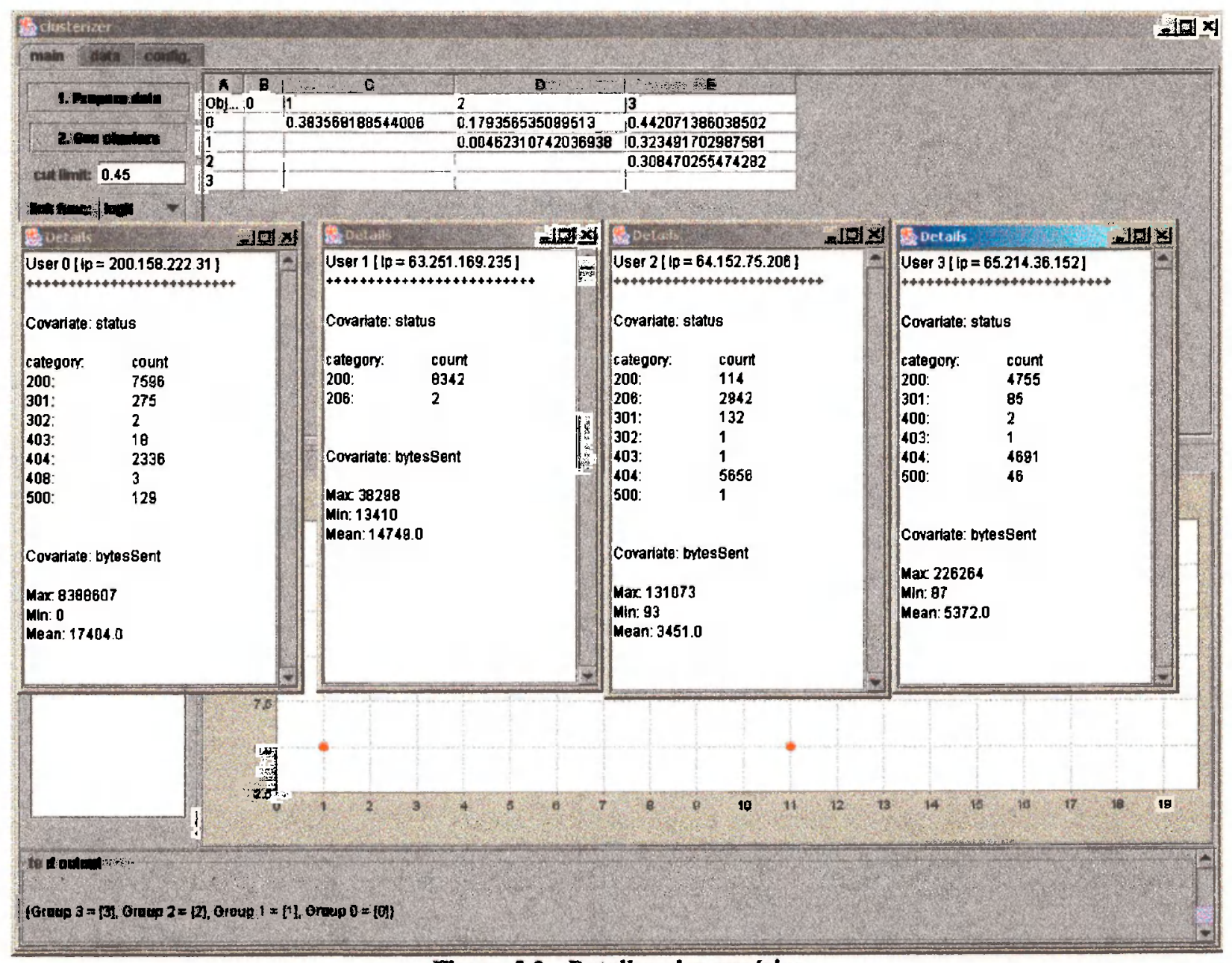

Figura 5.3 - Detalhes dos usuários

\section{3 - Resultados dos experimentos}

Foram executados inúmeros experimentos com os dados de acesso a dois diferentes Web sites: 
- Agents Research (http//java.icmc.usp.br): site mantido pelo Prof. Dr. Dilvan de Abreu Moreira. Apresenta a linha de pesquisa seguida por este. Contém material didático de diversos cursos ligados ao ICMC-USP. Como descrito no item 2.4, os dados relativos a este site foram coletados de duas maneiras: via Javascript e pelo log do servidor $\mathrm{Web}$.

\section{- Homepage do Instituto de Ciências Matemáticas e de Computação}

(http://www.icmc.usp.br): este site contém informações gerais sobre o Instituto, como docentes, áreas de pesquisa etc. Neste site, os dados vieram exclusivamente do log do servidor Web

Antes dos experimentos serem executados, foi feita uma análise preliminar dos dados a fim de identificar variáveis que possam ser eliminadas das análises. Por exemplo, dentre as variáveis coletadas via Javascript no site Agents Research, constatou-se que a variável method possuia o mesmo valor, GET, para a maioria esmagadora da observações (veja Tabela 5.1). Obviamente, esta variável não pode distinguir os usuários e deve ser excluída da análise.

\begin{tabular}{|} 
Tabela 5.1 - Ocorrências da variável method \\
\begin{tabular}{|c|c|}
\hline method & ocorrências \\
\hline GET & 19168 \\
\hline HEAD & 3 \\
\hline
\end{tabular}
\end{tabular}

Deve-se buscar casos como o apresentado não apenas no conjunto de dados como um todo, mas também nos dados classificados por usuário. Por exemplo, é de se esperar que um determinado usuário use um mesmo navegador e um mesmo sistema operacional em todos seus acessos. Então, se tentarmos comparar dois usuários que possuam os mesmos valores em todas as observações, a regressão não terá sucesso. Variáveis com esta característica devem ser evitadas.

Além dos cuidados apontados, tendo em mente a motivação inicial deste trabalho, procurou-se selecionar apenas as variáveis que pudessem caracterizar o usuário de alguma forma.

Após a análise preliminar, procedeu-se com experimentos incluindo apenas uma variável por vez e, depois, elas foram sendo combinadas e os grupos formados comparados entre sí.

Usou-se o pacote estatístico Minitab para gerar relatórios para algumas das regressões executadas como forma de auxiliar no entendimento do método LogiCluster. 


\subsection{1 - Dados do Web site Agents Research (http://java.icmc.usp.br)}

\subsubsection{1 - Coleta com Javascript}

A forma como os dados deste Web site foram coletados é descrita em detalhes no Capítulo 2. 0 número total de acessos registrados no período de 5 de novembro de 2002 até 31 de janeiro de 2003 foi de 19171, dos quais 5487 (28,6\%) vieram da USP. Os acessos vieram de 3400 endereços I.P. diferentes. Endereços I.P. que possuiam baixo número de observações (menos que 150) foram descartados da análise porque é preciso um volume razoável de dados para que o método de regressão tenha sucesso. Também foram descartados os I.P.s onde o número de observações era muito superior à média (mais que 400), pois isso pode indicar a existência de proxies ou firewalls. Usando estes critérios para identificar os usuários obteve-se 11 supostos usuários "ideais", os quais são vistos na Tabela 5.2.

Tabela 5.2 - Usuários identificados por I.P.

\begin{tabular}{|c|c|c|}
\hline I.P. & Dominio & Número de. obsenvações \\
\hline 143.107 .183 .47 & desconhecido & 173 \\
\hline 143.107 .183 .52 & desconhecido & 271 \\
\hline 143.107 .231 .163 & desconhecido & 239 \\
\hline 143.107 .231 .194 & buteko.icmc.usp.br & 236 \\
\hline 143.107 .231 .202 & catuaba.icmc.usp.br & 331 \\
\hline 143.107 .231 .208 & pilsen.intermidia.icmc.usp.br & 207 \\
\hline 143.107 .232 .170 & desconhecido & 180 \\
\hline 200.158 .116 .108 & dsl.telesp.net.br & 239 \\
\hline 200.158 .185 .183 & dsl.telesp.net.br & 171 \\
\hline 200.161 .154 .186 & dsl.telesp.net.br & 182 \\
\hline 200.176 .226 .59 & desconhecido & 280 \\
\hline
\end{tabular}

De acordo com o que é afirmado no item 2.4, pode-se identificar usuários com maior fidelidade com cookies. Dadas as mesmas restrições anteriores $(150<$ número de observações $<400)$, identificou-se 8 supostos usuários, como se vê na Tabela 5.3 . 


\begin{tabular}{|c|c|}
\hline \multicolumn{2}{|c|}{ Tabela 5.3 - Usuários identificados por cookie } \\
\hline ckagents & Número de observaçöes \\
\hline 2147483648 & 240 \\
\hline 334812860089 & 174 \\
\hline 457816528634 & 225 \\
\hline 490414380095 & 225 \\
\hline 67209313143 & 173 \\
\hline 740771314318 & 209 \\
\hline 763646631261 & 324 \\
\hline 816814718016 & 175 \\
\hline
\end{tabular}

Como os resultados não foram significativamente diferentes, optou-se por usar o I.P. como forma de identificação porque isto permite comparar os resultados com os dos outros conjuntos de dados.

Observou-se uma média de pouco mais de 200 registros por usuário, tanto para os identificados por cookie quanto para os identificados por I.P.. Os experimentos irão indicar se esse volume de dados é suficiente para aplicação com sucesso do método LogiCluster.

As variáveis coletadas foram:

1. timestamp: representa a data e hora do acesso. Em sua forma natural não é interessante para o agrupamento, mas dela se pode extrair informações úteis como a variável period;

2. period: a variável anterior é classificada em periodos do dia. Os possíveis valores para esta variável são: down, morning, afternoon e night;

3. I.P.: endereço I.P. do host. É usado como uma heurística na identificação dos usuários que acessaram o site;

4. ckagents: valor numérico armazenado em um cookie no cliente com o objetivo de identificar o usuário (anonimamente). É mais preciso que o uso do I.P., porém o usuário pode se recusar a armazená-lo (ver item 2.2);

5. ckapache: valor gerado pelo servidor Web Apache como forma de identificar uma sessão de acessos. Não é diretamente útil para o agrupamento; 
6. referrer: host de onde se originou o atual pedido ao servidor. Pode ser interessante para o agrupamento se parcelas consideráveis dos usuários vierem dos mesmos lugares. Caso os referrers sejam muitos, diminui-se as chances de se formarem grupos;

7. referrerqs: este valor é retirado da variável anterior. Contém a string de consulta (querystring), se existir, enviada pelo referrer. Quando o referrer é um mecanismo de busca, este campo pode conter as palavras usadas pelo usuário na busca. Apenas 15,4\% (2955) dos acessos registraram algum valor para esta variável, portanto esta não deve ser útil para 0 agrupamento;

8. URL: representa o recurso acessado, o que geralmente é um hiperdocumento. Esta variável apresenta um número muito elevado de categorias, o que diminui as chances de serem formados grupos. Como forma de se diminuir o número de categorias, buscou-se agrupar URL semelhantes. Veja a variável URLgroup;

9. URLqs: este valor é retirado da variável anterior. Contém a string de consulta (querystring), se existir, enviada pelo usuário. Isso ocorre, comumente, em preenchimento de formulários Dos 19171 acessos, 19151 não registram valores para esta variável devendo a mesma ser excluída dos experimentos;

10.URLgroup: obtida da URL, a qual é classificada em grupos formados em função das seções do site. Todas as URLs pertencentes a um curso são identificadas por um mesmo valor, por exemplo, os course/ do curso sobre Sistemas Operacionais;

11.method: contém o método HTTP usado (GET, POST, HEAD etc). Como visto na Tabela 5.1, esta variável apresenta na esmagadora maioria dos casos o mesmo valor, GET, e deve ser excluída:

12.java: valor booleano indicando a existência ou não de Máquina Virtual Java no cliente. O valor true predomina nos dados (18316 ocorrências). Apesar de ser interessante saber que a maioria dos usuários possui uma JVM, esta variável não é interessante para o agrupamento devido à baixa variabilidade;

13.useragent. contém informações sobre o navegador e sistema operacional usados pelo cliente Para um mesmo navegador e mesmo sistema operacional, o valor desta variável pode ser enunciado de diferentes formas. Então, é importante tratá-la de modo a uniformizar a 
informação;

14.browser: obtido da variável useragent, contém o navegador usado pelo cliente;

15.os: obtido da variável useragent, contém o sistema operacional usado pelo cliente;

16.te: tempo que um hiperdocumento permaneceu aberto no navegador. $\dot{\mathrm{E}}$ uma variável interessante pois pode diferenciar usuários que apenas "folheam" o conteúdo dos que o lêem;

17.tc: tempo que o navegador levou para carregar completamente o hiperdocumento acessado. Não é interessante para o agrupamento;

18.sr: resolução da tela do cliente. Esta variável sofre do mesmo problema das variáveis browser e os, um usuário tende a usar sempre as mesmas configurações de tela;

19.ed: profundidade de cor da tela do cliente. Idem anterior;

20.ul: preferências linguísticas do cliente. Esta informação é fornecida pelo navegador. Na grande maioria dos acessos (18583) foi registrado o valor undefined, portanto esta variável foi excluída.

Veja na Tabela 5.4 um registro escolhido aleatóriamente contendo todas as variáveis citadas:

Tabela 5.4 - Registro com variáveis coletadas via Javascript

\begin{tabular}{|c|c|c|c|}
\hline Timestamp & Period & I.P. & ckagents \\
\hline 2002-12-01 03:19:48.0 & dawn & 200175187102 & 89460173159 \\
\hline \multicolumn{2}{|c|}{ chapoche } & Referrer & Referrergs \\
\hline \multicolumn{2}{|c|}{200.175 .187 .102 .38191038719607874} & /java_course/index.html & NA \\
\hline \multicolumn{3}{|c|}{ URL } & URLq \\
\hline \multicolumn{3}{|c|}{ /java_course/Javalang.sld l.html } & NA \\
\hline \multicolumn{2}{|c|}{ URLgroup } & method & java \\
\hline \multicolumn{2}{|c|}{ java_course/Javalang } & GET & true \\
\hline \multicolumn{3}{|c|}{ Useragent } & Browuser \\
\hline \multicolumn{3}{|c|}{ Mozilla/4.0 (compatible; MSIE 5.0; Windows 98; DigExt) } & Netscape 7.x \\
\hline os & $\mathrm{te}$ & $\boldsymbol{t c}$ & sr \\
\hline Windows 98 & 5930 & 8790 & $800 \times 600$ \\
\hline$c d$ & $\boldsymbol{u l}$ & & \\
\hline 16 & undefined & & \\
\hline
\end{tabular}


Pelas razões apresentadas foram incluídas nos experimentos as variáveis period, URLgroup, browser, os, cd, sr e te. Nenhuma destas variáveis quando processada sozinha produziu modelos de boa qualidade. Provavelmente, isso se deve ao volume relativamente baixo de dados. Isso diminui a variabilidade dos mesmos comprometendo as regressões. Porém, não se pode descartar a hipótese de que, simplesmente, não existem grupos a serem formados.

Em seguida, aumentou-se para duas o número de variáveis usadas. Evitou-se usar as variáveis browser, os, sr e ed em conjunto devido ao problema citado anteriormente (ver item 5.3). $\mathrm{Na}$ verdade, em teste usando apenas browser e os, a maioria das regressões não puderam ser executadas sendo que tanto Minitab quanto S-Plus informaram não haver variabilidade suficiente.

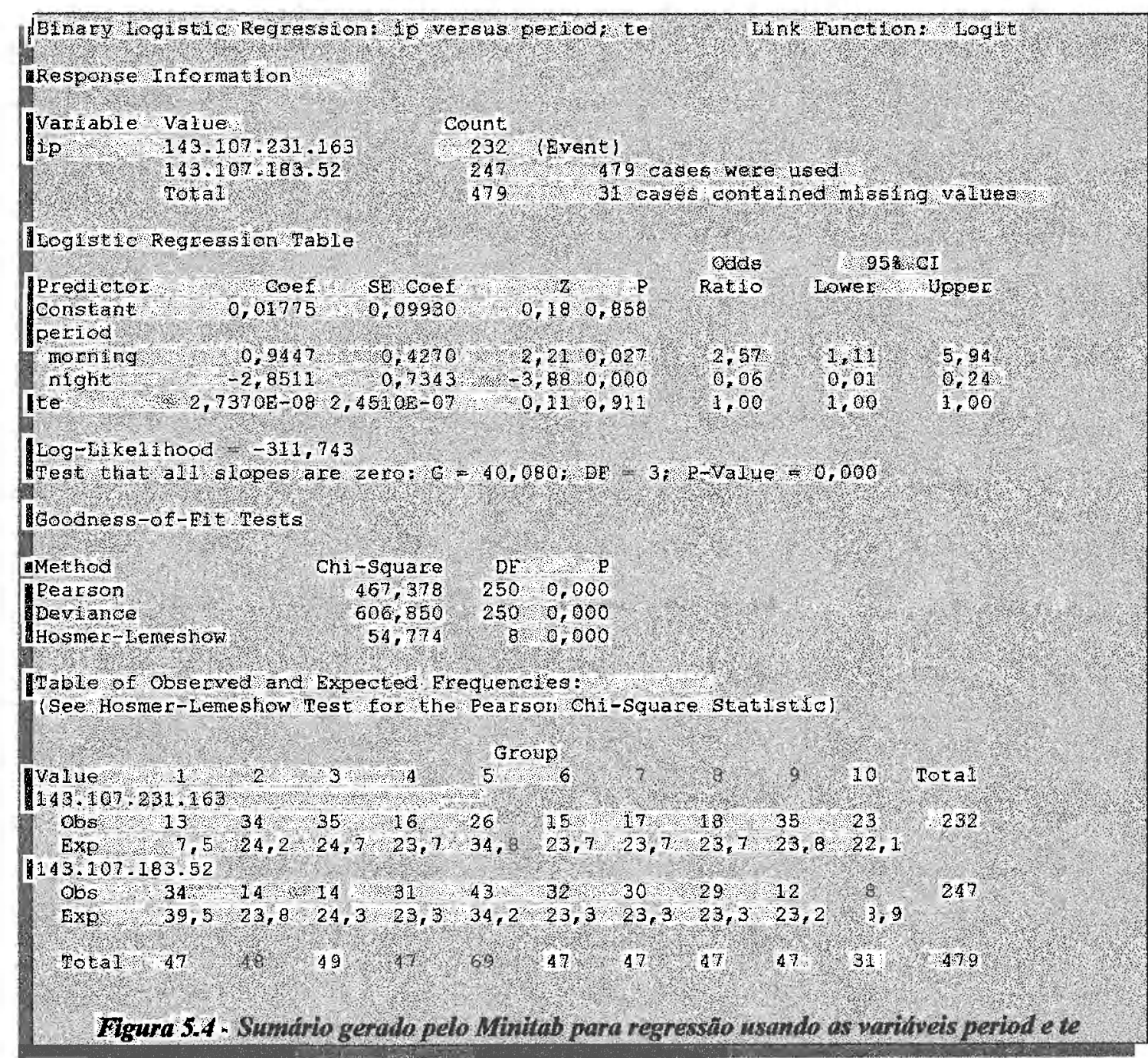

Das 22 possíveis combinações entre as variáveis escolhidas, apenas para as combinações period $\mathrm{X}$ te e period $\mathrm{X}$ sr a maior parte das regressões teve sucesso. Porém, nenhum grupo foi formado nos dois casos. Nota-se que as regressões do caso period $\mathrm{X}$ te não foram de boa qualidade, o que 
é indicado pelos testes de qualidade de ajuste. Veja nas Figuras 5.4 e 5.5 os relatórios gerados pelo Minitab para regressões de ambos os casos.

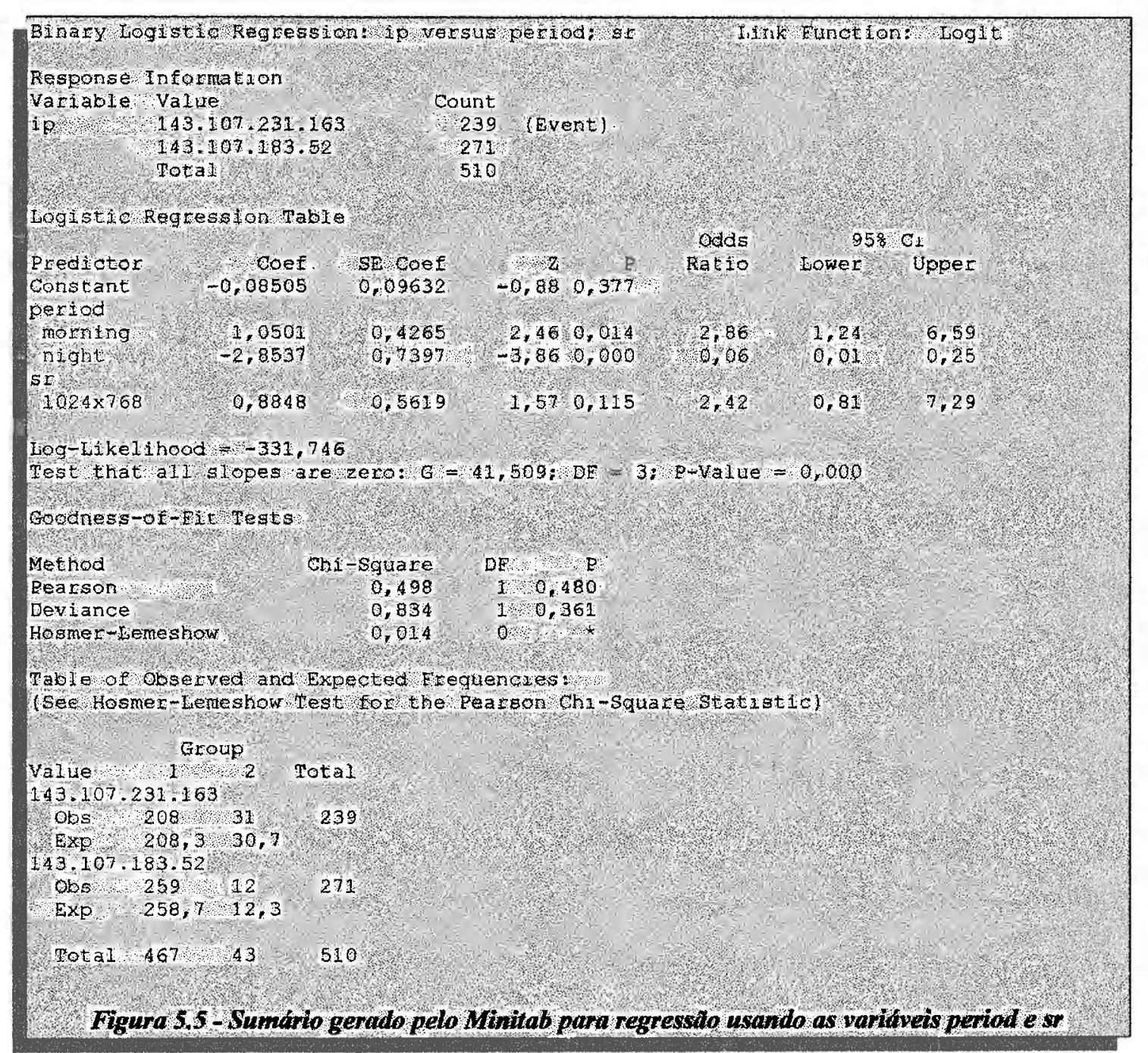

\subsubsection{2 - Coleta com log 'do servidor Web}

O número total de acessos registrados pelo servidor $W e b$ no período de 5 de março de 2002 até 26 de novembro de 2002 foi de 609585, dos quais 118771 (19,5\%) vieram da USP. Os acessos vieram de 35857 endereços I.P. diferentes.

Após se constatar, com os experimentos apresentados no item 5.3.1.1 (onde a média de observações era de 200), que esse valor não é suficiente para garantir bons resultados, ampliou-se o limite inferior de corte para 500 observações. Feito isto, o número de I.P.s distintos reduziu-se 
para apenas 166 (superior em 10000). Esta é uma redução drástica, mas necessária. Este fato nos leva à seguinte consideração: o método LogiCluster necessita de grandes volumes de dados por usuário para ser útil.

Elevando o limite superior para 1000 obtém-se 64 I.P.s; elevando-o para 2000 obtém-se 32; para 3000, 26; para 4000, 16 e para 5000, 15. Nota-se que para valores acima de 2000, o número de I.P.s cai de forma suave. Isto indica que este é um bom valor para o limite superior de corte. Desta forma, o que se têm são 166 menos 32, o que nos deixa com 134 usuários. Como este valor dificultaria a realização dos numerosos experimentos planejados, diıninuiu-se o intervalo a fim de diminuir o número de usuários. Escolheu-se finalmente os valores 1200 e 1500 como limites inferior e superior. Isto gerou 10 usuários (um bom número para efeito de testes de validação do método).

As variáveis coletadas do log do servidor Web foram:

1. Iimestamp: não é usada diretamente, como tratado no item 5.3.1.1;

2. period: é usada de acordo com item 5.3.1.1;

3. I.P.: é usada para identificar possíveis usuários. Ver item 5.3.1.1;

4. ckapache: não é usada pelas razões discutidas no item 5.3.1.1;

5. referrer: também não é usada. Ver item 5.3.1.1;

6. referrerqs: este valor é retirado da variável anterior. Contém a string de consulta (querystring), se existir, enviada pelo referrer. Quando o referrer é um mecanismo de busca, este campo pode conter as palavras usadas pelo usuário na busca. Apenas 13,5\% (82253 acessos) dos acessos registraram algum valor para esta variável, portanto esta não deve ser útil para o agrupamento;

7. URL: não é usada diretamente, ver item 5.3.1.1;

8. URLqs: este valor é retirado da variável anterior. Contém a string de consulta (querystring), se existir, enviada pelo usuário. Isso ocorre, comumente, em preenchimento de formulários Dos 609585 acessos, apenas 536 registraram algum valor para esta variável devendo a mesma ser excluída dos experimentos; 
9. URLgroup: é usada conforme descrito no item 5.3.1.1;

10. method: contém o método HTTP usado (GET, POST, HEAD etc). Esta variável apresenta na esmagadora maioria dos casos $(579559=95 \%)$ o mesmo valor, GET, e deve ser excluída;

11. protocol: contém o protocolo usado no acesso (HTTP/1.1, FTP/1.0 etc). A grande maioria apresentou os valores HTTP/1.0 (239143) e HTTP/1.1 (369080), os quais juntos representam $99,8 \%$ dos acessos. Além da baixa variabilidade, esta variável não é interessante quanto à caracterização de um usuário. Será, portanto, excluída,

12. useragent: não é usada diretamente, ver item 5.3.1.1;

13. browser: é usada conforme descrito no item 5.3.1.1;

14. os: é usada conforme descrito no item 5.3.1.1;

15. status: código indicando o resultado do serviço provido pelo servidor Web. O código de sucesso é 200 e o código de falha mais comum é 404 (Arquivo não encontrado);

16. connStatus: código usado pelo servidor Apache para indicar se um conexão foi encerrada ou pode ser reusada. Como é um parâmetro do servidor, não deve ser usado para caracterizar o usuário e será, portanto, excluído;

17. ts: tempo gasto pelo servidor Web para servir o pedido. Tambẻm é um parâmetro do servidor e não deve ser usado para caracterizar o usuário. Será, portanto, excluído;

18. bytesSent: quantidade de bytes enviados ao cliente. É mais um parâmetro do servidor que será excluído dos experimentos;

19. acceptLang: preferências linguísticas do cliente. Esta informação é fornecida pelo navegador. Uma valor para esta variável foi registrado em 286618 acessos, o que representa $47 \%$ do total de acessos. Portanto, diferentemente do caso nos dados coletados via Javascript, esta variável será utilizada.

Veja na Tabela 5.5 um registro contendo as variáveis citadas 
Tabela 5.5 - Registro com variáveis coletadas via log do servidor Web - (Agents Research)

\begin{tabular}{|c|c|c|c|}
\hline W. Irmes tamp & Reriod & $x \cdot \boldsymbol{P}$. & elkapache \\
\hline $2002-03-05$ & \multirow[t]{2}{*}{ afternoon } & \multirow[t]{2}{*}{64.45 .165 .194} & 64.45 .165 .194 .29793101534948267 \\
\hline $14: 31: 22.0$ & & & 2 \\
\hline 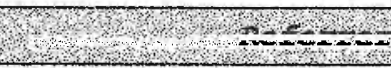 & (5) & Referrergs & geferrercroup \\
\hline \multicolumn{2}{|c|}{ www.google.com/search } & ?q=+resume+bicmos & 1 \\
\hline vRt & \multicolumn{2}{|r|}{ UREqs } & W, urégronp \\
\hline dilvan/resume.html & \multicolumn{2}{|r|}{ NA } & dilvan/ \\
\hline \multicolumn{4}{|c|}{ Useragent } \\
\hline \multicolumn{4}{|c|}{ 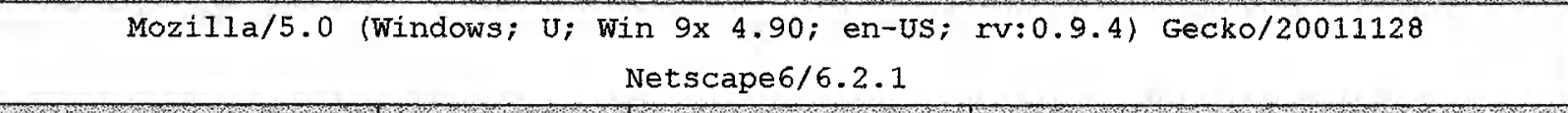 } \\
\hline browser & $\operatorname{cs}^{(x)}$ & protocol & method \\
\hline Netscape $6 \cdot x$ & Windows 98 & HTTP/1.1 & GET \\
\hline status & Connstatus & ts & bytessent \\
\hline 200 & + & 0 & 11990 \\
\hline \multicolumn{4}{|l|}{ Accepthanguage } \\
\hline en-us & & & \\
\hline
\end{tabular}

Pelas razões apresentadas foram incluídas nos experimentos as variáveis period, URLgroup, browser, os, status e acceptLang (variáveis explicativas). Nenhuma destas, quando processada sozinha, produziu modelos de boa qualidade. Provavelmente, isso se deve à características intrínsecas aos dados, os quais não devem atender às hipóteses fundamentais do Modelo de Regressão Logístico. Em outras palavras, o Modelo Logístico não necessariamente é adequado para relacionar $\pi$ (ver item 4 ) com as variáveis explicativas apontadas acima.

Em seguida, aumentou-se para duas o número de variáveis usadas. Evitou-se usar as variáveis browser e os em conjunto devido ao problema citado anteriormente (ver item 5.3).

Com as variáveis period e URLgroup poucas regressões atingiram boa qualidade. 0 mesmo ocorreu para period $\mathrm{X}$ browser e period $\mathrm{X}$ status. Com as combinações de variáveis period $\mathrm{X}$ os e period $X$ acceptLang, apesar de uma considerável parte das regressões não terem tido sucesso, algumas foram de boa qualidade e permitiram comparar usuários.

No primeiro caso foi formado um grupo com os usuários 2, 3, 4 e 5 . As regressões entre 2 e 4, 2 e 5 foram de excelente qualidade, porém a regressão entre 2 e 3 não foi igualmente boa.

A Figura 5.6 mostra que as contagens das categorias de cada variável para os usuários 2,4 e 5 são muito próximas, enquanto as do usuário 3 destoam um pouco das contagens dos outros. Este 


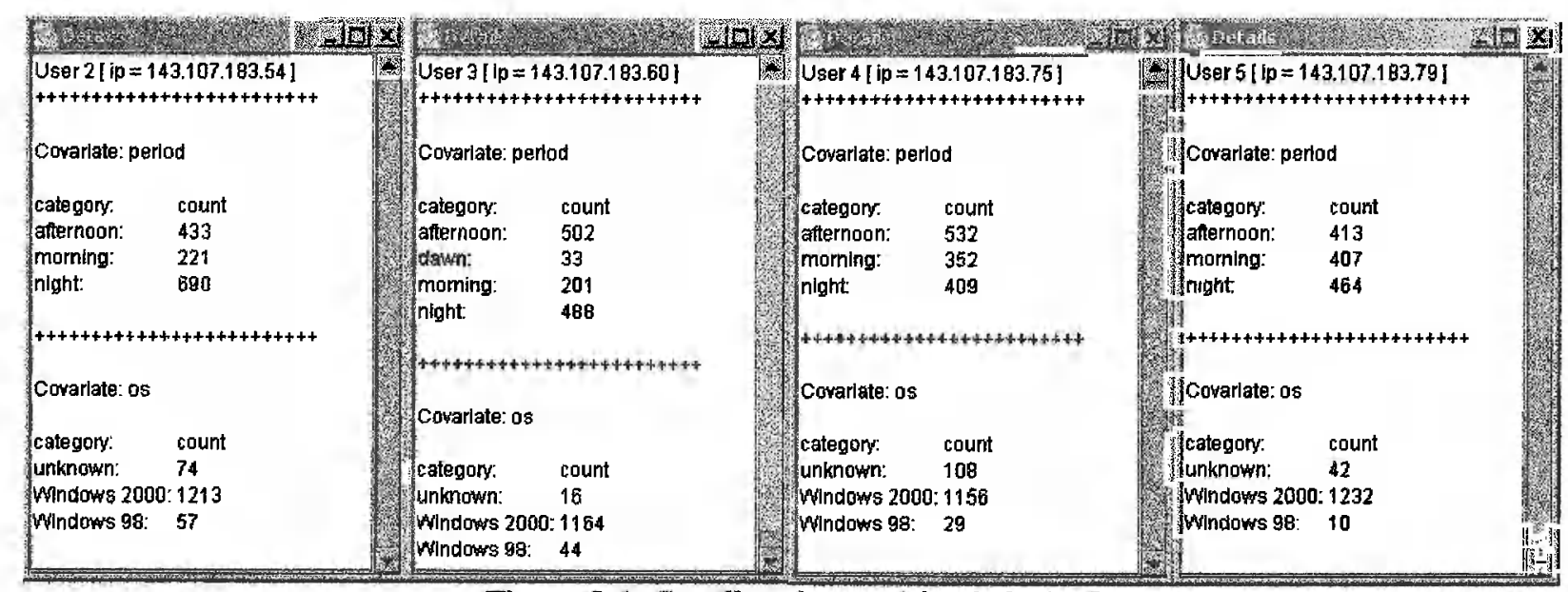

Figura 5.6 - Detalhes dos usuários 2, 3, 4 e.5

foi o único a registrar acessos de madrugada (categorias dawn). Isto ocorre porque, quanto melhor a qualidade da regressão, mais precisa é a comparação entre os usuários e mesmo as menores diferenças são levadas em conta. Veja um sumário do Minitab na Figura 5.7.

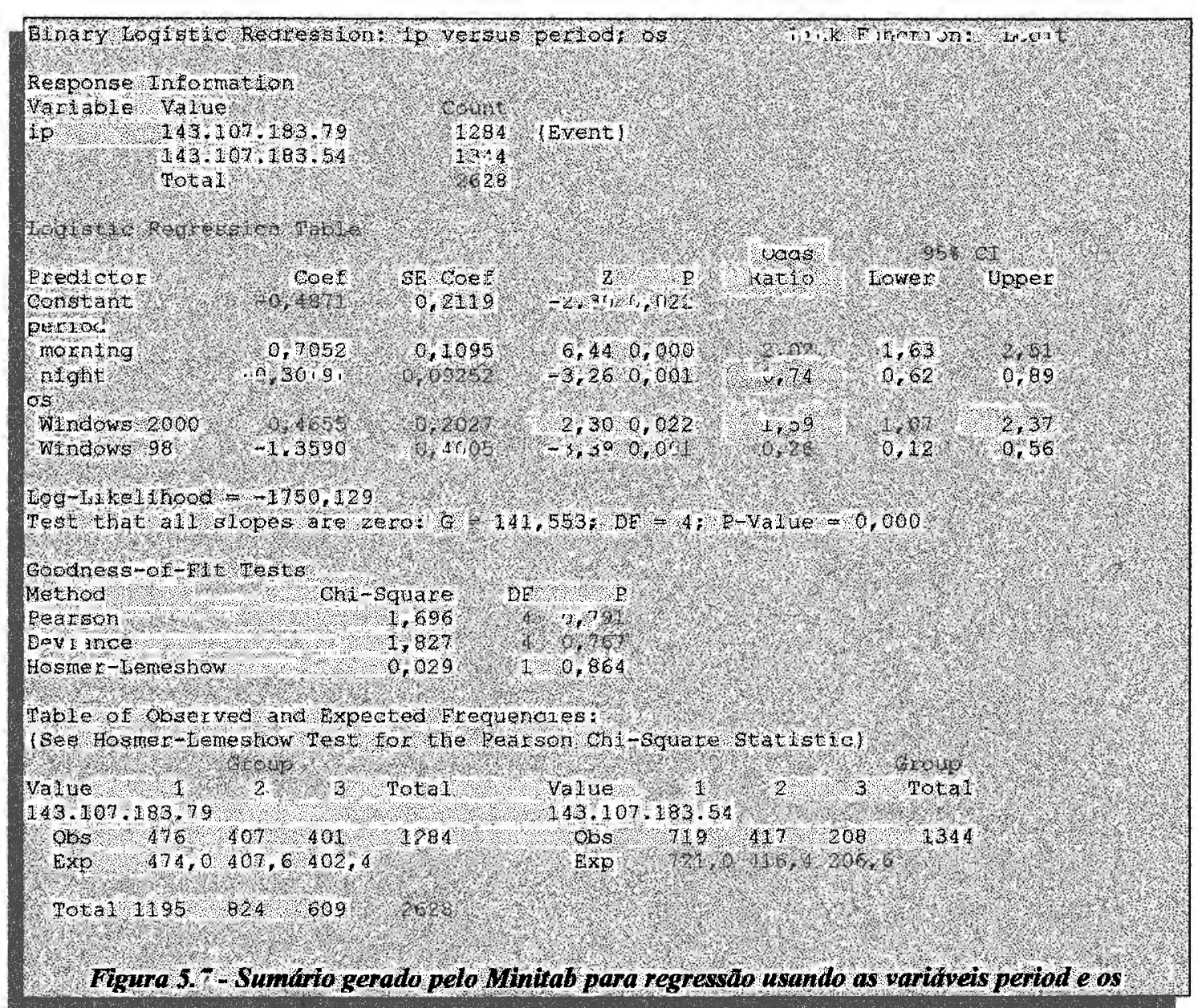

No segundo caso, period $\mathrm{X}$ acceptLang, também foi formado apenas um grupo, composto pelos 
usuários 4 e 5 . A regressão obtida para eles foi também muito boa. Pode-se, então, afirmar que 4 e 5 são muito parecidos e podem ser agrupados. A semelhança pode ser confirmada com a Figura 5.8. Para todas as demais combinações de variáveis não foram obtidos bons ajustes para as regressões

Numa análise geral, nota-se que os usuários 4 e 5 foram agrupados nos dois experimentos de maior sucesso. Isso nos leva a concluir que, em relação às variáveis period, os e acceptLang, os usuários 4 e 5 são altamente semelhantes e podem seguramente ser agrupados.

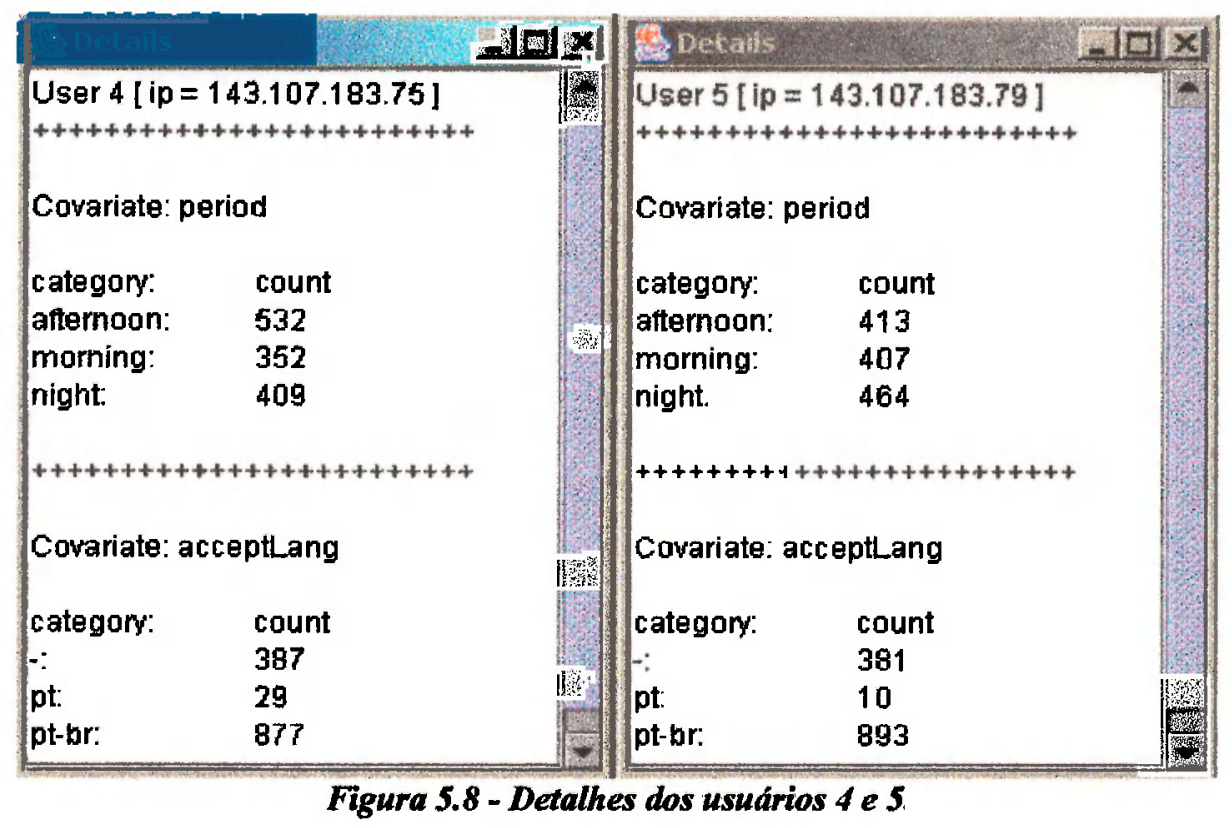

Foi afirmado que a variável bytesSent não era interessante porque era apenas um parâmetro do servidor $W e b$, entretanto a fim de demonstrar que o método trabalha com variáveis categóricas $\mathrm{e}$ continuas em conjunto executou-se um experimento incluindo esta variável. A qualidade das regressões foi muito boa e foi formado um grupo composto pelos usuários 1,2 e 3 , sendo que os demais não foram agrupados. Os detalhes de todos estes usuários são vistos na Figura 5.9.

As semelhanças entre os usuários agrupados é muito alta. Todos usaram o Windows $2000 \mathrm{e}$ fizeram o download de aproximadamente 20000 bytes. $\mathrm{O}$ usuário 5 também usou o Windows 2000 como sistema operacional, mas a média de bytes que recebeu foi bem inferior à anterior. Os outros dois usuários, 3 e 4, são visivelmente bem diferentes de todos os outros. $O$ usuário 4 usou apenas o Windows 98 enquanto o 3 usou cinco diferentes sistemas operacionais. 


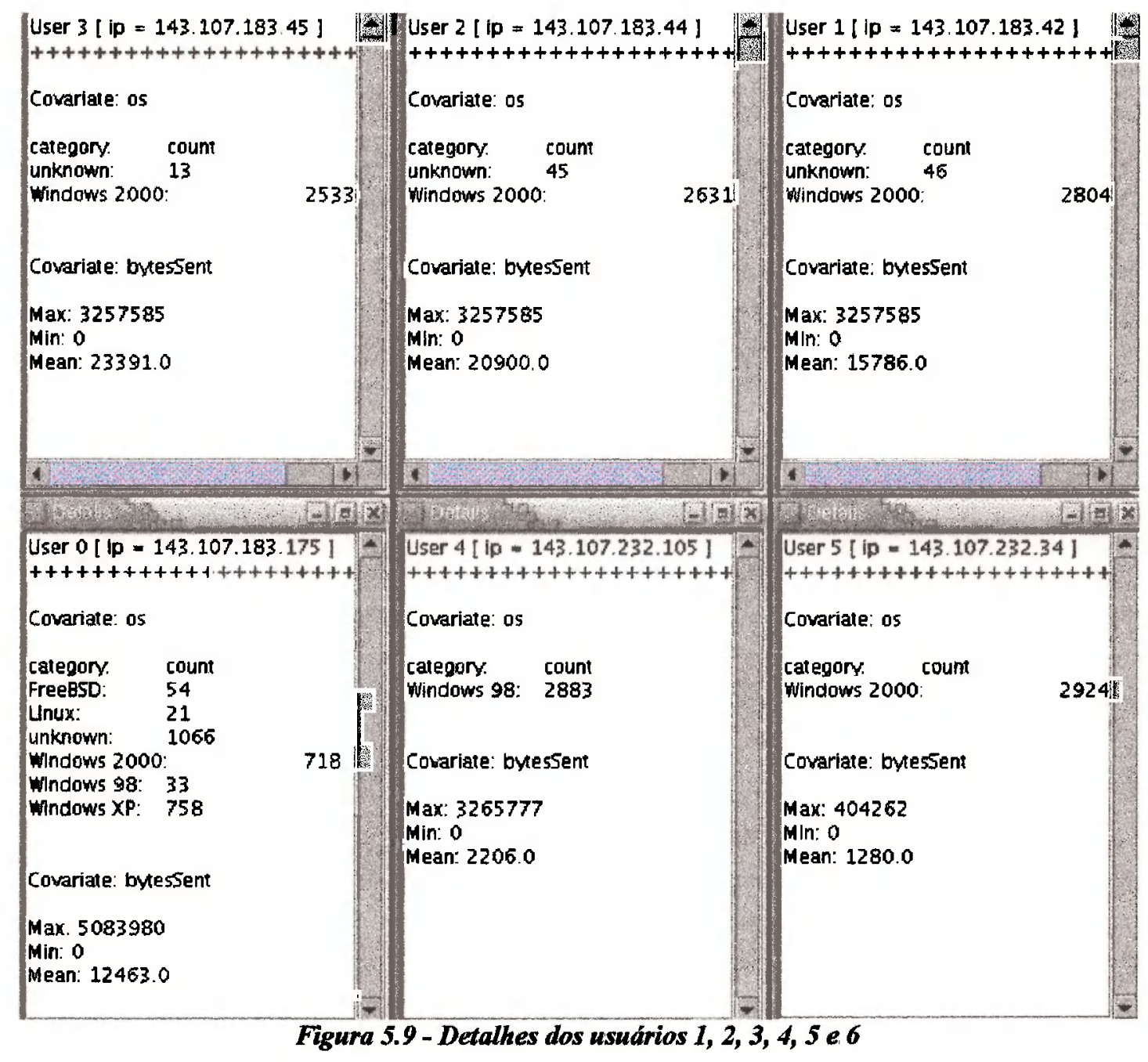

\subsection{2 - Dados do Web site ICMC-USP (http://www.icmc,usp.br)}

\subsubsection{1 - Coleta com log do servidor Web}

O número total de acessos registrados pelo servidor Web no período de 12 de Setembro de 2002 até 9 de Dezembro de 2002 foi de 1666074, dos quais 356248 (21,4\%) vieram da USP. Os acessos vieram de 138839 endereços I.P. diferentes.

Usando-se como limite inferior de corte 500 observações, o número de I.P.s distintos reduz-se para 418. Elevando-se o limite inferior para 1000 obtém-se 183 I.P.s; elevando-o para 2000 obtém-se 69 ; para 3000,43 ; para 4000,27 ; para 4500,18 e para 5000,16 . Nota-se que para valores acima de 4000 , o número de I.P.s cai de forma suave. Isto indica que este é um bom valor 
para o limite superior de corte. Deste forma, o que se têm são 418 menos 27 , o que nos deixa com 391 usuários. Mais uma vez, como este valor dificulta a realização dos numerosos experimentos planejados, diminuiu-se o intervalo a fim de diminuir o número de usuários. Escolheu-se os valores 2500 e 3000 como limites inferior e superior. Isto gerou 11 usuários

As variáveis coletadas do log do servidor Web foram:

1. timestamp: não foi diretamente empregada, ver item 5.3.2.1;

2. period: foi usada conforme descrito no item 5.3.2.1;

3. I.P.: foi usado na identificação de usuários, ver item 5.3.2.1;

4. referrer: não foi diretamente usada, ver item 5.3.2.1;

5. referrerqs: este valor é retirado da variável anterior. Contém a string de consulta (querystring), se existir, enviada pelo referrer. Quando o referrer é um mecanismo de busca, este campo pode conter as palavras usadas pelo usuário na busca. Apenas 13,6\% (225896 acessos) dos acessos registraram algum valor para esta variável, portanto esta não deve ser útil para o agrupamento;

6. URL: representa o recurso acessado, o que geralmente é um hiperdocumento. Esta variável apresenta um número muito elevado de categorias, o que diminui as chances de serem formados grupos. Como forma de se diminuir o número de categorias, poderia-se agrupar URL semelhantes, porém neste caso em particular as categorias eram muito numerosas (27879) de forma que mesmo depois de agrupadas ainda se tinha um número muito grande de categorias. Isto diminui muito a chance de serem formados grupos. Além disto, a performance do S-Plus cai drasticamente quando se tem muitas categorias;

7. URLqs: este valor é retirado da variável anterior. Contém a string de consulta (querystring), se existir, enviada pelo usuário. Isso ocorre, comumente, em preenchimento de formulários. Dos 609585 acessos, apenas 536 registram algum valor para esta variável devendo a mesma ser excluida dos experimentos;

8. method: contém o método HTTP usado (GET, POST, HEAD etc). Esta variảvel apresenta na esmagadora maioria dos casos $(579559=95 \%)$ o mesmo valor, GET, e deve ser excluída; 
9. protocol: contém o protocolo usado no acesso (HTTP/1.1, FTP/1.0 etc). A grande maioria apresentou os valores HTTP/1.0 (239143) e HTTP/1.1 (369080), os quais juntos representam $99,8 \%$ dos acessos. Além da baixa variabilidade, esta variável não é interessante quanto à caracterização de um usuário. Será, portanto, excluída;

10.useragent: não foi diretamente empregado, ver item 5.3.2.1;

11.browser: foi usado conforme descrito no item 5.3.2.1;

12.os: foi usado conforme descrito no item 5.3.2.1;

13.status: foi usado conforme descrito no item 5.3.2.1;

14.bytesSent: não foi empregada, ver item 5.3.2.1;

Veja na Tabela 5.6 um registro contendo as variáveis citadas:

Tabela 5.6 - Registro contendo dados coletados via log do servidor Web - (ICMC)

\begin{tabular}{|c|c|c|c|}
\hline Tímestang & Period & I.P. & Referrer \\
\hline $2002-09-12 \quad 11: 03: 00.0$ & morning & 200216243205 & www.google.com/search \\
\hline \multicolumn{2}{|l|}{ Referrergs } & Refextercroup & Unt \\
\hline \multicolumn{2}{|c|}{$? q=$ netiqueta\&ie $=U T F-8$} & 1 & $\begin{array}{c}\text { /manuals/BigDummy/netiqueta.htm } \\
1\end{array}$ \\
\hline URLgs & & Useragent & 10.2 \\
\hline Mozilla/4.0 & (compatible; & MSIE 6.0 ; window & WS NT 5.0； .NET CLR 1.0.3705) \\
\hline browser & os & protocol & method \\
\hline $\begin{array}{l}\text { MS Internet Explorer } \\
6 . x\end{array}$ & Windows 2000 & HTTP/1.0 & GET \\
\hline status & bytessent & 1.2. 8 & $x=0.0$ \\
\hline 200 & 17151 & & \\
\hline
\end{tabular}

Pelas razões apresentadas foram incluidas nos experimentos as variáveis period, browser, os e status. Desta vez, houve uma variável que, processada sozinha, produziu alguns modelos de boa qualidade. Esta foi a variável os. Foi formado um grupo com os usuários 1, 2, 3 e 5. Porém, apenas as regressões para os usuários 1 e 2, e 1 e 3 foram de boa qualidade.

Olhando-se para a Figura 5.10, vê-se que 1, 2, 3 e 5 usam o mesmo sistema operacional e todos, 
exceto o 5, possuem alguns acessos onde não foi possível identificar o sistema operacional. A existência da categoria unknown foi o que tornou as regressões viáveis. Sem ela, a variável os teria uma única categoria e não seria possivel efetuar uma regressão.

\begin{tabular}{|c|c|}
\hline 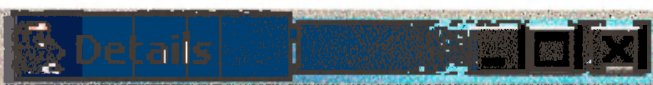 & 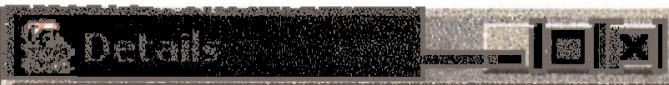 \\
\hline User $1[i p=143.107 .183 .42]$ & User $2[\mathrm{ip}=143.107 .183 .44]$ \\
\hline 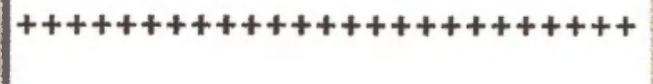 & 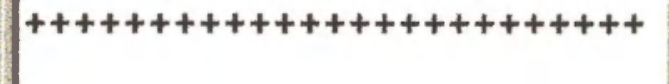 \\
\hline Covariate: os & Covariate: os \\
\hline $\begin{array}{ll}\text { category: } & \text { count } \\
\text { unknown: } & 46 \\
\text { Windows 2000: } & 2804\end{array}$ & $\begin{array}{ll}\text { category: } & \text { count } \\
\text { unknown: } & 45 \\
\text { Windows } 2000: & 2631\end{array}$ \\
\hline Soetails $\quad-[\square \mid x$ & Sotaís \\
\hline User $3[i p=143.107 .183 .45]$ & User $5[i p=143.107 .232 .34]$ \\
\hline$t+t+t+t+t+t+t+t+t+t+t+t+t$ & +++++++++++++++++++++++++++t \\
\hline Covariate: os & Covariate: os \\
\hline category: count & category: count \\
\hline $\begin{array}{lc}\text { unknown: } & 13 \\
\text { Windows } 2000: & 2533\end{array}$ & Windows 2000: 2924 \\
\hline
\end{tabular}

Figura 5.10 - Detalhes dos usuários 1, 2, 3 e 5 .

Em seguida, aumentou-se para duas o número de variáveis usadas. Com as variáveis period e browser algumas regressões tiveram sucesso. Foi identificado um grupo formado pelos usuários $1,2,3$ e 4 . Porém as regressões envolvendo 4 não foram de boa qualidade.

Os detalhes dos usuários são vistos na Figura 5.11. Nela se vê que o usuário 4 destoa um pouco dos outros membros do grupo por ter usado navegadores Netscape em alguns acessos. Pode ser desejável excluí-lo do grupo. Esta decisão deve ser tomada pelo operador do programa. 


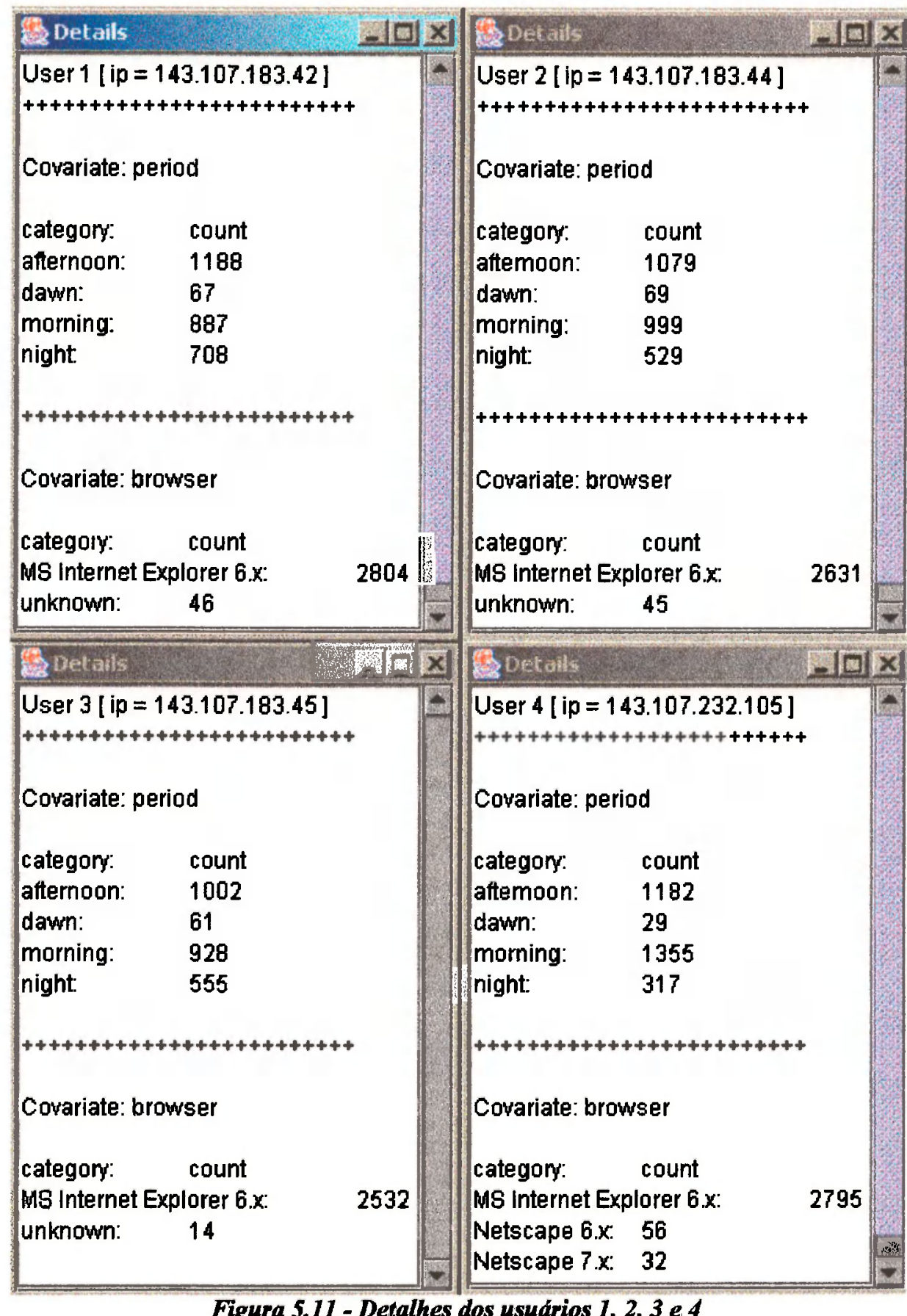

Com as variáveis period e os os resultados foram semelhantes e apenas algumas regressões foram de boa qualidade. Estas identificaram um grupo formado pelos usuários 1, 2, e 3. Os detalhes dos usuários são vistos na Figura 5.12.

A combinação period e status produziu modelos de pior qualidade em relação aos anteriores. Foi identificado um grupo formado pelos mesmos usuários: 1, 2, e 3. Porém, apenas a regressão envolvendo 1 e 2 teve boa qualidade. Pode-se ver os detalhes dos usuários na Figura 5.13. 


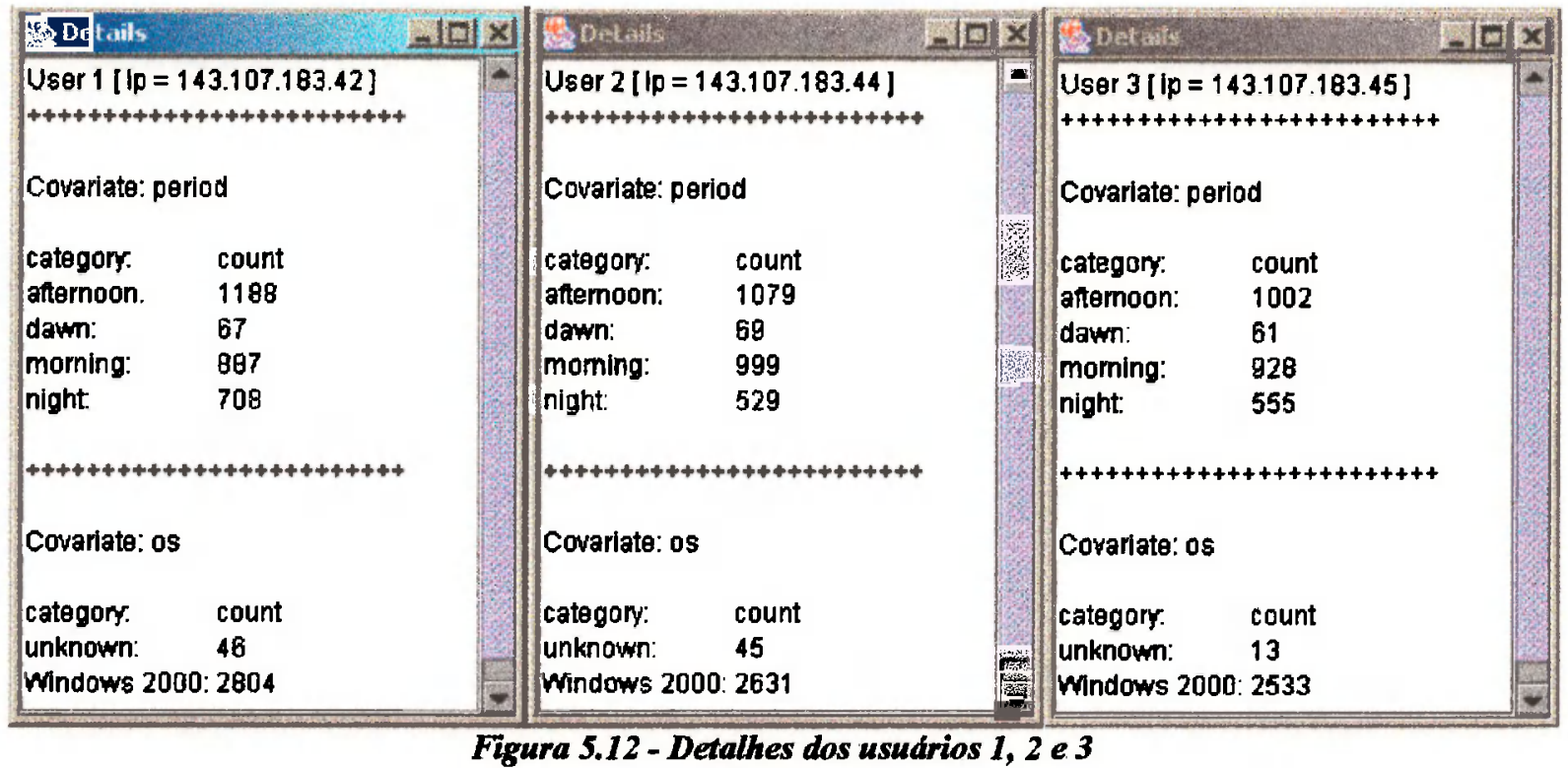

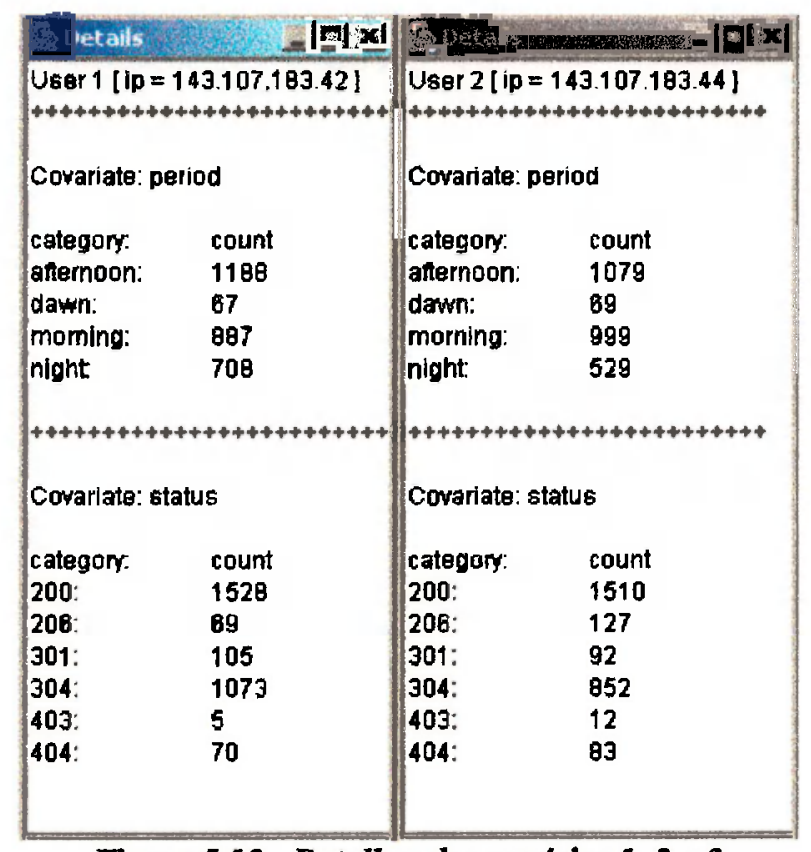

Figura 5.13 - Detalhes dos usudirios 1, 2 e 3

Para a combinação os e status, os resultados foram iguais ao anterior. Foi identificado um grupo formado pelos usuários 1,2 , e 3 . Porém, apenas a regressão envolvendo 1 e 2 teve qualidade aceitável. Pode-se ver os detalhes dos usuários na Figura 5.14. 


\begin{tabular}{|c|c|c|c|}
\hline isetails & I $\quad-\mid[|x|$ & \multicolumn{2}{|l|}{ Sost Dets: } \\
\hline \multicolumn{2}{|c|}{ User $6[i p=200.201 .0 .210]$} & \multicolumn{2}{|c|}{ User 9 [ip = 200.255.122.8] } \\
\hline \multicolumn{2}{|c|}{ p+t+t+t+t+t+t+t+t++t++t+t+t+t} & \multicolumn{2}{|c|}{ t+t+t+t+t+t+t+t+t+t+t+t+t+t} \\
\hline \multicolumn{2}{|l|}{ Covariate: os } & \multicolumn{2}{|l|}{ Covariate: os } \\
\hline category. & count & category: & count \\
\hline Linux: & 7 & Linux: & 1 \\
\hline unknown: & 339 & unknown: & 294 \\
\hline Windows 200 & $0: 1038$ & Windows 200 & 562 \\
\hline Windows 95: & 12 & Windows 98: & 1551 \\
\hline Windows 98: & 964 & Windows NT: & 445 \\
\hline Windows NT: & 302 & & \\
\hline Windows XP: & 68 & +++++++++++ & $++++++++++t+$ \\
\hline \multicolumn{2}{|c|}{ t+t+t+t++t+t+t++t++t+++t+++t+} & \multicolumn{2}{|c|}{ Covariate: status } \\
\hline Covariate: stat & & $\begin{array}{l}\text { category: } \\
200 \text { : }\end{array}$ & $\begin{array}{l}\text { count } \\
2068\end{array}$ \\
\hline categony: & count & 206: & 154 \\
\hline $200:$ & 1664 & 301: & 54 \\
\hline 206: & 33 & 304: & 411 \\
\hline 301: & 272 & 403: & 15 \\
\hline 304: & 592 & 404: & 151 \\
\hline 403: & 16 & & \\
\hline 404: & 150 & & \\
\hline 408: & 3 & & \\
\hline
\end{tabular}

Após as combinações de duas variáveis, experimentou-se combinações com três. Para a cobinação period X browser X status obteve-se um grupo com os usuários 1 e 2, para os quais a regressão foi muito boa. $O$ mesmo ocorreu com a combinação period X os X status. Os detalhes podem ser vistos nas Figuras 5.16 e 5.15. As demais não produziram bons resultados. 


\begin{tabular}{|c|c|c|c|}
\hline $8[$ ing & 渻同 $x$ & Soetails & $-|a| x \mid$ \\
\hline \multicolumn{2}{|c|}{ User $1[i p=143.107 .183 .42]$} & \multicolumn{2}{|c|}{ User $2[l p=143.107 .183 .44]$} \\
\hline \multicolumn{2}{|c|}{ t+t+t+t+t+t+t+t+t+t+t+t+t+t+t} & \multicolumn{2}{|c|}{ Lt+t+t+t+t+t+t+t+t+t+t+t+t+t+ } \\
\hline \multicolumn{2}{|c|}{ Covariate: period } & \multicolumn{2}{|c|}{ Coyariate: period } \\
\hline category: & count & category: & count \\
\hline afternoon: & 1188 & anemoon: & 1079 \\
\hline dawn: & 67 & dawn: & 69 \\
\hline morning: & 887 & morning: & 999 \\
\hline night: & 708 & night: & 529 \\
\hline \multicolumn{2}{|c|}{ t+t++t+t++t+t++t++t+t+t++t++t+ } & \multicolumn{2}{|c|}{ 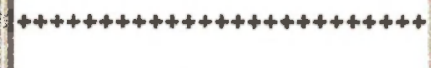 } \\
\hline \multicolumn{2}{|c|}{ Covariate: os } & \multicolumn{2}{|c|}{ Cowariate: os } \\
\hline $\begin{array}{l}\text { category: } \\
\text { unknown: }\end{array}$ & $\begin{array}{l}\text { count } \\
46\end{array}$ & $\begin{array}{l}\text { category: } \\
\text { unknown: }\end{array}$ & $\begin{array}{l}\text { count } \\
45\end{array}$ \\
\hline \multicolumn{2}{|c|}{ Windows 2000: 2804} & \multicolumn{2}{|c|}{ Windows 2000: 2631} \\
\hline \multicolumn{2}{|c|}{ t+t+t+t+t+t+t+t+t+t+t+t+t+t+ } & \multicolumn{2}{|c|}{ ht+t+t+t+t+t+t+t+t+t+t+t+t+t} \\
\hline \multicolumn{2}{|c|}{ Covariate: status } & \multicolumn{2}{|c|}{ Co*ariate: status } \\
\hline categony: & count & category: & count \\
\hline $200:$ & 1528 & $200:$ & 1510 \\
\hline 206: & 69 & 206: & 127 \\
\hline 301: & 105 & 301: & 92 \\
\hline 304: & 1073 & 304: & 852 \\
\hline 403: & 5 & 403: & 12 \\
\hline 404: & 70 & 404: & 83 \\
\hline
\end{tabular}

Figura 5.15 - Detalhes dos usudrios 1 e 2

Experimentou-se, ainda, com todas as variáveis juntas, mas a grande maioria das regressões não apresentou boa qualidade.

Percebe-se que bons resultados com uma ou duas variáveis são mais frequentes que com três ou mais. É por esta razão que a análise dos dados deve ser feita em etapas. Primeiramente, testa-se uma variável por vez, depois testa-se as combinações destas e assim por diante. 


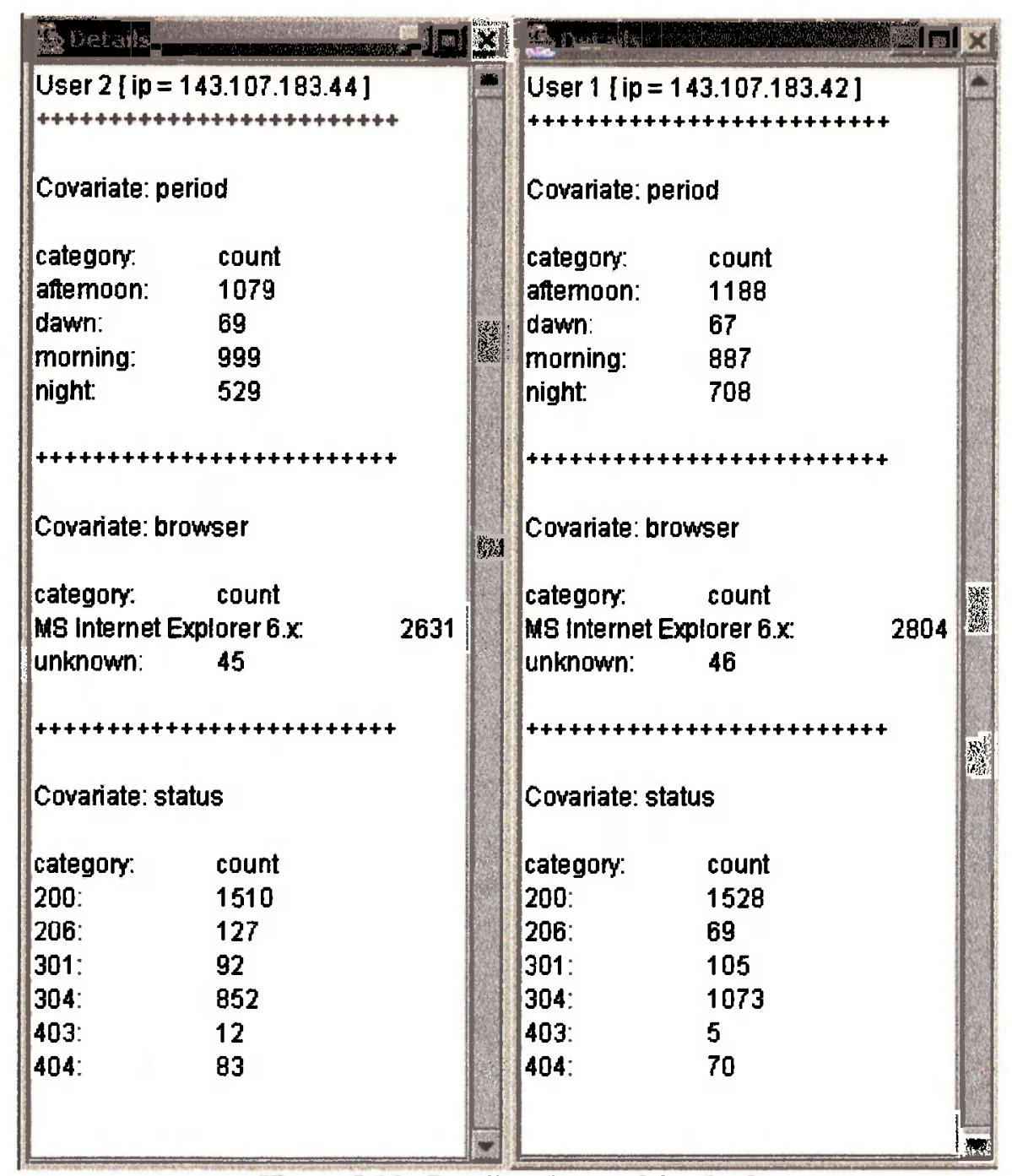

Figura 5.16 - Detalkes dos usudrios 1 e 2

\subsection{3 - Experimento final}

Para concluir, foi executado um experimento com os dados do site ICMC-USP com um número maior de usuários, 22 no total, numa tentativa de se obter resultados mais interessantes. Os valores 1450 e 3000 foram usados para os limites inferior e superior.

Como pode ser notado pelos experimentos anteriores, com o aumento do número de variáveis, a eficiência do método cai. Então, é importante que a análise seja interativa. As variáveis period, os e status foram analisadas, pois foram as que melhor resultados apresentaram nos experimentos anteriores. Elas foram analisadas separadamente e depois em conjunto. E, então, comparou-se os resultados em busca de grupos. 
A primeira análise levou em consideração a variável period. $O$ resultado pode ser visto na Figura 5.17 .

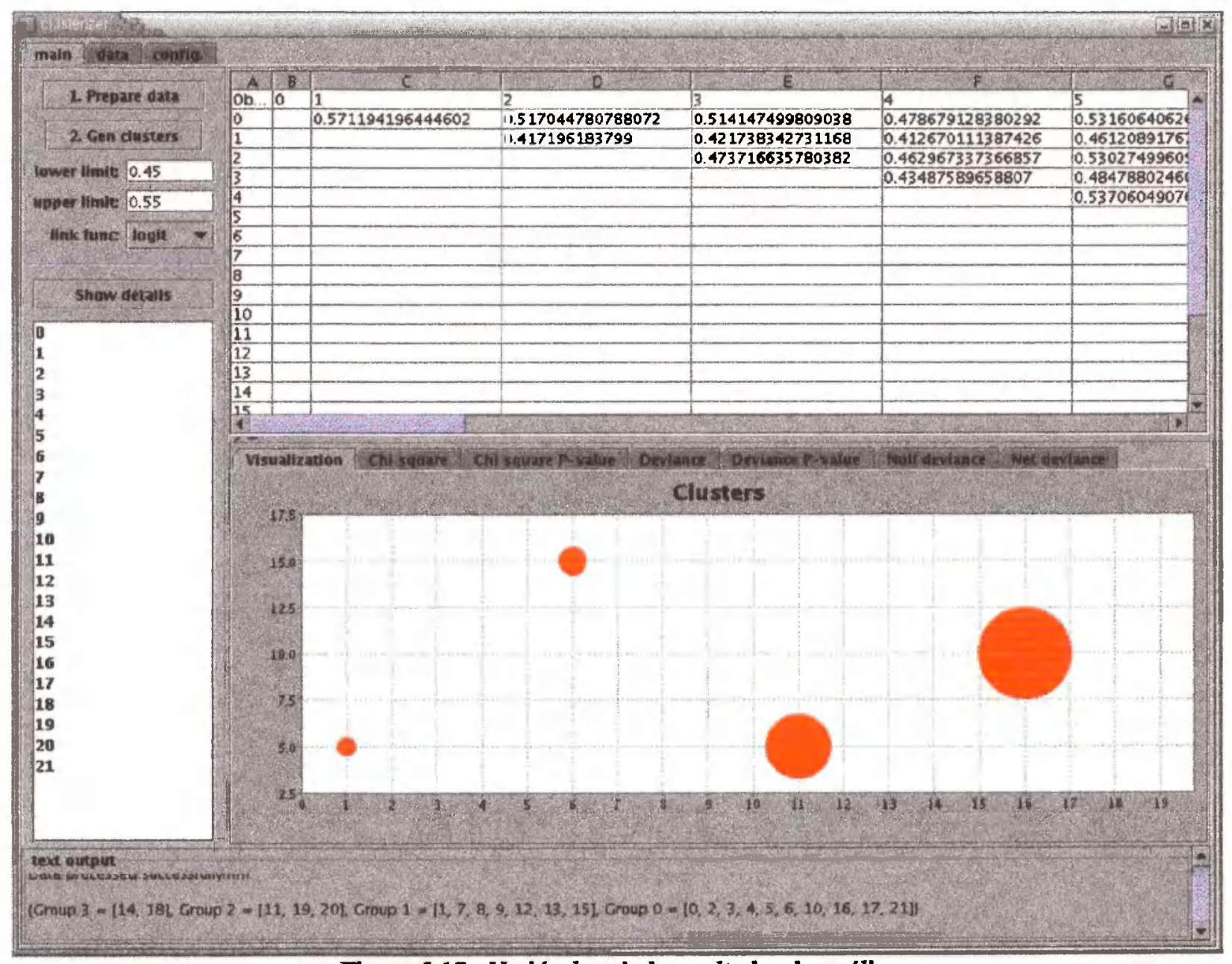

Figura 5.17 - Varióvel period: resullados da análise

Houve a formação de quatro grupos que incorporaram todos os usuários. São eles: $\{14,18\}$; $\{11,19,20\} ;\{1,7,8,9,12,13,15\}$ e $\{0,2,3,4,5,6,10,16,17$ e 21$\}$. Todas as regressões convergiram, porém não foram de alta qualidade.

A análise seguinte considerou a variável os. Foram formados também quatro grupos, sendo que quatro usuários não foram incluídos em nenhum deles. Os grupos foram: $\{1,13\} ;\{7,8,9,17\}$; $\{0,2,6,10,18,19\} ;\{3,4,12,16,20,21\}$. Veja a Figura 5.18 .

Neste caso, a qualidade das regressões foi maior, portanto espera-se uma precisão maior no agrupamento. 


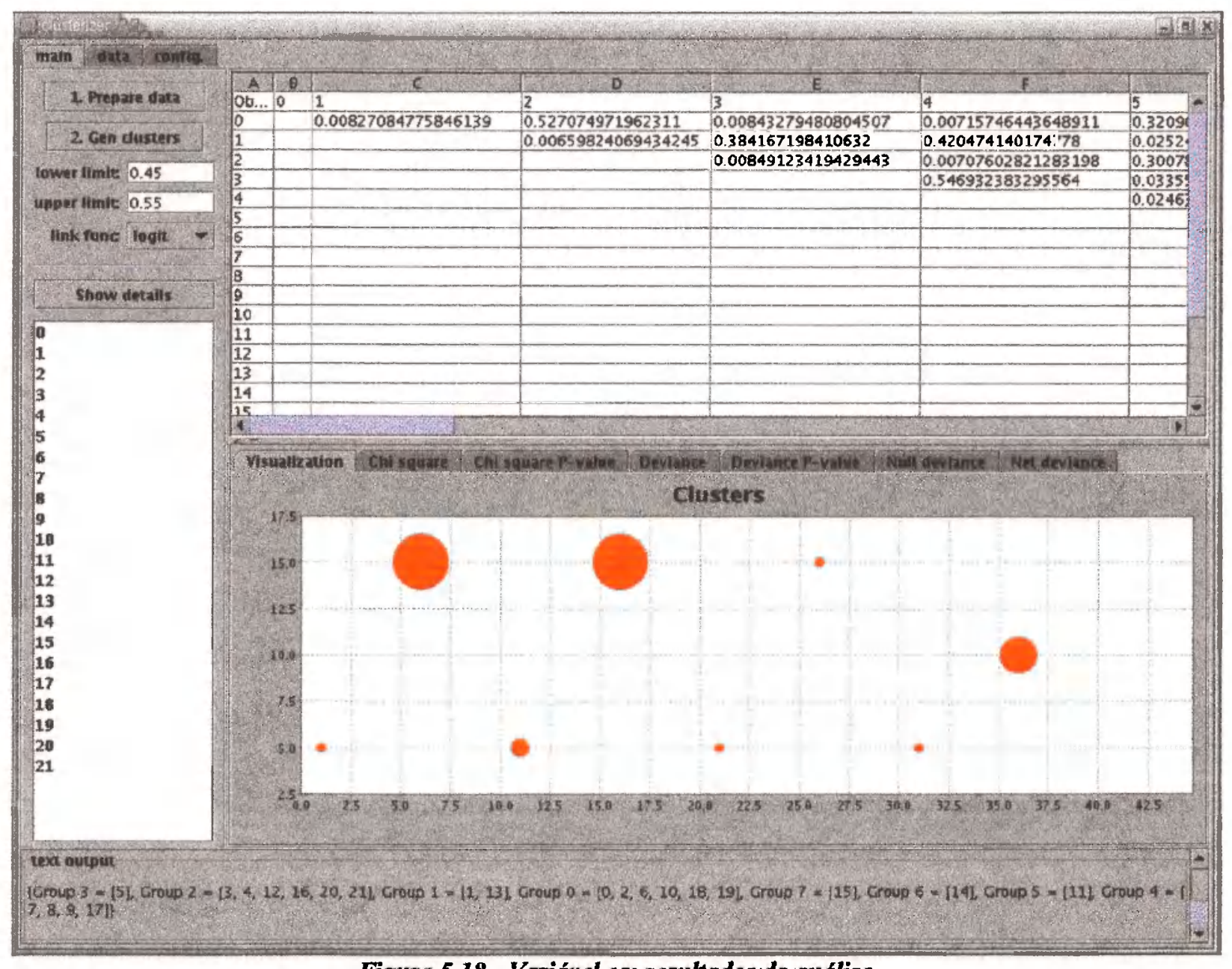

Figura 5.18 - Variável os: resultados da análise

A última variável analisada independentemente foi status. Foram formados dois grandes grupos, sendo que quatro usuários não foram incluídos em nenhum deles. Como se vê na Figura 5.19, os grupos foram: $\{0,1,2,11,13,15,18,20\} ;\{3,4,5,6,8,9,12,16,21\}$. Aqui, também, as regressð̃es foram de boa qualidade.

Uma vez terminadas as análises com as variáveis independentemente, analisou-se a combinação os e status, pois foram estas as variáveis que produziram as regressð̃es de melhor qualidade nos testes anteriores. $O$ resultado pode ser visto na Figura 5.20.

Os grupos formados foram, mais uma vez, quatro. São eles: $\{0,2,10,18\} ;\{1,13\} ;\{3,4,12,16$, $21\} ;\{6,8,9\}$. Agora, oito usuários não foram incluídos em nenhum grupo. 


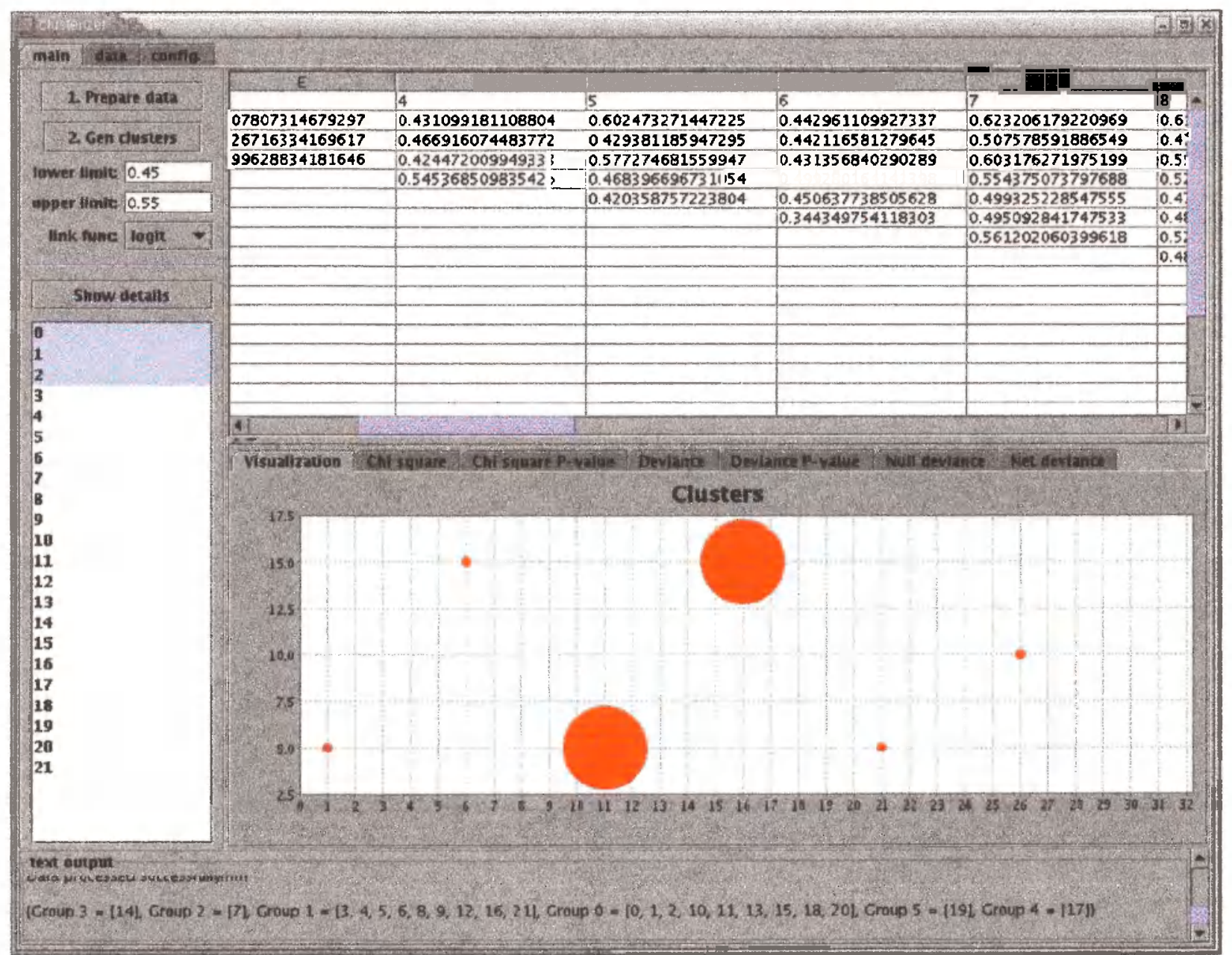

Figura 5.19 - Varidivel status: resultado da aridilise

Comparando o resultado deste último experimento com os anteriores nota-se que há intersecções nos grupos. Os usuários 0,2 e 10 foram agrupados em todos os experimentos. Isto também ocorreu com 3, 4, 16 e 21; e com 8 e 9. Pode-se, então, formar grupos de muito boa qualidade com estes.

Com a análise feita em etapas se conseguiu resultados bem mais abrangentes do se conseguiria com uma análise usando diversas variáveis ao mesmo tempo. 


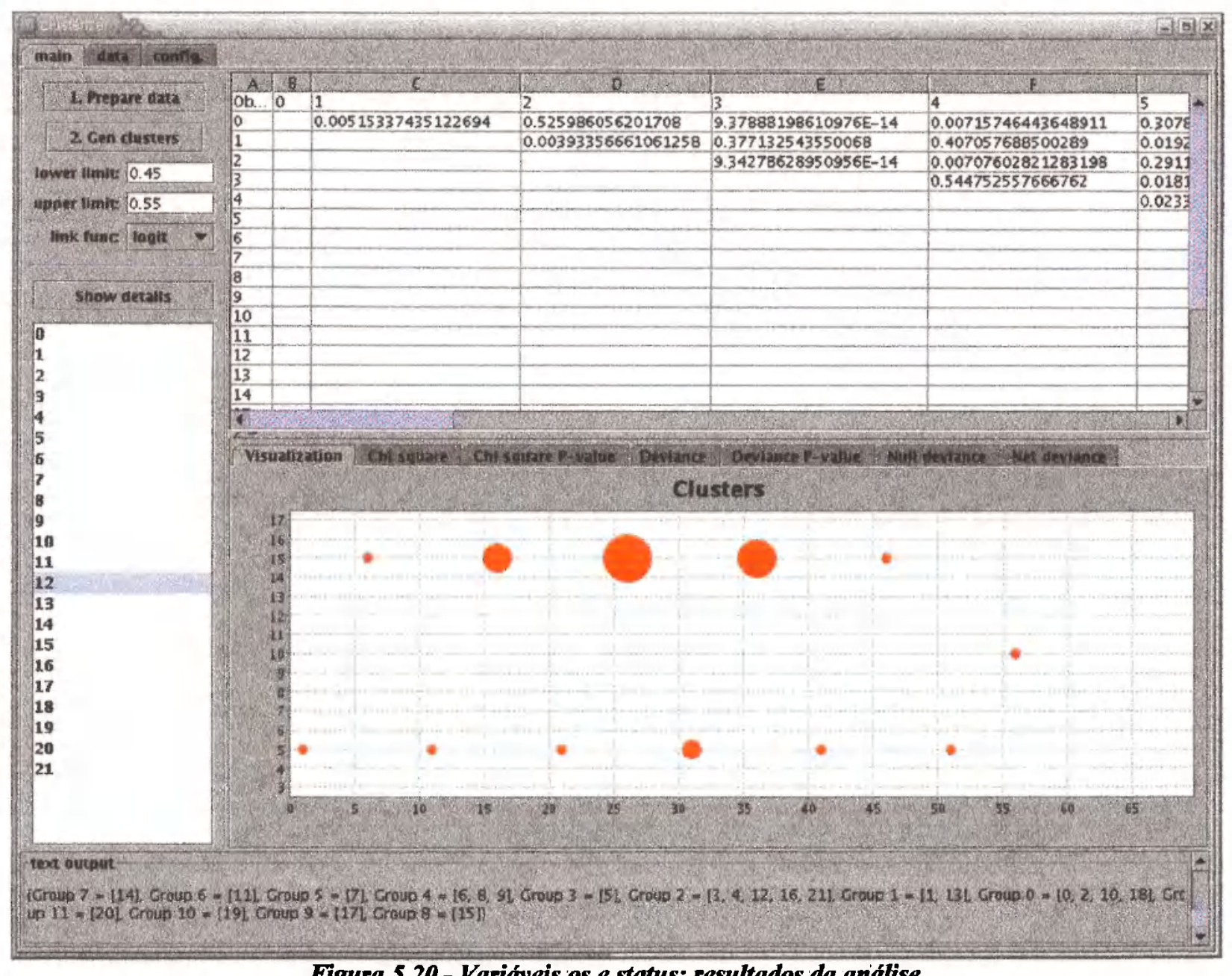

Figura 5.20 - Variáveis os e status: resultados da análise

\section{4 - Considerações finais}

Como pode ser notado nos experimentos, algumas vezes os algoritmos numéricos que calculam os parâmetros do modelo não convergem. Isso ocorre porque o Modelo Logístico não é necessariamente adequado para relacionar $\pi$ (ver item 4) com as variáveis explicativas analisadas. Por isso, espera-se que existam casos onde o método LogiCluster não é aplicável. É preciso verificar experimentalmente se os dados analisados podem ser modelados adequadamente pelo Modelo de Regressão Logístico. Porém, quando o método identificou usuários semelhantes, pode-se confirmar a veracidade desta semelhança em todos os experimentos.

Quanto às diferentes fontes de dados, acredita-se que os melhores resultados vieram do log do site do ICMC devido, apenas, ao maior volume de dados. Este era quase três vezes maior que o 
volume de dados coletados do site Agents Research. Isto ressalta a importância deste parâmetro.

Como outros métodos de agrupamento, o método proposto também é sensível à alta dimensionalidade. Nos experimentos efetuados, notou-se que com número de parâmetros maiores que 3 não houve formação de grupos. É importante, então, que se aplique a técnica de forma iterativa. Primeiro processando as variáveis em separado e depois suas combinações. Finalmente, analisa-se os grupos formados em busca de intersecções

A escalabilidade do método é altamente dependente da escalabilidade do algoritmo que efetua a regressão, neste caso o S-Plus, o qual, sabe-se, não escala bem quando o número de parâmetros é alto (maior que 10). Quanto ao número de usuários, entretanto, espera-se escalabilidade quadrática, já que o número de regressões que devem ser efetuadas é igual ao número de combinações de usuários dois a dois. Este número pode ser calculado pela fórmula:

$$
C=\frac{n \cdot(n-1)}{2} \text { onde } n \text { é o número de usuarios. }
$$




\section{CAPÍTULO 6 - CONCLUSÃO}

\section{1 - Considerações iniciais}

O objetivo deste trabalho foi desenvolver um novo método de agrupamento capaz de ser usado no agrupamento de dados de uso de Websites. Ou seja, este novo método se encarregaria de agrupar usuários com perfis semelhantes, dados parâmetros adequados.

Como visto no Capítulo 4, a idéia central do método de agrupamento proposto neste trabalho se baseia na aplicação do Modelo de Regressão Logístico para modelar os dados dos usuários (dois a dois), permitindo que se determine se os usuários são ou não semelhantes. Este método, batizado de LogiCluster, pode ser aplicado a outros domínios que, assim como a Web, também trabalhem simultaneamente com dados categóricos e contínuos

Os diversos experimentos efetuados mostraram que o método LogiCluster é capaz de produzir bons agrupamentos. Constatou-se, ainda, que não se pode esperar que as regressões tenham sucesso para todas as possiveis combinações de usuários. Na verdade, uma parcela não desprezivel das regressões não ficou bem ajustada para todos os usuários nos experimentos executados, contudo as regressões não têm de ser perfeitas para gerarem bons agrupamentos. Notou-se também que trabalhar com grande volume de dados melhora o grau de ajuste das regressões. De qualquer forma, foi constatada a boa qualidade dos grupos formados.

A aplicação do método é altamente interativa. Deve-se fazer a análise em etapas, começando com uma variável apenas e depois acrescentando outras. Após estas analises tem-se, possivelmente, alguns grupos formados para cada análise. Resta, então, analisar estes grupos a fim de avaliar os usuários em relação as variáveis de interesse.

\section{2 - Contribuições}

A principal contribuição deste trabalho é a proposta de um novo método de agrupamento em dados baseado no Modelo de Regressão Logístico, o qual foi chamado LogiCluster. Não foram encontradas referências bibliográficas que tratassem do uso do Modelo Logístico como forma de 
se agrupar elementos.

Outra contribuição relevante é o uso do Modelo de Regressão Logístico num domínio atípico: a World Wide Web. Este modelo é tipicamente empregado nas áreas de Ciências Biológicas e Médicas como forma, por exemplo, de se analisar a influência de variáveis (ex. peso e idade) na ocorrência de doenças.

Também relevante é o fato deste trabalho tratar da aplicação da Web Usage Mining em dados no domínio da EAD via Internet, que é uma área pouco explorada. É importante ressaltar que o desenvolvimento deste trabalho não se prendeu a conceitos ou sistemas de EAD. $\mathrm{O}$ algoritmo desenvolvido pode ser aplicado à qualquer outro domínio onde se tenha dados com variável de resposta categórica ou mista.

Finalmente, acredita-se que este trabalho traz contribuições a qualquer um que faça uso da Internet, mais especificamente da WWW, como meio de disseminação de informação e queira entender melhor seus usuários

\section{3 - Trabalhos futuros}

Como discutido anteriormente, algumas vezes os algoritmos numéricos que calculam os parâmetros do modelo não convergem. Isso ocorre porque o Modelo Logístico não é necessariamente adequado para relacionar $\pi$ (ver item 4 ) com as variáveis explicativas analisadas. Isso se deve à escolha da função de link (ver item 4.2.3), a qual pode se mostrar uma aproximação grosseira em alguns casos. Então, a procura por funções de link mais sofisticadas e sua classificação em função dos domínios a que se adequam pode produzir pesquisas muito interessantes e úteis.

A carga cognitiva envolvida na análise dos dados na Tabela 4.2 (que contém a Matriz II) pode ser drasticamente diminuída com uma representação gráfica que exprima o grau de diferença entre os grupos como as distâncias entre os elementos do gráfico. Usando um gráfico em duas dimensões do tipo Scatter Plot pode-se representar os grupos como círculos distribuídos num plano de acordo com suas distâncias (ver Figura 6.1). Os atributos dos círculos (tamanho e cor) podem codificar atributos do grupos. Entretanto, não foi encontrado na literatura técnica capaz de dispor num plano pontos em função das distâncias. Sabe-se que existe um esforço por parte de docentes 
do ICMC-USP em desenvolver um algoritmo que resolva este problema. Porém, até a conclusão deste trabalho, não existia um protótipo funcional que pudesse ser usado

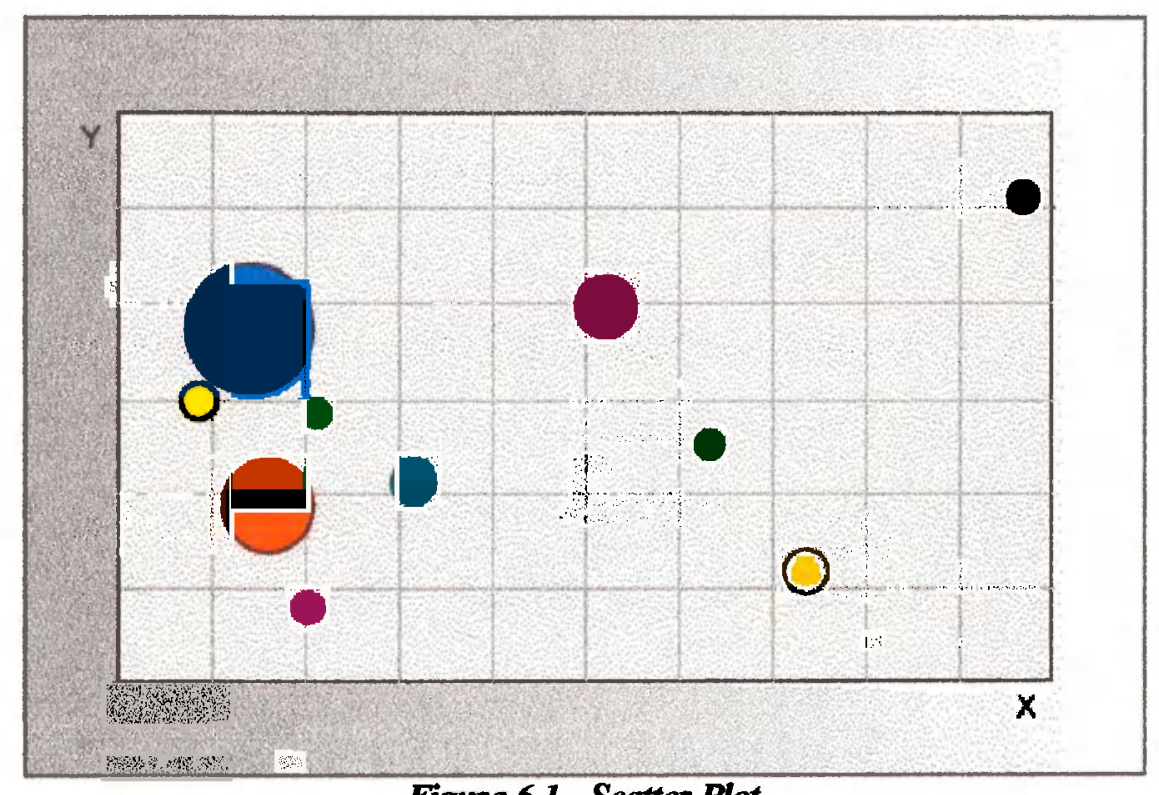

Figura 6.1 - Scatter Plot

\section{4 - Considerações finais}

Os objetivos pretendidos com este trabalho foram alcançados. $\mathrm{O}$ algoritmo desenvolvido se provou adequado à aplicação. Entretanto, existem aspectos que podem ser melhorados e que podem dar origem a outros trabalhos como, por exemplo, o uso de novas funções de link que melhor modelem os dados no domínio Web. 


\section{REFERÊNCIAS BIBLIOGRÁFICAS}

[ABC, 2003] , ABC Interactive Audits, 2003,

http://www.abcinteractiveaudits.com/pdf/exhibito.pdf

[Abowd, 1999] ABOWD, G.D., Classroom 2000: an experiment with instrumentation of a living educational environment, IBM Systems Journal, Volume 4, 1999.

[Angel, 2003] Angel Project, http://www.cyberlearnings.com, 2003

[Ankerst et al., 1999] ANKERST, M.; BREUNIG, M.; KRIEGEL, H-P., SANDER, J., OPTICS: Ordering points to identify clustering structure, Proceedings of the ACM SIGMOD Conference, Filadélfia, PA, 1999.

[Aulanet, 2003] Projeto Aulanet, http://guiaaulanet.eduweb.com.br, 2003

[Baranauskas, Monard \& Batista, 2000] BARANAUSKAS, J. A., MONARD, M. C., BATISTA, G. E. A. P. A., A computational environment for extracting rules from databases, Cambridge University, UK, 2000

[Blackboard, 2003] Blackboard Learning System, http://www.blackboard.com, 2003.

[Cooley et al., 1997] COOLEY, R.; MOBASHER, B.; SRIVASTAVA, J., Data Preparation for Mining WWW Browsing Patterns, Knowledge and Information Systems, Volume 1, http://wwwusers.cs.umn.edu/ cooley/pubs.html, 1997.

[Ester et al., 1996] ESTER, M.; KRIEGEL, H-P.; SANDER, J.; XU, X., A density-based algorithm for discovering clusters in large spatial databases with noise, Proceedings of the 2 nd ACM SIGKDD, Portland, Oregon, 1996.

[Fayyad, 1996] FAYYAD, U., PIATETSKY-SHAPIRO, G., AND SMYTH, P., Knowledge discovery and data mining: Towards a unifying framework, 2nd Int. Conf on DM and KD, AAAI Press, Menlo Park, US, 1996.

[Fisher, 1987] FISHER, D., Machine Learning, Knowledge acquisition via incremental conceptual clustering, Volume 2, 1987.

[Guha et al., 1998] GUHA, S.; RASTOGI, R.; SHIM, K., CURE: An efficient clustering algorithm for large databases, Proceedings of the ACM SIGMOD Conference, Seattle, WA, 1998

[Guha et al., 1999] GUHA, S.; RASTOGI, R.; SHIM, K., ROCK: A robust clustering algorithm 
for categorical attributes, Proceedings of the 15th ICDE, Sydney, Austrália, 1999

[Hall et al., 1999] HALL, L.O.; OZYURT, B.; BEZDEK, J.C., Clustering with a genetically optimized approach, IEEE Transactions on Evolutionary Computation, Volume 3, 1999.

[Hartigan, 1975] HARTIGAN, J., Clustering Algorithms, John Wiley \& Sons, New York, NY, 1975 .

[Hosmer \& Lemeshow, 1989] HOSMER, D.W.; LEMESHOW, S., Applied Logistic Regression, John Wiley \& Sons Inc., 1989

[IBOPE, 2003] Instituto Brasileiro de Opinião Pública e Estatística, Divisão eRatings,

http://www ibope.com.br/eratings, 2003

[Karypis et al., 1999] KARYPIS, G.; HAN, E.-H.; KUMAR, V., CHAMELEON. A hierarchical clustering algorithm using dynamic modeling, IEEE COMPUTER magazine, Volume 32, pg 68$74,1999$.

[Kaufman \& Rousseeuw, 1990] KAUFMAN, L.; ROUSSEEUW, P. J.; An Itroduction to Cluster Analysis, Finding Groups in Data, John Wiley \& Sons, Brussels, Belgium, 1990

[Keegan, 1996] KEEGAN, D., Foundations of Distance Education, Terceira Edição, Routledge, 1996.

[Kohonen, 1990] KOHONEN, T., The self-organizing map, Proceedings of the IEEE, 1990.

[LearningSpace, 2003] IBM Lotus LearningSpace,

http://www.lotus.com/products/learnspace.nfs/wdocs/homepage, 2003.

[Macromedia, 2003] Macromedia Inc., http://www.macromedia.com, 2003

[Minitab, 2003] , Minitab, Making Data Analysis Easy, http://www.minitab.com, 2003.

[Neter et al., 1996] NETER, J., KUTNER, M. H.; NACHTSHEIM, C. J., WASSERMAN, W., Applied Linear Statistical Models, Quarta Edição, McGraw-Hill / Irwin, 1996

[Ng \& Han, 1994] NG, R.; HAN, J., Efficient and effective clustering methods for spatial data mining, Proceedings of the 20th Conference on VLDB, Santiago, Chile, 1994.

[Nichols, 2003] NICHOLS, M.S., A look at the effects of caching on web server log accuracy, IBM SurfAid Analytics, 2003

[Nielsen, 2003] Nielsen//NetRatings, http://www.nielsen-netratings.com, 2003.

[Sander et al., 1998] SANDER, J., ESTER, M.; KRIEGEL, H-P., XU, X., Density-based 
clustering in spatial databases, Data Mining and Knowledge Discovery, Volume 2, 1998.

[Shahabi \& Banaei-Kashani, 2001] SHAHABI, C.; BANAEI-KASHANI, F., A Framework for Efficient and Anonymous Web Usage Mining Based on Client-Side Tracking, WEBKDD, Springer-Verlag New York, 2001.

[Sibson, 1973] SIBSON, R., An optimally efficient algorithm for the single link cluster method, Computer Journal, Volume 16, 1973.

[Silva \& Moreira, 2000] SILVA, E.Q. e MOREIRA, D.A., Agente Gerenciador de Cursos a Distância via Internet, ICMC - USP, São Carlos - SP, http://java.icmc.usp.br/research, 2000.

[S-Plus, 2003] Insightful, http://www.insightful.com/products/default.asp, 2003.

[Srivastava et al., 2000] SRIVASTAVA, J.; COOLEY, R.; DESHPANDE, M.; TAN, P., Web Usage Mining: Discovery and Applications of Usage Patterns from Web Data, ACM SIGKDD, Volume 2, 2000 .

[TelEduc, 2003] Projeto TelEduc, http://www.nied unicamp.br, 2003

[TopClass, 2003] TopClass e-Learning Suite, http://www.wbtsystems.com, 2003.

[WebCT, 2003] Web Course Tools, http://www.webct.com, 2003.

[Whestphal \& Blaxton, 1998] WHESTPHAL, C.; BLAXTON, T., Data Mining Solutions Methods and Tools for Solving Real World Problems, Wiley Computer Publishing, 1998.

[Xu et al., 1998] XU, X.; ESTER, M.; KRIEGEL, H-P.; SANDER, J., A distribution-based clustering algorithm for mining large spatial datasets, Proceedings of the 14th ICDE, Orlando, FL, 1998

[Zaiane, 2001] ZAlANE, O; Web Usage Mining for a Better Web-Based Learning Environment, 27 a 28 de Junho, Conference on Advanced Technology for Education, Banff, Alberta, 2001.

[Zhang et al., 1996] ZHANG, T.; RAMAKRISHNAN, R; LIVNY, M., BIRCH. An Efficient Data Clustering Method for Very Large Databases, ACM SIGMOD, 1996. 